\title{
Covid-19: Applied Sociology Of The Pandemic And The Dynamics Beyond 'The New Normal' In The Context Of The Social Pen Theory Of Structural Change
}

\author{
Dr. Mustapha Bintube, (ECRTD, UK).
}

National Assembly, Directorate of Senate, Department of Journal and Visiting Senior Lecturer, University of Maiduguri, (Unimaid), Department of Sociology and Anthropology, Nigeria: drm.bintube@gmail.com (+234 8023586870, (+234 905239 4036)

DOI: $10.29322 /$ IJSRP.10.07.2020.p10353

http://dx.doi.org/10.29322/IJSRP.10.07.2020.p10353

\begin{abstract}
Advisory: This research was carried out and report written by $D r$. Mustpaha Bintube as 'self sponsored postdoctoral thesis and/or monograph' with the advisory team made up of seven (7) reputable professors in the area studied thus: (1) Professor S.A. Zuru; ProChancellor, University of Petroleum, Efurum, Delta state, (2) Prof. Waziri Ahamed Gazali; Sociology, University of Maiduguri, Nigeria, (3) Prof. Emmanuel Onyeozili; Sociology, University of Maryland Eastern Shore, USA, (4) Prof Sam O. Smah; Sociology, National Open University, Nigeria, (5) Prof. Musa Abdullahi; Sociology, University of Maiduguri, Nigeria, (6) Prof. Darlington Iwarimie-jaja; Sociology, University of Port Harcourt, Nigeria and (7) Professor Hamza Kankiya; Sociology, Bayero University, Kano.
\end{abstract}

Contributor: Dr. Mohammed Ibrahim, Sociology, University of Maiduguri, Nigeria.

Abstract- There is strong niche for inference supported by empirical and theoretical grounds from profiled data, both primary and secondary, that one fact is universally eminent about COVID19 pandemic. For the first time in the history of mankind a phenomenon came to dominate and change man's life so momentarily with obnoxious burden and consequential effects which is overwhelming while cutting across all facets of man's life and institutions. COVID-19 has induced newer culture and finetuned social group networking attitude and behaviour as well as gradually changing the working and interdependence of institutions in phases. The research on Sociology of COVID-19 employs an integrated theoretical framework thus: (I) Social PEN Theory of Structural Change to provide analysis and change in social structures and relationship among members of the society and family as primary unit structure and by extension communities' needs and expectations as support under lockdown during the pandemic. (II) Social Evolutionism, the impact of COVID-19 is overwhelming, shaping structures and gradually changing the human society and in that process social evolution is unavoidable and unstoppable, it's not sudden but a gradual process increasing, from strength to strength, intensity to intensity and from time-to-time to inform further change of the society, a transition from modernism-to-postmodernism and into 'The New Normal' and beyond to establish Comteam positive stage of the society that is highly scientific. Again, 'The New Normal' is also synonymous to Marx Webers Ideal Society build on the basis of rationalization. Corollary to this complex process is explained by social evolutionism. (III) Postmodernism as a philosophy to define the dynamics of ' The New Normal' and beyond post COVID-19 society. (IV) Ecological theory to explain man's social and physical environment deserted for COVID-19 pandemic and its consequential effects at various levels during the lockdown and beyond into 'The New Normal' and postmodernism. The theories were intermittently paraphrased with data and variables analysed at different ranges of analysis and measured at appropriate levels of measurement during the study and demonstrate the nexus with elements of COVID-19 as a social phenomenon and presented thematic areas of general Sociology and issues that are sociological. This brings about change in man's life and relations to groups, socio-economic and political structures in parts and as a whole, reminiscent of 'structuralism' in Sociology and newer culture reaffirming the social thoughts of Edward B. Taylor. For example, ' work from home' has changed organizational culture, consequentially transformed behaviour and to some extent attitude of staffers and by extension the structures. Social distancing has reduced social group homogeneity and heterogeneity and the attached benefits around social grouping reminiscent of W.A.Ghazali's sociological thoughts with effects on fundamentals which sustain social relationship among diverse human race from around the world. This research examines COVID-19: the sociology of the pandemic. It is a social impact research which seeks to investigate the momentum of the pandemic on social structures, relationships and institutions. It extensively dwells on thematic areas identified in this survey as areas of interests to sociology to explore its suitability for applied Sociology of COVID-19. The research examines four key areas that are thematic and methodologically cross sectional and real-timenarratives to explore on the social impacts and changes that have taken place and those likely to occur as a result of the pandemic. Analysis of qualitative data has established the nexus with empiricist finding that leadership response around containment of the pandemic as global emergency which was (and still is) found unparallel in the fight against COVID-19 within the continent of Africa and other nations to stamp it out. The research design is qualitative. It considers primary and secondary data, interview, electronic sources and content analysis were utilized to explore on Sociology of COVID-19 as a new vista of social impact research to aid policy bearing, direction and enhance academic credentials. Also, Sociology of COVID-19 integrates narratives and observations as some methodological consideration on thematic 
areas analyzed in general sociology entangled with cross section of the society as study population and randomly sampled respondents as snowball for study. This study employs mixed method of triangulation as method discovered and reflected in 'Haralambus and Holborn Sociology'. It combines both qualitative and to some degree elements of quantitative blend with real-time narratives as some data utilized are measured at nominal level. Ratio and percentile are utilized which depict the quantitative bearing of this research and active utilization of verbal narratives or content analysis that are qualitative in posture and derivatives. The research highlights key challenges as problematic areas for examination and consideration was made around justifying the approach and research design scaffolding the architecture for the study. Broader objectives are formulated and broken down to specific to enable us achieve the most appropriate result. Key terms such as; modernism, modernity, postmodernism, post modernities, social PEN Protoneous $\mathrm{p}+$, positive social value, social PEN electroneous (E-) social value are defined and operationalized and provide sociological perspective to 'social distancing' which debunk the terms 'physical distancing' as inappropriate while lacking social niche in this endeavour and imperatives of social grouping in designated high risks society and difficulties of community members to adhere to the COVID-19 guidelines and nonchalant attitude of not deploying face masks and other personal protective equipment gear (PPEG). The research also examines difficulties around adherence to social distancing guidelines, social grouping complexes and dynamic structures and community systems in vulnerable and designated high risks societies and inability of human to adhere to guidelines is to struggle for survival, social solidarity and biological issues also hinders adherence to social distancing, natural instinct and desire for social cohesion, human feeling, emotions, habituations confirming theoretical support from George Simmel's sociology on 'sociation' and the survey has proffered solutions that are sociological as value addition to policy issues and recommendations based on stronger evidence; empirical and theoretical on the grounds of evidence of what works. When science is mention in social sciences management and development for social change and Sociology in particular, it's to the credit of Auguste Comte; the founder of Sociology and master of positivism who reinvigorated his philosophy on the pedestal of science with emphasis and relevance on sense perception while describing the apex of society as scientific stage of human development. Literature and facts behind this research have supported the establishment of 'The new normal' and beyond postmodernism as a society driven by normative scientific cultural standards with pattern in its operations are indicatively procedural to determine man's life and existence and operation of things. This is a proof to the confirmation of Auguste Comte's scientific stage scaffolding the establishment of the apex of societal progress to depict change enabled by post modernities. The human society is evolving and changing. This is to the credit of Charles Darwin Evolutionism enabled by social PEN energy (+-n) for moves of static phenomenon to get into a dynamic state of affairs as exponentially propounded by Herbert Spencer. Similarly, responsibility and commitment at the level of the high powered authorities: WHO, PTF and CDC to combat COVID-19 is marvelous with minimal gaps which are naturally unavoidable. The leadership and authorities have deployed huge $\mathrm{P}+$ (protoneous capital funding in their desire to end COVID-19) as supports and E- electroneous (human resource capacity medical and otherwise for containment of the pandemic). Citizens' cooperation was splendid at the height of the pandemic and suddenly dropped when palliatives seem to be insufficient to cover most vulnerable communities to alleviate their suffering and the desire for social mobility being human, especially at the time of the lockdown. There is strong evidence to support the facts that, there is sustained compliance to guideline, especially by government officials and private sector on skeleton service and enlightened individuals and ecological zones. Some countries in Africa such as Nigeria, Madagascar, south Africa, Kenya and Ghana have made curative and innovative attempts deploying indigenous know-how of design of basic equipments such as motorized ventilators and sanitizers among other countries who have done their very best to mitigate the impact of the pandemic. The first phase of ease of lockdown and the dynamics of reopening along the curve was dramatic shooting-up while changing and frustrating countries around the world such as COVID-19 ease of lockdown has degenerated as hangover while pushing the USA under fire to contain geometric increase of confirm cases coupled with Blacks' uprising for racial discrimination as post COVID-19 social degenerations and issues of depression, stigmatization, anxiety and loneliness due to work from home, boredom and suicide issues are expected to be high by longitudinal projection and 'Internet of Things' (IoTM2M) is actively changing the world and many are becoming jobless as Telecom Technology is taking the lead in almost all institutions and societies. The research has operationalized concepts and explained variables and is measured at different levels to suit the architectural framework for the study. Investigation has been made on COVID-19 precautionary measures and burden on the society. This research has examined the dynamics around isolation centers, facilities and gerontological consideration in relation to COVID-19 pandemics, the position of political sociology vis-à-vis imperialism and development strategies post pandemic. The social impact of COVID-19 on family and labour force and labour power is immeasurable. The research has stressed the significance of discouraging human traffic connection, the essence and difficulties on ramping up testing, case identification and contact tracing for COVID-19 cases and conscious effort to flatten the curve to reduce the intensity and dynamics of the $\mathrm{X}$ and $\mathrm{Y}$ Axis complexes for achieving perfect 'New Normal 'and beyond that postmodernism and to Comtean positive stage of societal development. The survey on sociology of COVID-19 has showcased the critical issues and radical departure from metanarratives; public views and opinion were measured at different levels of data but predominantly dominated by nominal data with gender categories as male and female. To this end, the research has interrogated black uprising around the world for racism, protest staged, group behaviour and its escalation, police and manhandling of Ranshard Brook's and the demised of George Floyd by kneeling down on his neck, killing him. Finally, the research has presented summary of major and minor findings, conclusion and provided recommendations as policy guide going forward dealing with COVID-19 pandemic and beyond 'The New Normal' postmodernism and Comtean positive positive stage of societal developments as scientific. Lastly, references are 
provided as sources of data; qualitative and quantitative to cover the thesis.

Index Terms- Sociology of COVID-19/ The New Normal/Social PEN Theory/ Social distancing/Applied Thematic Sociology of COVID-19/Social PEN Invisibility; PEN visibility and PEN Indivisibility/Social PEN Protoneous P+ capital Social PEN Electroneous E- human resource capacity and Social PEN Neutroneous $\mathrm{N}$ neutral value as societal norm and value system for Calibration of any social system to attain social context and relative equilibrium for change. COVID-19: The Sociology of the Pandemic.

\section{INTRODUCTION}

$\mathrm{T}$ his thesis is on Sociology of COVID-19 pandemic. It is a social impact research; a new vista and it employs cross sectional qualitative survey research method entangled with real time narratives as mixed method, exploratory and observational. It examines the causes and effects of COVID-19 pandemic on social structures and institutions at the height of the pandemic characterized by tremendous fear, sorrow and grief. The crux of the Sociology of COVID-19 is an examination of the dynamics of the pandemic and the dramatic alterations of social structures and social relationships around families, social pressure, cultural; artifacts and non-artifacts, norms and value systems which have been altered or transformed by the forces associated with COVID19 pandemic and the implications of such changes on individual members of the society, communities and various governments around the world. The momentum behind COVID-19 pandemic and its effect on amplifying the behaviour, attitude and knowledge of the individual members of the society is enormous.

It is an independent post doctoral social scientific research, solely conducted for academic purpose as 'self help' with the aim and intent of adding value to existing body of thoughts on sociological issues around COVID-19 pandemic, its complexes and dynamic structures and beyond 'The New Normal' as postmodernism and positive or scientific society in Comtean connotations of society. The social impacts of the pandemic are analyzed in thematic areas of interest to sociology to guage the efficacy of the context of the 'Social PEN Theory of Structural Change'. The social PEN theory argues that, there are invisible Atomic PEN structural forces (+-n) capable of bringing about social change in the society for example, the likes of Corona virus as an invisible and as well indivisible phenomenon and it has social energy of (+-n) to enable moves, form and combine to produce severe structural effects with newer patterns and structures capable of changing man's social life and it has impact on institutional structural shifts. Those patterns and structural shifts are by product of the previous society which in this context represent modernism or pre-COVID society to give birth to a newer social system called 'The New Normal' as a new lease of life as an indivisible social system which in Anthony Giddens classification of society referred to as ' high modernity and beyond' reflected in 'Haralambus and Holborn Sociology' Pg:895.

This research is NOT connected to any personal interest, groups or individuals and/or any organizational interest and its null of political undertones, but purely aggregates of survey research findings; theoretical and empirical base that may be useful for academic exercise and social impact debates on COVID-19 pandemic as a new vista in Sociology and COVID-19 emergency situation. The survey probes into immediate and long term consequential effects of the pandemic now and beyond 'The New Normal' postmodernism. This research receives NO internal or external grants, technical support, funding or stipend of whatever sort for its conduction.

One thing is universally crystal that, COVID-19 or Corona Virus will definitely perish, same as other pandemics experienced in human phased out of existence, but the effects and the forces left behind into Post COVID-19 as 'The New Normal' are powerful to further redefine our existence as human species on the surface of the planet earth for the changes associated with it is enormous. Some of these changes might be harsh to contend with, while others are friendly for improvement and may flip developmental fundamentals with tractions in their appearance and fashion. Again, Sociology of COVID-19 is interested in the dynamics of the past and the present changes that is gradually sloping down the society to newer norms and value systems for attainment of a state of normalcy and in between there would be crisis and conflict situations to ensure adaptation to the newer way of life as envisaged by structuralist such as Emile Durkheim and Talcot Parson. (Durkheim and Mauss, M, 1703; Giddens Anthony, 2009). The conservative statistics of the affected persons on global scale for COVID-19 is estimated at 4,165,752 confirmed cases and 285,307 deaths as at 11 th, May 2020 compared to $10,168,657$ confirmed cases and 502,387 deaths as at 29th June 2020 . However United States alone recorded approximately 80,000 deaths and 1,345,307 confined cases for COVID-19 in May 2020 and 2,549,069 confirmed cases and 125, 803 deaths as at 29th, June 2020. COVID-19 is an invisible virus and as well indivisible as to it's existence as real which has ravaged the universe of diverse human race. Corollary to that, COVID-19 pandemic is ravaging and changing the world albeit, gradual and that change must happen in phases reminiscent of social evolution of C. Darwin, W.W. Rousseau phases of development, Maslonian hierarchy of human needs or Comtean theoretical phases of human progress of scientific stage and so ' The New Normal' is not an exception to such gradualism in its evolution as a transition towards comtean positive stage of the society. ( Maslow, A. H. 1970; Darwin, A. Comte; WW Rousseau; John Hopkins, 2020).

Consequently, COVID-19 pandemic has entrenched social ills, difficulties and experiences. Worthy of note is its negative effects on individual members of diverse communities around the world in general, especially during the lockdown as it affects social mobility and the work closure has created tremendous gaps. What that means to Sociology of COVID-19 is that, the pandemic has enormous implications around families and severe economic pressure on individual households affected by the pandemic.(ILO, April 2020); (Globe and Mail, May, 2020).

COVID-19 World, would experience what Francis Fukoyama referred to as 'the passing away', a pathway and roadmap to 'The New Normal' in Professor, O.Ogunika's coinage on society and transition of sociology as a discipline, in 1998 referred to as the 'sociology of one world' and Anthony Giddens often times referred to as high modernity and beyond in 'Haralambus and Holborn pg $895^{\prime}$ It is the general believe of the critic's that, after the Corona virus scenario, economies and markets of the fragile nations would be in shamble. The inequality gap amongst individual members of 
the society will either increase or decrease depending on the dynamics of 'The New Normal' for it' $s$ all determined by the fundamentals of the COVID-19 World.( Anthony Giddens; 1973); ( Olu Ogunika;1998).

A number of changes are likely to happen during such transition and the future challenges that are sociological both latent and manifest as destitution's are apparent in many countries due to COVID-19 pandemics. Life after COVID-19 as 'The New Normal' is characterizes by a numbers of automated services which will eventually, sustain connection between 'Thing-toThings' and 'People-to-Things' and 'Things-to-Heterogeneous set of people' and then communication takes place instantaneously among the subjects not only within the local environment but also share such communication with diverse and heterogeneous communication networks and groups to inform value chain and delivery services or messages for social activities to inform development. (M. E. Sayed Sharestani, 2015).

Most people are waiting for the end of COVID-19, but in strict sense of social evolution, change and development are unending processes and COVID-19 has no end, the virus would perish but the impact would be there for long, so to speak. Simply because it's an ongoing process and not means to an end, but an end onto itself. It is a social evolution that would continue to entrench change from strength to phenomenal strength, lifestyles and fundamentals of postmodernism untill the Comtean positive stage in societal development comes to stay thus establishing the full blown 'New Normal' as an 'Ideal society' in Weberian sense and Sociology as the science of society to provide analytical examination of; Sub and Super structures and it's implications around development in the history of mankind. The forces acting around COVID-19 are enormous and a lot needs to be learned to better understand ourselves as human and for moral and ethical consciousness of human race as COVID-19 is changing the World. The research highlights some of the structural impacts of COVID19 and their implications on the immediate social milieu and by extension diverse societies from around the world in general.(Lyotard Francois, L 1884; Anthony Glidden, 1990).

COVID-19 has crippled economies of nations worldwide and some are faced with galloping conditions with severe structural bleeds that may have enormous consequential multiplier effects on many households and their survival as well as their social life, family and political structures and decisions of our leaders may be of concern for COVID-19 has posed challenges that are by extension sociological which require discourse around improved welfare, revival of family values and socialization of the younger ones through programmatic actions both latent and manifest solutions that are sociological. Many perceive corona virus from the view point of having bio-effects that may kill or rather eliminate human instantaneously (or is it gradually and case in point is the UK Prime Minister was once admitted in the hospital at the Intensive Care Unit ICU for corona virus).

Thus, 'The Social PEN Theory' suggests that, post pandemic corrections of structural collapse can be achieved by (1); mobilization and reinvigoration of the PEN components of social protoneous $\mathrm{P}+$ (capital reintegration and sufficient funding for liquidity, encouraging stimulus packages and palliative as response to immediate and far reaching problems associated with COVID-19 pandemic ensuring revamping and resuscitation of the devastated structures and systems in the first instance and as safeguard for future pandemic and increase preparedness to contain the challenges of 'The New Normal') and beyond postmodernism and comtean positive stage of the development of society. (2) the social electroneous E-component of the social PEN theory is (human resource capacity, mobilization and audition of skilled capacity; both IT, techonological and lobour of citizens that can withstand the dynamics and challenges associated with complexes of 'The New Normal' in the next phases of societal evolution).

And, (3); the social Neutroneous N component of the social PEN theory of structural change advocates for societal support for the calibration of the $\mathrm{P}+$ and $\mathrm{E}$ - components to context, i.e. (political structure's onerous support through collective representation and collective consciousness of the citizens and societal norms and values systems as the support and conscious efforts to enable the calibrations and further recalibration of the PEN components, especially the $\mathrm{P}+$ and the $\mathrm{E}$ - to context and relative equilibrium for change and social transformation of the existing structures devastated by COVID-19 pandemic to fit the prerequisites and/or normative cultural standard of 'The New Normal' as the requirement for change and adaptation to the newer environment of postmodernism for social progress of mankind). The social PEN theory argues that structural change and recovery from the pandemic can only be possible when the three components of the $(\mathrm{P}+\mathrm{E}-$ and $\mathrm{N})$ play role equivalent and simultaneously so, for change to happen and in this context, to achieve perfect structural change and transition to postmodernism as the world of science. (Dr. Mustapha Bintube, 2020); 'The Social Atomic PEN Structural Theory of Change' International Journal of Scientific and Research Publication Doi: ttp://dx.Doi.org/10.29322/IJSRP and European American Journal, 2020).

However, there are approaches ranging from philosophical, formal and general sociological viewpoints that should provide analytical examination of COVID-19 quagmire. Some of the structural and systemic dynamics around social life in the 'The New Normal' and beyond, postmodernism could be understood from longitudinal sense of the changes that should happen in man's life with the influence of IT in Post COVID-19 pandemic postmodernism as enormous that, today people work from home with the support of IT as 'The New Normal' unlike offices in modernism albeit, with severity around boredom, anxiety and stress for social isolation due to fear of contracting COVID-19 pandemic while science is increasingly becoming dominant and relevant so much so that, it has proved the Comtean positive stage of man's developmental phase and change of society from theological to metaphysical and beyond that to scientific stage 'The New Normal' postmodernism. (Lyotard Francois, L 1884; Anthony Glidden, 1990).

Although COVID-19 has fractured smaller businesses with increased vulnerability to cyber attacks, data fraud, pilfering and looting especially, during the lockdown and ease of lockdown, social distancing and work from home have the potential of thwarting social relationship as well as slimming down human presence around ecological zones and social environment for practical connectivity as over 120 countries were subjected to lockdown at the peak of the pandemic. Conversely, the lockdown is different stroke for different folks. For some members of the society it is an opportunity to restrategize and rethink going forward after the pandemic, while for others it may mean monumental siege as nearly 500 million people are estimated to 
risk poverty situation due to lockdown at the height of COVID-19 pandemic. Again, COVID-19 has equally dislocated a number of priorities as well as negatively transformed the life styles of significant members of diverse societies across the globe. It is a situation that can best be described as a double-edged sword with challenges and enormous burden on families, groups, communities, societies and governments at all levels all over the world.(S. Probst, N. Carrington; A.A. Howat; 2020;World Economic Forum: Insight Report, 2020), (G. Emefiele, 2020), (Marsh and Maclenan etal, May 2020).

So, is it safe to say that, COVID-19 is ushering in a radical structural change into a new world, a society to be determined by the social PEN energy (+-n) of indivisibility as one, pivotal on science and the dynamic of social protoneous $\mathrm{P}+$ and social electroneous $\mathrm{E}$ - and the support of social neutroneous $\mathrm{N}$ integral for structural change as the impact of COVID-19 on the present day society has been overwhelming? Or is it a leeway to a new world ? Or a transition from capitalism to a society synonymous to Marxian coinage of ' egalitarianism' in which all men are the same? ' The New Normal' is not an unknown social phenomenon or setting, but a social system that emerges from the recovery of lost glory of the previous society as natural selection upon forming and combining political economy aided by the social PEN energy (+-n) in all spheres of man's life hitherto devastated by COVID19 pandemic as it evolves from the previous patterns created by man. The ' New Normal' as renewed kind of society is a transition from modernism or modernism substituted by postmodernism in almost all of its ramifications which requires time to consolidate and stabilize for recovery and sustainability. Hence, the present day society can never be the same with life before year 2020 and the new changes would continue to differentiate and consolidate and it would be gradual, some invisible while others visible, and the changes caused by the pandemic, some reversible while others irreversible and are all indivisible as to their existence as social reality. ( Karl Marx and Engels, F. (1950[1808]); (Dr. Mustapha Bintube, 2020); 'The Social Atomic PEN Structural Theory of Change'

There is the notion that lack of adequate preparation to nip COVID-19 pandemic in the bud and its subsequent escalations is a matter which numerous critics and commentators attributed to the world' s power wrangling. The USA and China are in faceoff, capitalism is under severe threat while communism and socialism are no longer tenable and the world is graduating into 'The New Normal'. Beyond that, it is saddled with the burden of American blacks' revolt (or is it disobedience; an outright protest with popular slogans as; 'Blacks Lives Matters' against racism and subsequent stage of protest for alleged police brutality in the murder of George Floyd and Ranshard Brook's and many other invisible unauthorized police brutality as claimed by the protesters which had happened in the past, but gone down the drain. George Floyd' s case has degenerated to further escalation of sustained systemic frustrations, anger, anxiety, displeasure and unhappiness around colonialism, subjugation, perceived exploitation of the Blacks by the Macworld and to some larger extent historical slavery as the protesters claimed. (Karl Marx (1964, [1840]); ( Marx Weber; 1947).

Similarly, there was push and pull around credibility and responsibility of whether or not one of the two countries; USA and China is responsible for the spread of COVID-19 pandemic, especially its escalation. USA is blaming China and China is turning 'donkey ears'. USA President was asked by a journalist at the White House press conference that COVID-19 is a catastrophe of global magnitude and why is it so? The USA President in response felt that question was so nasty and retorted, 'Ask China'. USA and China are in face-off using threat words at each 'bloc', suspicious of each other while COVID-19 is ravaging humanity around the world with enormous negative impacts on structures; primary, secondary and tertiary and the masses are suffering by day and erupted ethno-racial crisis and domestic violence for palpable lack of capacity of some individual me.vers of the society's to attain social responsibilities at family levels and that by extensions and multiplier effects affects on child socialization and psyche among other social ills that concerns Sociology of COVID-19.

There is no gain saying that, COVID-19 pandemic has caused monumental structural imbalance and systemic shift in almost all facets of man's life. Sociology of COVID-19 focuses on those changes and examines their implications on individuals, groups, diverse societies and institutions; formal, semi-formal and informal. For example, on its escalation and impact in January, 2020, and measures to arrest the pandemic through policy guidelines occasioned by subsequent lockdown has affected the income and jobs of numerous members of the society, especially the informal workers were hard hit as it declined to $60 \%$ globally. This negative impact has sociological implications on the families, relations and dependants of those whose jobs were at risks for COVID-19 pandemic. Again, the expected decline, according to experts, is more likely to affect Africa and Latin America.

Also, there is evidence to support the fact that COVID-19 has disrupted 436 million enterprises, 232 million are retailers and whole sellers globally and COVID-19 has disrupted 1.6 million informal workers globally, (ILO, April 2020). Corollary to that, available studies have suggested that Corona Virus is relative to geography and therefore, the impact varies from country to country and those in the United States of America (UAS) are ten times more likely to be infected and four times likely to die of COVID-19 pandemic however, asymptomatic are not that infectious as the real carrier of Corona virus.

The dominance of IT and man's activities in post COVID-19 society as postmodernism are felt everywhere and life is been dominated by IT in all spheres of existence ranging from hospitals, market places, schools, work places, eatery to ATM dispenser and payments for purchases and other transactions are done electronically online with the use of value-MasterCard supported by IT as 'Internet of Things' (IoTM2M) post modernities, variables for it's definition and that has been the way of life in mordernism long before the advent of the novel Corona virus pandemic and that would be sustained and further differentiates and transforms into 'Machine-to-Machine Communication' $(\mathrm{M} 2 \mathrm{M})$ and its relevance and significant are retain and projected furthermore in it's trajectory right into 'The New Normal' and beyond as improvement upon man's life enable by science and empiricist fundamentals as 'smart' way of life in the society. (M. E. Sayed Sharestani, 2015);(India, Ministry of Communication; March,2020).

There are theoretical and empirical grounds as to establishes nexus with what this research envisaged to achieve as there exist post modernities as evidence on how things in our homes are 
smartly managed from afar through internet connection and it's observed fact that, nowadays human society is driven more by 'Internet of Things; as a two tier model' which enables sending of information sensed by things or actuating the social environment through IT facilities and the basic sensing and actuation of services to quickly connect with other services provided by 'Smart Things' in our homes, offices and other public domain with other 'Internet of Things Appliances' and that would automatically lead to the automation of various forms of 'Internet of Things' to deliver on specific tasks on the internet life beyond 'The New Normal' as postmodernism this milestone in the history of mankind is reminiscent of Auguste Comte's classification of society as 'positive' or scientific stage.

These are some of the dynamics that are more likely to happen beyond 'The New Normal', a post COVID-19 society postmodernism utilizing 'Internet of Things' as rapid revolutionary communication network and assist in the diversification of production in industries and man's social existence and as scientific innovation for the improvement of humanity as opposed to the tough, archaic and analog ways of doing things around us and at our homes, a situation to confirm the theoretical underpinning around Auguste Comte scientific stage of development.(M.S.E, Shahrentani, 2015);(India, Ministry of Communication; March,2020).

There is the need for policy responses to protect the low income earners, especially the workers in informal businesses in poorer countries from around the world. The risk posed by COVID-19 on labour force and labour power globally is so severe and the most hard-hit are accommodation and food services. Also, existing evidence had showed that, there were sociological implications on gender based issues, domestic frictions and concern over feminism as during the lockdown for COVID-19 pandemic, many people have lost their jobs and in Ontario Canada alone, about 2.2 million people lost their jobs. In April, 2020 alone, the data and statistics reveal that about 689,200 people lost their jobs and unemployment rate rise to $11.3 \%$ in Ontario Canada. The job loss of almost $87 \%$ during the lockdown, just within two months and the sociological implications on both micro and macro-demographic characteristics of those affected were significantly on women from the private sector. About 577,200 women lost their jobs compared to 514,800 men and are mostly from the industrial sector and that event alone has the potency to severely pressurize their families and for the single mothers it's a catastrophic an early warning signals for broken homes and major threat to the socialization of the younger ones. The job loss has also affected wholesalers and retailers as 230,900 jobs were lost while accommodation and food services account for 215,800 job loss. At least one out of three jobs was affected during COVID-19 pandemic. (ILO, April 2020); (G. Emefiele, 2020)

'The New Normal' is new lease of life as social transformation of the previous or pre-Corona society modernism to a newer society postmodernism with evolutionary strength differentiating the society to open up newer windows for change in man's life as we work from home and transact businesses online and other fundamentals to a higher life than that of the previous society with distinct features that are somewhat, similar and as well slightly different in comparison to our former life style before COVIID-19 pandemic which our generation must witness as phase change in life and therefore, it's normal as the theory of natural selections claims. However, at the other end of the spectrum, there exist an inevitable systemic transformation guaranteed by the social PEN energy (+-n) while societies require more social protoneous $\mathrm{P}+$ capacity, social electroneous E- human resource capacity and capital integration to bounce back largely due to the momentum of COVID-19 pandemic to enable us pick the pieces for Socioeconomic and political recovery and sustainability. (Dr. Mustapha Bintube, 2020).

'The New Normal' as the name implies is an 'Ideal Society' and this is to the credit of Max Weber as Weber constructed an ideal type of rationale-legal bureaucratic organization with the following characteristics as; activities required to achieve organizational goals are distributed in a fixed way as official duties well rationalized. This feature of a rational legal bureaucracy has stressed the importance of Kinsley Davis and Wilbert E. More theorizing on stratification system for each official has a clearly defined area of responsibility for the attainment of organizational goals in a rational legal bureaucratic setting. Complex tasks are broken down into manageable parts with each official specializing in a particular area. Bureaucracy's complexes and dynamic structures of institutions are intertwine just like the thoughts of Max Weber and Karl Marx are inseparable because you cannot talk about economic system that is achieved via e-institutions without the protoneous $\mathrm{P}+$ capital for liquidity of systems and electroneous E- (human resource capacity IT and otherwise ) as advocates of social PEN theoretical components beings prime source of decision making at all levels as COVID had engaged the E- component capacity for bureaucratic know-how dealing with the pandemic at the centre of decision making at the level of UN and policy formulation at level of various governmental levels as bureaucrats and/or administrators are working round the clock tirelessly briefing media to get out of COVID-19 quagmire. ( Marx Weber; 1947).(Karl Marx (1978[1867])( Robert K. Merton; 1968) ( Spencer H. 1971).

Subsequently change would take place in the process. The impact of COVID-19 is sharper, overwhelming and has created a number of scenarios which have changed our lives and those changes are dramatic and the effects are immeasurable. Lockdown and complete seizures of human activities on the surface of the planet earth, during COVID-19 pandemic had greater effects on our lives, some of the changes are reversible while others are irreversible and would continue to evolve to its greater heights with consistent change to shape our lives as individual members of the society.

There are great changes around systems and structures around us and are slowly galloping and inflation is creeping deeply into the very fabric of the society due to COVID-19 pandemic and the panics for scarcity or shortages of commodities necessitates for market price speculation and that increased hoarding of foods stuff during COVID-19 pandemic for the fear of unknown with severe effects on low income earners' families and the lower working class especially in capitalist societies. Also, Issues of interest to Sociology of COVID-19 as existing literature has provided evidence that, some of the events characterized by racism, stigmatization and protest with obnoxious implications on homes which are said to be on the increase only during COVID-19 pandemic. The case of George Floyd erupted and Ranshard Brook's recap the struggle, Vancouver police recorded 20 hate incidences in 5 month compared to 12 altogether in 2019 mostly 
directed on Eastern Asians. They were looked at with disdain by accusers as COVID-19 blossomed from China. The attitude of the public on Chinese people was disturbing and the level of stigmatization and hate was said to be on the increase. Data obtained reveal that an insulting statements directed at Eastern Asians were recorded as 'go back to your country; that is where it all started'. All these happened after COVID-19 pandemic has blossomed. (Globe and Mail, May, 2020).

The Chinese were seen with suspicion all over the world for the Wuhan escalation of the novel Corona Virus and Africans manhandled and humiliated in some jurisdictions. There were hate-fuelled incidences, racism and protesters littered around the streets and major roads of USA and UK are more pronounced. And, there were agitation and bigotry in Canada and such scenario appeared to be strength for the Chinese and they lamented of physical, mental and psychological imbalance for such accusations just being citizens of China and the labeled against their person. For COVID-19, the Chinese all over the world are in great fear, anxiety and some are depressed for the unnecessary harassment. (Globe and Mail, May, 2020).

As COVID-19 'risks outlook, preliminary mapping and it implications' suggest that, the lives and livelihood of over 500 million households are facing threat of poverty. All these are social conditions which form an integral variable that provides weights for the science and discipline of Sociology at large. Some analysts opined that, in April, 2020, more than 102 export restrictions were placed by 75 countries on goods and critical medical supplies and drugs and should this situation remains constant for 'The New Normal', it will have enormous sociological implications and health seeking behaviour of the members of the society, communities, families and households would feel the brunt and those directly affected by the pandemic would grumble and for the damaging effect there would be much more of systemic rumbling. Aside escalation of COVID-19, there seems to be poverty, the rate is higher and individuals who lived below poverty lines as another factor which correlate the rate of transmission and makes it difficult for the government and relevant authorities to achieve significant milestone around contact tracing and isolation of infected victims more especially in low income earning societies (G. Emefiele, 2020; Marsh and Maclenan etal, May 2020).

The theory of evolution has reinvigorated the fact that, human society evolved and such evolutionary strength according to the social PEN theory is an invisible social phenomenon, but it happens in its indivisibility and the structural changes are visible at later stage of structural change and development. It's gradual and so it attains its visibility stage while nursing 'The New Normal' which at the moment is rather infant evolving and therefore, it has to undergo stable, but guided activities of man's ensuring phased change of the society to attain relative social equilibrium. The activities of the members of the society in post COVID-19 society and the dynamics of the institutions within the ecosystem and global power relations as determinant for the stabilization of 'The New Normal' as society which exemplify a complex whole and are PEN indivisible. (August Comte, 1986; Darwin, C. 1859]); Auguste Comte; 1986).

Social evolution is to the credit of Charles Darwin and Herbert Spencer. The former emphasized on the survival of the fittest and the latter corroborated that, human society is never static but rather dynamic and therefore change is necessary social condition and the changing nature is that of the 'survival of the fittest'. COVID19 has changed the world and equally induced major shift in human thinking and entrenched power wrangling for global power balancing. Sociology of COVID-19 believes that, the process and forces which ensure the change to 'The New Normal' is enabled by the dynamic process' and the interplay and interdependence nature of phenomenal; natural and social fact and it is gradual and would happen overtime as illuminated by Charles Darwin.(August Comte, 1986; Darwin, C. 1859]); Auguste Comte; 1986).

The phased change of the society, due to the impact of COVID19 pandemic is unstoppable and it is beyond an individual control to put an end to it, but will happen though gradual, guided and controlled to some extent by man's conscious actions, activities and relations to institutions, science and entrenchment of technological modernities for social progress to ensure change and the effects would be felt almost everywhere, some overt while others convert and sleeper for the stability of 'The New Normal' as another phase in our existence which come with numerous social and natural phenomena sugeneris as 'social facts' for its definition.(Darwin,C.1859]); (Durkheim and Mauss, M, 1703; Giddens Anthony, 2009).

COVID-19 has challenged leaders of various nations and they are taking bold steps ramping up testing, making concerted efforts around case identification and isolation with pathways for contact tracing, all are possible with the power and authority established and sustained around leadership for success going forward dealing with COVID-19 pandemic. For example, the USA under the leadership of Donald Trump has appropriated 113 Billion USD (One Hundred and Thirteen Billion Dollars) to achieve testing and at least 1.9 million of her citizen have been tested in the second week of May, 2020 through hospital and community testing programmes. Similarly, there were complexes which border the leadership especially, human traffic connections and difficulties around contact tracing are seen as herculean tasks overcoming Corona virus. And, the Rockefeller foundation has since presented guidelines on phased reopening plan of about 48 states of the USA in the third week of May, 2020 as phased modifying measures with tremendous precautionary measures around biosafety were reinvigorated for safety and security of US citizens. (D. Trump,2020);(John Hopkins, 2020) (D.Kieghe, 2020).

'The New Nornal' is achieved by man's relations to institutions supported by IT facilities and technologically mundane postmodernism as a sort of society driven by scientific and higher sophistication with less human labour and social group participation. In that sense, social group segregation/social distancing is rather, a new norm and 'social Telesis' as opposed to social dynamic situation to reinforce George Simmel's 'sociation' translated to German 'Vergesellschaftung'. 'The New Normal' is a way of life, and in postmodernism, the way of life may no longer be in accordance with the previous definition of socialization as it was practiced in modernism, a corona virus ridden society that has changed the global thinking. For example; social distancing may be a relative thing to mean, "he who contemplates of marriage between the whites and blacks, is more likely to also assume to live in the same street with the whites or the blacks" (Hogan, 2006; Giddens Anthony, 2009). 
'The New Normal' which is evolving and synthesizing to transit to PEN structural visibility of normalcy albeit gradual. But, there is a pointer to its trajectory and whatever decision taken sooner rather than later by the governments, institutions and people that matter from around the world, would in no small measure affect things around us and to determine the working of the newer world; postmodernism with effects on our lives and transform the future and that happens through global consensus building, stability and change to 'The New Normal' stability and sustainability.

Although, COVID-19 is public health issue, but its impacts has nexus or bearing with social structures, economy and so it does with polity and by extension shifts in our social lives and fundamentals in general. The consequential effects of COVID-19 on social, economic and political structures as institutions had equivalently and it trickles down to communities and societies from around the world, and thereby changing individual's and group's attitudes and behaviour in search of and in the quest for finding solution to attain normalcy. (Lyotard Francois, L 1884);(Parson T. Bales, R.F. 1955; Parson, T. 1977); (Durkheim, E. Mauss, M, 1703; Spencer, H. 1971)

COVID-19 has increased panic buying and hoarding of food items was on the increase for the fear of unknown leading to artificial high prices with disrupted supply chain and high demand due to COVID-19 pandemic. To correct the ills of COVID-19 may require serious public health reinvigoration, psycho-social support and counseling to reduce its impacts on members of the society. The escalation of COVID-19 with flying banner and shining armour has really galvanized the entire globe and with numerous changes in all spheres of man's life. Some of these changes are permanent and irreversible while others are temporary and dissoluble. For example, the ' ease of lockdown' came with numerous politics and social tensions such as anger and frustration from the individual members of the society.

Amidst these controversies is the fact that the world is changing, though gradual, and that has underscored the claim of social evolutionism. COVID-19 may disappear over time, but the impact it will leave behind would definitely change the world and it is happening albeit, gradually and socially PEN invisible and are in phases to affect social, economic, political, business and educational systems. For example, the sociological implications of the gaps in labour force is that, COVID-19 has thrown many families and individual households into crisis and shift in family structures is the rule and not an exception where jobs are under severe threat of loss with negative effects on individual worker's nuclear and extended family systems and the worse hit family may be either hetronomous and matriarchal or consanguine and matrilocal residence in which the former is dependent with weaker source of livelihood and the later, the wife, saddled with the burdens of the family and exercise enormous power with influence over the father together with their relations may be constrain and restrain by the momentum of COVID-19 pandemic as the labour force has been altered by COVID-19 and labour power are being shifted, in some cases loss of jobs from lockdown and social distancing a nightmare around the globe . (ILO, April, 2020);(W. Bosyauni; 2020); ( T. Honjo; 2020)

COVID-19 has transformed global culture and has shifted many aspect of it both artifacts and non-artifacts. This is reminiscent of the social thoughts of Edward Bronson Taylor on Culture and George Simmel's Sociology on 'Sociation' 'Dyad' and 'Triad' relations to provide us with better understanding of the dynamics of COVID-19 pandemic from around the globe. There are variables and/or indicators at community level to provide credible insight that should allow us have better grasps of COVID-19 and its transmission in relations to variables such as population density, homogeneous or heterogeneous and the extent of transmission among community members through social interactions.(Edward Bronson Taylor, 1891); ( G. Simmel; 1948);(Durkheim, E. Mauss, M, 1703; Spencer, H. 1971).

The behaviour of diverse human groups from around the world, their attitudes, value systems, knowledge and belief systems may contradict the distancing guidelines and are afraid of being infected of COVID-19. This is to the credit of (Burgess and Parks) 'Ecological Theory' and to some extent, 'Cultural Transmission Theory' as it shared a large network of researches with 'Ecological Theory'. (H. Kankiya, 2014; S.O. Smah, 2013).

\section{Key Challenges/Problematic Statement For the RESEARCH}

As the world is now moving away from face-to-face context of social interaction with work from home, social gathering and community meeting are banned ( is it suspended or put on hold ) due to COVID-19 epidemic as caricature of the philosophy governing postmodernism and as a driver for COVID-19 reality for social, economic and political change enabled by social PEN forces (+-n), society is ravaged by Corona virus pandemic as social distancing becomes the rules and not an exception.

There is panic around fragile societies which is obviously provided for by the rate at which it transmits across nations, cultures, traditions and regions of the world with enormous anthropological implications is actually impactful with enormous capacity/potential as it' s slowing down global socio-economic and political activities of human in their respective countries with serious threat around social relationships as sociological fundamental which define individuals social life and existence.

Should corona virus increase in its intensity, (may God forbid), what would be the fate of those who get their daily meals from the opportunities unveiled by social gatherings and events in the society? Some people have to move in and out of their houses and participate in social gathering for their survival, which requires coming together in mass to achieve social purpose in life? What will happen to the down trodden masses, especially those in fragile communities in remote rural areas where social security is tied down to relations?

As COVID-19 escalates in Wuhan China, to the level of pandemic, the media all over the world - print, electronic and new media went agog on COVID-19 influenza. Consequent upon that, Sociology of COVID-19 is interested in the social aspects of the pandemic and it's contractions through social interactions, impact on social structures and sociological safeguards to reduce severity of the virus on humanity in general.

From all indications, one can only get infected of Corona virus (COVID-19) through social interactions, hence the need for social distancing as mitigating measure. I was so disturbed that I wrote to Professor S.A. Zuru, Pro-Chancellor, University of Petroleum, Efurum, Delta state on the 29th of February, 2020 when Corona virus was barely a month old in Nigeria just to share thoughts and perspectives with him on its escalation. The conversation went thus: Pro-Chancellor sir, comparative analysis of the two clips, 
(the one you sent to me and that which I posted in response), suggest a compelling question on Corona virus.

One question is eminent here sir, the epidemic called Corona Virus is known to have neither a vaccine at the moment nor does it have an antidote. So, what is China disinfecting and/or fumigating and sterilizing in Wuhan? Professor sir, With all sense of respect, don't you think that, this quagmire called Corona Virus is sociologically inclined establishing nexus with Maxwell Atkinson theory of 'Coroners' on suicide, in Ethnomethodology-Sociology of Zimmerman and Harold Gafinkel" -Haralambus and Holborn: pg, 885.

There are numerous challenges achieving social distancing and enforcement of COVID-19 guidelines to free the society of the pandemic and associated negative effects of the pandemic on man's social life. Most high risks societies around the world by their very nature and setting, in the first instance, are densely populated with numerous errors in Postmodern-Architectural designs and specifications while lacking in town planning principles with more houses poorly built on faulty foundations.

This situation is a palpable challenge as achieving social distancing seems a nightmare. Most victims of COVID-19 are in absolute poverty with ill-health status who cannot afford to buy disinfectants and alcohol based sanitizers to use for safety measures and are more worried of hunger than the real Corona Virus. How do we protect ourselves of COVID-19 pandemic? As we may recall Abraham $\mathrm{H}$. Maslow of human needs, the problem around poor people is physiological needs, the urge to get basic needs for survival as food, portable drinking water and shelter. Without fulfilling those needs they cannot afford to buy hand sanitizers, face masks, etc. This increases the level of their vulnerability for COVDI-19 pandemic. So, how can we ensure social distancing?

There exists another challenge of lack of enlightenment and sensitization to create more awareness as it is seemingly lacking as social contacts at community level is unavoidable for the mass of population density and dynamic of interactions. The daily press briefings by the appropriate agencies and authorities require expansion of coverage of its activities to penetrate the society and to trickle down to the grassroots level for the masses to hear the government' $s$ advice and recommendation on COVID-19 issues to keep the citizens well informed.

To understand the effects of the pandemic on individuals and society at large, there is the need to provide an applied sociological study in thematic areas in sociology for critical analysis to unveil ways of improving social distancing measure, understanding the effects on short, medium and long term and on how to promote community awareness as safeguards against COVID-19 pandemic and the nexus between COVID-19 and its impact on social structures and institutions such as family system, groups, diverse cultures and how it impacts social change and relationship among human race in diversity.

Again, there are problems around overcoming cultural forces which allow handshake in congregation within communities during weddings, naming ceremonies, funeral services, market places that are congested and other processions as their cultural imperatives demand. So, what can we do to be safe of COVID-19 pandemic? Social distancing is a nightmare in fragile societies and may turn out to be failed and fruitless largely due to the fact that traditional and cultural fundamental define community members' way of life and achieving social distancing is a nightmare

The demography of the fragile societies also suggest social distancing a nightmare due to rampant birthrates, congestion and procession during festivities and routines for places of worship, funeral and other similar inter-ethnic festivals and meetings a nightmare to observe social distancing in most fragile societies.

The social distancing and lockdown as measures to curtail spread of COVID-19 has severe socio-economic and political implications as well as the survival of especially, the downtrodden masses in remote communities; their survival comes first before anything in most fragile societies, hence some break the guidelines and the need to have stringent measures to contain the violations of law and order promulgated by the higher authorities to safeguard members of community from being infected by the carriers of the virus.

There are numerous existential threats from within the community for inter-community relations and human traffic connections as it is natural for humans to move as they remain socially mobile. The guidelines and lockdown has not been easy for members of fragile societies are finding it difficult to contain it as their sources of livelihood are somewhat blocked and palliative to cushion their hardship are in short supply hence, move around in violation of the guidelines.

There are more than enough reasons and issues for members of various communities to abuse and self administer drugs as most hospitals are closed while others are deserted apparently with no doctors and the options left for the masses are to get referral to COVID-19 isolation centres with the fear of being infected, hence they avoid hospitalization completely with dare consequential effects of such change in behavior as drugs abuse.

And, what do we stand to benefit from analytical examination of this situation from the viewpoints of sociology of COVID-19? Closure of most healthcare centres and paucity of health services may generate situational tension capable of escalating into distress leading to eventual trauma, depression, anxiety and psycho- physiological conditions ultimately leading to death and in some cases to aggravate suicide conditions and domestic violence for excessive regulations and inadequate integration of palliative and stipend as support to members of the society with numerous issues around counseling and establishing therapeutic relationship among members of the fragile societies. So, what do we need to learn from the Sociology of COVID-19?

And, what would happen after the pandemic? We need social psychology to handle that and more often than not, the role of medical sociology cannot be over emphasized in giving social analytical advise and sequence of narratives to help paramedics to understand the social factors and reasons for contamination of COVID-19 in various communities and hospital for overcoming the pandemic.

What is sociology of COVID-19 saying on the social aspect of COVID-19 patients and relationship with health workers and it's medical implications? Socio-economic and political development issues and governance are halted for COVID-19 social distancing measures and members of the fragile societies are stranded with no social amenities of life and we require sociology of development for better explanation and to map out post COVID19 world leadership and governance issues to liberate the masses 
and to create hope for better tomorrow and what has been the focus of the sociology of COVID-19 on that?

There are problems around congestion in places of worship such as mosques and churches as rapid epicentre for transmission of corona virus which informed government decision to close down worship places and to reopen when the pandemic is over and sociology of religion is there to tell us much to better understand the synthesis to subdue crises and clear hope of the masses who have nothing but religion as source of hope and revival for better tomorrow so what do we stand to learn from sociology of COVID19 on that?

The social distancing order as philosophy to drive postmodernism has scaled and pushed many out of businesses, especially in fragile societies for social distancing measures as characteristics which define fragile societies and many are out of job today as motorcycle riders, tricycle riders and informal business which allows coming together of many persons to achieve social economic and political purpose in life and such a scenario is a palpable nightmare, especially to members of the fragile societies as we usher in postmodernism world enabled by corona virus and COVID-19 pandemic and social distancing a serious issues which takes away means of livelihood of the poor masses. So, what would happen after the pandemic?

The downtrodden masses are lamenting and seeking for reversal of those measures against their survival and livelihood. Will that get the attention of the authorities? Certainly society would evolve to differentiate and open up opportunities for the fit ones to have a substitute job as residual paid job to make ends meet as the tenets of evolutionism suggest. There are also domestic issues for COVID-19 and social distancing may be maintained by wife and children but for the roaming husband may be a source of concern and fear of corona virus importation to the family and in some cases the rate of domestic violence is on the increase and domestic workers who come from outside to do routine cleaning and washing may also be on the guilt side and at times looked at with disdain with the fear of COVID-19.

Individuals are in lockdown and the quest to have share of their palliate relief materials that is apparently inadequate makes members of fragile societies to fight over to collect and in the process get infected or become more vulnerable to COVID-19 as individuals are seen push, pull drag to have their share of palliative and some fight for apparent insufficient food items being distributed by the government and concerned philanthropic individuals and well-spirited members of the society. Some churches and mega mosques also extend hands of gesture to support poor and needy members of their respective places of worship. So, what do we learn from sociology of COVID-19 on that?

The first phased ease of lockdown in most fragile societies is rather adding salt to injury as most banks were jam parked and most people do not use face mask and as the standing order of some official places instructed to offer skeletal services require customers to use facemasks to enter and some people borrowed their peers' facemasks to gain entry. It was rather a nightmare and observing the social distancing as philosophy which drives postmodernism are actually zero and the number of cases from the day one of the ease of lockdown shoot up and increase the curve along $\mathrm{Y}$ axis of index cases graph against $\mathrm{X}$ axis per capita population density. COVID-19 is really spreading, which perhaps left many asymptomatic as the incubation period is rather long. This left many with mild to moderate symptoms and the aged are also passing away due to their age and associated fear and ailments due to fragility and apparent lack of immunity to fight back corona virus in most fragile societies. So, how can we be safe of COVID19 ?

From around the world, there were cases of people who tested positive for COVID-19 and referred to isolation centres just for them to be dancing around and some got back to the society to come back when it' $s$ time for either lunch or supper to be fed by government as another source for working against hunger in some fewer societies across the world that are fragile and many are being arrested and charged, in some cases convicted for violations of COVID-19 guidelines order and enforcement principle. The NCDC has been seen on Television on daily basis cautioning members of the society to safeguard and that includes the use of social media messaging and daily press briefing by PTF for donkey years yet many tend to violate the stay-at-home order during the lockdown time and the confirmed infected cases are on the increase. The tests and other requirements for confirmation are centralized and results are not quick in coming for further actions in dealing with COVID-19 pandemic.

\section{JUSTIFICATION FOR THE RESEARCH ON THE SOCIOLOGY OF THE PANDEMIC}

The crux of the Sociology of COVID-19 is to provide analytical examinations of the dramatic changes in thematic areas of man's life and existence; alterations of social systems, modifications and transformation of man's entire life due to the impact of COVID19 pandemic are worth researching. Again, there is the need to explore a ground for sociological debates improving on social distancing; social ills, destitution, suffering and cognitive dissonance entrenched by fear and to provide sociological literature as reference point on COVID-19 pandemic. Also, there are tremendous issues and facts which make social distancing difficult, if not impossible or nightmare and this research is determined to unveil the way forward as solution in addition to the dispute among scholars on the why and how distancing should be described or defined. This research would generate sufficient data for referral and policy aids for policymakers and practitioners and serve as pedestal for longitudinal production and prevention from contracting the virus. It has enormous academic benefit in understanding sociological issues behind the pandemic. Also, it is so appealing to a researcher to make enquiries and raise fundamental philosophical questions that are compelling on happenings and events around man' s social milieu due to OVID19 pandemic and the effects on the changes on man's livelihood has underscored the imperatives of this thesis.

More so, worth knowing of it all is our social relationship in the society as members and the effect of social distancing and the effects of the pandemic in general and the need to know "what" and "why" of the dynamics on ' change in social structures', 'contact tracing within communities', 'social groups distancing' and 'social interactions' through which people get contracted of COVID-19' and all of these concerns Sociology of COVID-19.

The focus of Sociology as a discipline is society and face-to-face social interactions and to some extent the transition of the society in phases from hitherto stable pre-Corona society as somewhat, simple with semi and informal structures evolved into another 
phase characterized by chaotic COVID-19 era and to another phase of post COVID-19 world of 'The New Normal' as it is evolving to define human society by technologies and the power of science and IT for uniformity and normalcy is worthy analytical examination by sociologists.

At the core of the Sociology of COVID-19 lies the belief that post COVID-19 society as a new phase of man's social existence ('The New Normal') may not be the same with what was tenable before the year 2020. Normalization can be achieved as doctrine of the theory of natural selection as a way of life and this is to the credit of (Charles Darwin) who made us to believe it as one of the basic tenets of evolutionism.

As corroboration to the overwhelming thoughts of Darwin, (Herbert Spencer) proved that human society is never static but it is dynamic hence, changes from one phase to another phase is unavoidable situation and, 'The New Normal' as a way of life perhaps, would come to stay in phases and it is unavoidable. This is a theory rather than speculation, guess or assumption and that happens gradually. Human society would from then require more sophistication and science to exist with certain norms, basic rules and fundamental principles as it would have normative cultural standards to define life and as well as guide to a new lease of life of 'The New Normal'. Sociology of COVID-19 is there to provide timely, consistent and theoretical understanding of the complexes and dynamic structures of those phases as it affects man and social systems in our social milieu.

\section{OVER ARCHING OBJECTIVE OF THE RESEARCH}

The broad objective of this research is to examine the social impact of the pandemic and to demonstrate the adequacy of the 'Social PEN theory of structural change' in giving sufficient explanation on COVId-19 pandemic and its consequential effects on social structures and man's life in the society and by extension into 'The New Normal' and beyond. The findings from this research enable us to benefit a lot from the thematic areas on applied sociology of the pandemic and to outline the preventive and/or precautionary measures that are socially inclined and response to contain COVID-19 as global emergency situation. The research also seek to achieve more on the 'why' of the difficulties around adherence to social distancing guidelines as, especially in social groups and communities and in the end it seeks to provide sociological findings and solutions from the bulk of data analysed and inferred to the populations from which study sample was drawn. Lastly, it is to highlight sociological steps to be taken to improve on measures, social distancing and social life during and after COVID-19 pandemic.

The research is also to establish a new vista in sociology to be known as "Sociology of COVID-19". The thesis is to uncover the philosophy governing postmodernism as a driver for newer changes due to the momentum of the pandemic and as cutting edge research, employs an integrated theoretical framework that seeks to uncover challenges and changes faced in all spheres of human endeavour. General Sociology as a science of human society, applies various scientific methods, ranging from qualitative to quantitative, ethnographic approaches, Anthropological, historical and excavations, rules and measurement technique.

Sociology of COVID-19 is to X-ray COVID-19 pandemic and examine its impact and offer suggestions that may provoke conversation in finding immediate, short and long term solutions that are sociologically tenable and tackle some of the social problems caused by COVID-19. This research would identify clog in the wheels of progress inhibiting achieving social distancing measures in designated high risks societies and to suggest newer ways for enhanced social distancing within the peculiarity of cultural context of society of research that would be integrated for best practice and result. When the virus was mentioned in January, 2020, it was so mind boggling that several compelling but sociological questions readily came to my mind; they were so appealing for social scientific examination within the realm of social consciousness.

\section{SPECIFIC OBJECTIVES OF THE RESEARCH}

This research examines the following specific questions to achieve the overarching objective stated above. Thus:

(1) How can 'The Social PEN Structural Theory of Change' explain consequential effects of COVId-19 Pandemic into 'The New Normal' and beyond?

(2) What do we need to learn from the thematic areas on COVID19: Sociology of the pandemic?

(3) What are the precautionary measures and responses to contain COVID-19 as global emergency situation?

(4) Why adherence to social distancing guidelines is difficult in social groups and communities?

(5) What are the sociological steps to be taken to improve social life during and after COVID-19 pandemic?

\section{Thesis PRofile, Operational DeFinition OF KeY TERMS, CONCEPTS AND VARIABLES}

The theme of this research is Covid-19: Applied Sociology of the Pandemic and The Dynamics Beyond 'The New Normal' in the Context of Social PEN Theory of Structural Change.

The research was conducted between January and July, 2020. It was carried out and as well report written by Dr. Mustapha Bintube, (ECRTD, UK). Dr. Bintube is of the National Assembly, Directorate of Senate, Department of Journal and Visiting Senior Lecturer, University of Maiduguri, Department of Sociology and Anthropology, (Unimaid), Nigeria.

The advisory team for this research is made up of the following professors in the field studied thus: (1) Professor S.A. Zuru, ProChancellor, University of Petroleum, Efurum, Delta state, (2) Prof. Waziri Ahmed Gazali; Sociology, University of Maiduguri, Nigeria, (3) Prof. Emmanuel Onyeozili, Sociology, University of Maryland Eastern Shore, USA, (4) Prof Sam O. Smah, Sociology, National Open University, Nigeria, (5) Prof. Musa Abdullahi, Sociology, University of Maiduguri, Nigeria. (6) Prof. Darlington Iwarimie-jaja; Sociology, University of Port Harcourt, Nigeria,(7) Professor Hamza Kankiya; Sociology, Bayero University, Kano and Dr. Mohammed Ibrahim, Sociology, University of Maiduguri, Nigeria has contributed to the research.

This research has the following sub-themes thus: (1) Abstract with the following Index Terms- : Sociology of COVID-19/ The New Normal/ Social PEN Theory/ Social distancing/Applied Thematic Sociology of COVID-19/Social PEN Invisibility; PEN visibility and PEN Indivisibility/Social PEN Protoneous P+ capital Social PEN Electroneous E- human resource and Social PEN Neutroneous $\mathrm{N}$ neutral value as societal norm and value system for Calibration of any social system to attain social context and 
relative equilibrium for change. COVID-19: The Sociology of the Pandemic. (2) Introduction (3) Key challenges/Problematic statement for the Research. (4) Justification for the research. (5) Broad objective of the research; (6) Specific Objectives of the research; (7) Ethical Value consideration, Scope, Significance and limitation of the research; (8) Operational Definitions of Key Terms, Concepts and Variables.

Concepts defined and operationalized are: (1) Sociology of COVID-19 as a cutting edge research and social impacts analysis of the social elements of the phenomenon of COVID-19 in thematic areas in relations to the branches of general Sociology and Anthropology.

(2) Social distancing simply connotes, moving away from social group to be safer and taking responsibility to ensure safer society. It's purely 'social' and the definition of 'social distancing' has been supported by established sociological literature in the work of ('Hogan Sociology', 2006, Pg: 331).

The terms " social distancing", "physical distancing" and "Social Telesis" were first coined and operationalized by Hogan in 2006 pg. 331 and pg. 332 respectively. The most appropriate one out of the three to describe human social grouping vis-à-vis distancing from groups to take cover from COVID-19 is the term 'Social distancing' and NOT 'physical distancing'. However, as corroboration to Hogan definitions, this research discovered that, social distancing is more appropriate terms to be utilized and therefore, there is nothing like physical distancing when talking about social interactions as enabler for the transmission of COVID-19. (Lester F. W. 1968).

Social distancing is also supported by global paradigms on COVID-19. It has a philosophy as well as epistemology loaded as guidelines and policy of the WHO and CDC on COVID-19. Social distancing is to discourage person to person transmission of COVID-19 through social interaction. Therefore, to avoid being infected, members of the society need to be socially distanced from one another and safeguard themselves with face masks and as well adhere to the high powered authorities briefing at the level of the United Nations, UN and Centre for Disease Control, CDC guidelines and at various governmental levels on principles on ' social distancing'.

(3) Modernism: Pre COVID-19 society or social life before Corona Virus. Modernity: Features which defines Pre COVID-19 society.

'The New Normal' is interchangeable with Postmodernism and beyond as PEN indivisible society of Post COVID-19 environment driven by science and technology. It is synonymous with Comtean connotation of society as positive stage driven by scientific fundamentals to its greater height. Consequently, " The New Normal' is post pandemic society driven by social PEN energy of (+-n) and dominance of the role of $\mathrm{P}+, \mathrm{E}-$ and $\mathrm{N}$ to enable 'The New Normal' to come into force due to the effects of COVID-19 which have been overwhelming, shaping structures and gradually changing the human society and in that process social evolution is unavoidable and unstoppable, achieving full blown 'New Normal'. It is not sudden but a gradual process to inform further change of the society, a transition from modernismto-postmodernism and into 'The New Normal' and beyond to establish Comteam positive stage of the society that is highly scientific and synonymous to Marx Webers Ideal Society that is highly rationale. This complex process is also explained by social evolutionism.

(4) Social PEN: The three integral components of the 'Social Atomic PEN Structural Theory of Change' which must work simultaneously and in harmony to inform structural change. Social Protoneous $(\mathrm{P}+)$ is positive social value as capital integration and funding support for liquidity of any system for change. Social Electroneous (E-): negative social value as human resource capacity both IT and Telecom Technological capacity and individual capability, natural or acquired by man in the society through training to support change for development. Social neutroneous $(\mathrm{N})$ : the societal norms and values systems to serve as calibre to support protoneous ( $\mathrm{P}+$ ) and electroneous (E-) to calibrate and further recalibrate any social structure or system to context and relative social equilibrium for change to happen (societal support).

(5) 'The New Normal': What is key to the stabilization of the society to attain 'The New Normal' are the newer scientific norms and the role of e-institutions and the emerging structural fundamentals would have influence on social, economic and political activities of societies to enable the change in phases in post COVID-19 society while such reconstruction requires adherence to normative scientific cultural standards around marshal plans for development to inform reconstruction of the devastated societies to attain normalcy. To reinforced the viewpoint on the role of Telecom technology, and some of the dynamics beyond 'The New Normal' is explicit. Postmodernism is a turning point in the history of man's existence with major systemic and structural shift to define complexes and dynamic structures beyond 'The New Normal'.

(6) UN: A high powered authority of the United Nation. (7) PTF: A high powered authority of Presidential Task Force on COVID19 for the implementation of policy on guidelines for the control and protection of citizens against COVID-19 pandemic. (8) CDC: Centre for Disease Control front liners.

(9) Methodological Design: Modified Cross-Sectional qualitative survey. (10) Theoretical Framework: The social PEN THEORY of Structural CHANGE. (11) Thematic Applied Sociology: Theoretical and empirical Review, Analysis and Discussion of Critical Sociological Issues (12) Sociology of COVID-19: Precautionary Measure. (13) Sociology of Covid-19: Government Official Briefings, Centre for Disease Control (CDC) Taskforce and the Role of mass media (14) Sociology of Covid-19: Trunk A, $B$ and C Roads, COMMUNITY and Neighbourhood. (15) Sociology of COVID-19: Crime and Deviant Behaviour, Mobile Court and Enforcement Task Force. (16) Sociology of Covid-19: A Clarion Call to Defeat the Pandemic as Global Emergency and Leadership Response. (17) Sociology of Covid-19: Medical, Gerontology, Facilities and Isolation Centres. (18) Sociology of Covid-19: Urbanism and Interstate lockdown, lower working Class and Social Immobility. (19) Sociology of COVID-19: Social Grouping and Designated High Risk, Fragile Society: A hub for Corona virus Pandemic (20) Sociology OF COVID-19: The Dynamics of the X, Y Axis and Conscious Effort to Flatten the Curve to Discourage Human Traffic Connection. (20) Sociology of COVID-19: Social Distancing, a Sociological Perspective, the First Phase Ease of Lockdown and the Dynamics of Reopening. (21) Sociology of Covid-19: Philanthropic Gesture, Volunteerism and Family Palliative for Amelioration of Suffering. (22) 
Sociology of COVID-19: Social Demography, Research and Statistics. (23) Sociology of COVID-19: The Sociological Definition of the term 'Social Distancing'. (24) Sociology of COVID-19: Ease of lockdown, Stigmatization, Police Brutality and Blacks Uprising into 'The New Normal'. (25) Sociology of Covid-19: Critical Issues, Radical Departure from Meta narratives, Public Views and Opinion. (26) Sociology of Covid19: Anthropology African Society's Belief System and Religion. (27) Sociology of Covid-19: Postmodernism as Philosophy which defines the dynamics of 'The New Normal' and beyond. (28) Sociology of COVID-19: 'The New Normal' and the Nexus Between Marxian and Weberian Notion of Society. (29) Sociology of Covid-19: Political Sociology, Imperialism and Development Strategies. (30) Sociology of Covid-19: SemiFormal and Informal Businesses and Labour Force and Power. (31) Sociology of Covid-19: Summary of Major and Minor Findings. (32) Conclusion and Recommendations

References.

\section{Ethical Value Consideration, Scope, Significance AND LIMITATION OF THE RESEARCH}

This research is constrained by time as well as politics by few unscrupulous elements jamming researcher's head with subjects by misconstruing genuine research findings with coloration against the researcher. The survey is also constrained by the dynamic nature of COVID-19 pandemic. However, the survey is a glimpse of the social impacts of the pandemic, a global scenario and continentally invigorated an African perspectives and beyond. It's not a case of specific country but global context. The findings and results which emanate from this study have nothing to do with the stands of any African country or her government and/or any of the agencies, but a cross-sectional and narratives on COVID-19 pandemic and anonymity as methodological components of this research and purely a post doctoral independent research carried out as 'self sponsored thesis and/or monograph' under the guides of seven (7) reputable professors in the areas studied.

However, the finding is accessible for any end user to drive utility in a positive passion and as they desire for sociological debates. The findings are to add value to existing body of thoughts. The research mainly focuses on keenly selected countries as sizeable, representative, closely observed and studied for 7 months from January-July, 2020. Countries' names are not mentioned herein for unanimity and issues around ethical values, confidentiality and avoidance of politics as one of the cardinal principle of social scientific research. However, the consent of the few interviewed online through Skype and face-to-face are sorted to maintain confidentiality and informed consent. They are protected as their names and locations including countries of origins are made anonymous as ethical requirement in social scientific research.

However, a few among the advisors in the advisory column above have full knowledge of the countries observed and subjects studied, hence advised to withhold the source as anonymous to avoid confusion and mix-ups around politics of using findings against the researcher and ethical value consideration. Also, the research is constrained by the lockdown and interstate social immobility; hence the researcher faced difficulties around travels, accessibility, double checks and pilot as most respondents were einterviewed on Skype oftentimes, active phone conversation. An expensive and time consuming with data collection and titrating chains of information supplied in addition to the few interviewed on face-to-face basis only, albeit, it closes up gaps, pitfalls and chasm with interview schedule.

The findings and recommendations from this research may be useful for policy makers and practitioners and hope to be of value to national, regional and/or global discourse while going forward dealing with COVID-19 pandemic and its associated effects that have transformed and induced structural changes, challenges and issues that are 'Sociological'.

\section{METHOdOLOGICAL DESIGN: MODIFIED CROSS- SECTIONAL QUALITATIVE SURVEY}

The research employs cross-sectional, exploratory qualitative survey entangled with real time narrative as mixed method with observational approach from January to July, 2020; a global context and continental glimpse of Sociology of COVID-19. The research employs analytical examination of critical Sociological issues and changes due to COVID-19 pandemic and beyond and the provision of narratives and observational methods that are sociologically invigorated. The subject matter combines examination with cross sectional survey research while actively utilizing research schedule for data collections and content analysis with fewer elements of quantitative while triangulating the approach as mixed method to enable longitudinal projections and flexibility around predictions of life after COVID-19 pandemic and the changes that may likely take place overtime albeit gradual due to the impact of COVID-19 pandemic. The study population was randomly sampled as respondents snowball for study. The researcher was keen to source data with sense reliability and validity on their origin as nothing is hidden about COVID-19 pandemic for it is obvious as household name.

Triangulation as reflected and method discovered by (Haralambus and Holborn Sociology, ) is mixed method combining both qualitative and, to some degree, elements of quantitative blend with real time narratives as some data utilized are measured at nominal level. Ratio and percentile are utilized which depict the quantitative bearing of this research and active utilization of verbal narratives and content analysis that are qualitative in posture and derivatives. The research on Sociology of COVID-19 employs an integrated theoretical framework thus; (I) Social PEN Theory of Structural Change to provide analysis and change in social structures and relationship among members of the society and family especially during lockdown and when the pandemic was at its peak.

(II) Social Evolutionism, the impact of COVID-19 is overwhelming shaping structures and gradually changing the human society and in that process social evolution is unavoidable and unstoppable, it's not sudden but a gradual process increasing, from strength to strength, intensity to intensity and from time-totime to inform further change of the society, a transition from modernism-to-postmodernism and into 'The New Normal' and beyond positive stage of societal development as envisaged by August Comte and this complex process is explain by social evolutionism.

(III) Postmodernism as a philosophy to define the dynamics of ' The New Normal' and beyond post COVID-19 society. (IV) Ecological theory to explain man's social and physical environment deserted for COVID-19 pandemic and its consequential effects at various levels during the lockdown and 
beyond into 'The New Normal' and postmodernism. The theories were intermittently paraphrased with data, literature and empirical evidence and variables are analysed at different ranges of analysis and measured at appropriate levels of measurement of variables during the study and demonstrates the nexus with elements of COVID-19 as a social phenomenon and presented thematic areas of general Sociology and issues that are sociological.

The research highlights key challenges as problematic areas for examination and consideration was made around justifying the approach and research design scaffolding the architecture for the study. Broader objectives were formulated and broken down to specific to enable the researcher achieve the most appropriate result. Key terms such as; social distancing, modernism, modernity, postmodernism, post modernities, social PEN Protoneous ( $\mathrm{P}+$ ), positive social value social PEN electroneous (E-) social value are defined and operationalized and provide sociological perspective to 'social distancing' while this research debunks the terms 'physical distance' as it lacks social niche in this endeavour and imperatives of social grouping in designated high risks societies and difficulties of community members to adhere to the COVID-19 guidelines and nonchalant attitude of not deploying face masks and other personal protective equipment gear (PPEG) to confirm social distancing as the most rightful term to support precautionary measures against COVID-19 pandemic..

The sources of data are published literature and journal articles, lecture series, while some are unpublished content. While making comparative study of credible metanarratives built around electronic materials and information shared from credible sources from within African and abroad. They depict caricature of the epidemic called Corona virus as typical characteristics of postmodern society occasioned by COVID-19 pandemic. The researcher sorted and acted upon informed consent and anonymity of the study populations while bearing in mind issues around ethical value consideration and confidentiality as some sources of data are coded anonymous to protect the source of data.

\section{TheORETICAL Frame Work: The SOCIAL PEN THEORY OF STRUCTURAL CHANGE}

The research employs the following theories to make the framework as an integrated one to better analyze the social elements related to COVID-19 pandemic and to explore thematic areas in sociology as sociology of COVID-19 thus:

(I) Social PEN Theory of Structural Change: 'The New Normal' and beyond. The whole process of bringing back the lost glory and recovery from pandemic is facilitated by the social PEN energy of (+-n) and man's activities as support in achieving desired result in the subsequent phases of our existence. The blossoming nature of the dreaded, hydra-headed monster called COVID-19 (Corona virus) in January, 2020 appeared to many around the world just like a tsunami. What we call COVID-19 or if you like Corona Virus has created (and is still creating) tremendous fear in the minds of many around the globe. Primary quantitative data on infected cases and death associated with COVID-19 as evidence reveals that, most deaths from COVID-19 are somewhat, due to lingering bad health conditions and crisis around inadequate health facilities, deteriorated and poor health systems to support the fight against COVID-19 pandemic.Dr. Mustapha Bintube (2020); 'The Social Atomic PEN Structural Theory of Change' International
Journal of Scientific and Research Publication Doi: ttp://dx.Doi.org/10.29322/IJSRP.

(II) Social Evolutionism: is pioneered by Charles Darwin and Herbert Spencer and (S. Graham, 1957) notes that Park and Becker talk about sacred and secular societies, which also describes evolution from end to end. Sweedlum et al, 1956 further notes the organic transition and/or evolution of phenomena, as Redfield uses the terms ' folk society' and ' urban society'. Similarly, Boko Haram as a social phenomenon also evolved from its simpler stage to a more complex one which can be described as; ' Geomechanistic-jihadist' periodic attackers to 'Geo-organisticjihadist' periodic attackers. Similarly, society evolves from PEN Lone pathological to PEN molecular, PEN elementary, PEN composites and to a more organic PEN indivisible stage. (M. Bintube, 2015, 2015, European American Journal of Sociology and Anthropology Research eajsar). (August Comte, 1986; Darwin, C. 1859]); Auguste Comte; 1986).

(III) Postmodernism as a philosophy. Consequently, Sociology of COVID-19 examines the complex and dynamic structures of post modernism as a philosophy which provides a leeway for the change in phases in human evolution guided by the norms, basic principles, scientific and mundane cultural orientation and standards to define. (Lyotard Francois, L 1884; Anthony Glidden, 1990)

(IV) Ecological theory to explain man's social and physical environment affected by the pandemic were utilized to show theoretical nexus or links with COVID-19 pandemic and structural change. More so, what informed the used of an integrated theory is the fact that, no one theory is adequate to comprehensively explain or enable prediction and/or description of all elements of a phenomenon as COVID-19 pandemic as social reality, dynamic as it is still evolving for the consolidation of the 'The New Normal' and beyond postmodernism.( S.O. Smah;2013)

The theoretical framework to support this research is 'The Social PEN Theory of Structural Change' which advocates the need to configure the PEN components for rapid change to take place. That is crucial to cope with the future challenges and it is necessary social condition for change to happen and as well adaptation to the environment of " The New Normal'. COVID-19 has changed the behaviour, attitude and knowledge of the individual members of the society. To contain the challenges of the post COVID-19 World, 'The new Normal', the social PEN theory of change is telling us that, what has happened during the pandemic has left a monumental history in our entire life time and to attain normalcy for social greatness, societies are to focus on, and should get three things done to contain the dynamics associated with postmodernism and that has to take place simultaneously to contain the complexes of 'The New Normal' and beyond.

COVID-19 is a brakeless train, a sure transit to globalization and beyond postmodernism while erasing borders and collapsing human activities, making individual members of the society socially as PEN invisible around major roads and disserted streets, lonely and empty trunk $\mathrm{A}, \mathrm{B}$ and $\mathrm{C}$ roads. Its control requires perfect invigoration of the social PEN fundamentals $\mathrm{P}+$, E- and $\mathrm{N}$ for balancing and calibration for change, hopefully for better tomorrow for us and generation yet, unborn. The social PEN theory typically holds that individual members of the society carry social PEN energies (+-n) within them which make it possible for

This publication is licensed under Creative Commons Attribution CC BY

http://dx.doi.org/10.29322/IJSRP.10.07.2020.p10353

WwW.ijsrp.org 
them to attract one another and such attractions also enables transmission of COVID-19 as an invisible social phenomenon through social interaction, especially in our today's world of high technological penetrations dominated by COVID-19 pandemic.

Man is reacting and counter reacting consciously or subconsciously to social PEN invisible disease called COVID-19 with enormous capacity to bring about structural change and man's life is dominated by technologies and COVID-19 is everywhere in man's very social milieu to inform change in behaviour due to social PEN energies of (+-n) as COVID-19 has changed the entire social relations and interactions, especially for social distancing and his very social milieu dominated by IT facilities that are preponderated in cities, urban, semi and suburban areas disturbed by CO-VID19 pandemic. The impact of such IT facilities on man's behaviour, coupled with the fear of being infected with COVID-19, has affected his relationships with other members as well as his decision may inform further actions or inactions that may affect his relationship with groups and others in the society. The relationship of man to his ecosystem has social PEN invisible fundamentals which are significantly linked to his existence as human and the impact of COVID-19 is high and socially alarming and immeasurable to cause change in all spheres of his existence as individual member of the society. These dynamics may bring about relative change in structures of relations around him with $(\mathrm{P}+\mathrm{E}-$ and $\mathrm{N})$ capacity for further change and development of mankind. The social PEN structural theory of change argues that, the combustion from heavy duty machines releases socially PEN invisible charges, the likes of COVID-19 and man's social environment is dominated by all sorts of charges, but they are invisible in the atmosphere which calls for the use of facemasks as mitigating solutions overcoming invisibility of the most dangerously high COVID-19 ravaging the society with consequential effect on our everyday activities as human with capacity to change in our attitude, thinking and behaviour. Dr. Mustapha Bintube (2020); 'The Social Atomic PEN Structural Theory of Change' International Journal of Scientific and Research Publication Doi: ttp://dx.Doi.org/10.29322/IJSRP.

There are also effects of vibration of waves, telecommunications equipment and installation such as $4 \mathrm{G}$ and $5 \mathrm{G}$ as man's creation which have relationship with human activities in the society. All these combine to have social PEN invisible forces for structural change with effects on individual social life in the society, same as the COVID-19 that is socially PEN invisible. It is real in its social PEN indivisibility and the dynamics between man's social activities and IT driven facilities, installation and equipment, developed to improve humanity have the potency of producing charges which bring about change and such socially PEN invisibles forces of (+-n).

For instance, from mast signals, radio waves and similar frequencies and radioactive dissonance and mobile networks that are socially PEN invisible which change the behaviour of man with impacts are everywhere and significantly correlated with social, economic and political life of man for social change to bring about transformations in all spheres of man's life, that has the pedestal to spring the society to usher in post COVID-19 human world.

This scenario affects man's social ecology and the social PEN structural theory of change holds the belief that by extension, influence to bring about structural change as well as change in human cells which affects and by implication modify our behaviour and relationship of man with other individual members of the society, be it positively (+) or negatively (-). In that case, the social PEN structure is the vehicle which drives the society forward and a leeway into post COVID-19 world. It can be described as the force which enables change in the society and institutions for social progress of man and his society, in some instances.

To have an all-encompassing understanding of structural change, individual members of the society are not only to know the social PEN structures, but should also establish the strength of the (+-n) to enable the direction of the society to discover social facts such as COVID-19 and the mitigating precautionary measures of being safe and as civic duty to safe others from being infected of COVID-19. The direction of any existing social phenomenon can be understood employing the social PEN structural theory of change for better tomorrow in the world dominated by invisible forces established to bring about transformation of individual life in the society. Success and result dealing with COVID-19 is a matter of a conscious effort reinvigorating the social PEN fundamentals for change and as well to overcome the invisible forces which exist in our very social existence within the ecosystem.

The theory argues that society must configure the social PEN elements, reinvigorate and entrench same to calibrate structural issues associated with COVID-19 pandemic and that must play role equivalent and simultaneously so for balancing elements hitherto a clog in the wheels of advancement of the human society that was holding back the society from ending Corona virus through human social actions and to achieve structural change for a post COVID-19 world characterized by postmodernism; a society of human with tremendous social, economic and political opportunities, but only through instantaneous power of information technology (IT).

Thematic Applied Sociology of the Pandemic: Theoretical and Empirical Review, analysis and Discussion of Critical Sociological Issues

This section presents analysis and discussion of thematic areas in general Sociology as it concern COVID-19 pandemic, critical issues and antecedent that are historically located, politically potent, economically relevant and socially significant in relations to COVID-19 pandemic. However, discussion of major and minor findings; theoretical and empirical would be presented at the end of analysis of data on social impact and changes that may be likely experienced in post COVID-19 pandemic and the dynamics into 'The New Normal' and beyond postmodernism to confirm Comtean scientific stage in the development of society and the thematic areas are presented below:

\section{Sociology of COVID-19: Precautionary Measure}

Sociology of COVID-19 is there to tell us the finding from the survey, literature and empirical data on the perception of the cross section of the society as respondents in relation to COVID-19 pandemic, their attitude, behaviour relations to change structures, social relationships and general impact of COVID-19 on the society and how influential the power behind COVID-19 to change the behavior of individuals at the community levels and by extension propensity of narratives and counter and narratives build around COVID-19 pandemic. 
First and foremost, in the absence of drug and vaccine, the conventional precautionary measures against COVID-19 pandemic are individuals mindset and human consciousness to be on the alert against the ills of COVID-19 pandemic, self isolation and avoidance of crowds and social gathering. Above all, adherent to the WHO guidelines and CDC advisory and protocol against COVID-19 pandemics is uncompromisingly sacrosanct.

For me, COVID-19 is beyond what it means to other people. The pandemic is different thing to different people, hence it is a relative phenomenon which requires conventional scientific and uncontradictory as vaccine and drugs for complete healing than the fishing expedition and traditional approach lacking in methodological imperatives in terms of perception, knowledge, attitude, behaviour and practice of diversities around COVID-19, its prevention, control and mitigating precautionary measures.

The fact that the virus is there is even an underestimation. It is there 'live and direct'. The virus may disappear overtime but its impact and effects may be permanent and can cause enormous shift and monumental structural change of unimaginable magnitude around the world in social, economic, political and educational structures and institutions of human existence.

COVID-19 is a huge burden on the society, which requires stepby-step approach and conventional measures dealing with it scientific; medical to calm the virus and sociological for the examination of the effects on the society for development. That also requires better understanding of specific issues and professionalism dealing with human beings and it also requires having adequate knowledge about the people; through case study for knowing their medical history, anthropological to more of their culture and sociological for better understand of their society, communities and way of life of those whose lives should be protected against the harms of COVID-19.

Some of the precautionary measures as, among other things include; hygiene and personal protective gear; as the use of facemasks, individual self discipline to desist from unnecessarily torching of eyes, nose or mouth with bear hands, frequent use of alcohol-base hand sanitizer, encourage and periodic wash of hands for at least 20 seconds under a running tap is to be promoted to guards against COVID-19 pandemic. Others are social distancing from crowds, group/collective behaviour is banned, avoidance of handshake; instead, encourage elbow greeting, cover mouth and nose with the help of elbow while sneezing or under severe or whooping cough to discourage dispersion of the droplets, especially when having flu and maintain at least $6 \mathrm{ft}$ physical distancing while in an active face-to-face conversation. (Dr. Anthony Fauci);(Dr. T.S. Chandrasekar, Dr. K.R. Yogesh; 2020). It is also, advised that, people should avoid unnecessary licking lips with tongue to reduce vulnerability and should cultivate the habit of dislodging and/or disembarking cloths used as they return home from work and as well avoid touching objects from around their houses as they arrive immediately, until after regular bath and soaking of cloths into a detergent water and thoroughly wash hand disposed before settling down at home. It is also believed that touching any object around as one returns from outside the house may leave the virus in suspense and COVID-19 has the capacity and potential to live in suspense for at least about 9 hours.(Dr. Anthony Fauci);(Dr. T.S. Chandrasekar, Dr. K.R. Yogesh; 2020). However, there are pieces of advises from experts and medical practitioners from around the world. Dr. T.S, Chandrasekhar and
Dr. K. Raja Yogesh jointly in their article entitled "COVID-19's Guts Connections" pointed out that, in addition to the global best practice and advisory from the WHO and CDC, precautionary measures against COVID-19 pandemic, they emphasized on a 'healthy Toilet Hygiene' and confirmed to us that, COVID-19 also, affects Gastrointestinal tract too. COVID-19 they further noted presents symptoms as difficulty in breathing. In their analysis they noted that about $50 \%$ of COVID-19 patients present predominant digestive symptoms as their primary complain with symptoms such as lack of appetite and respiratory complains. (Dr. T.S. Chandrasekar, Dr. K.R. Yogesh; 2020).

They further added that, apart from nasal and respiratory secretions, COVID-19 is also actively and shed in the stools of infected patients and advised that, toilet should properly be closed before flushing to avoid bio-aerosols and avoidance of lavatory use immediately after usage by a person of unknown status of COVID-19. A healthier, positive attitude toward convenience with some degree of consciousness, they added, may help break the chain of the infection.

Furthermore, there are also instances of people using an integrated traditional non-orthodox, non-conventional approach as opposed to the orthodox drugs and vaccine in the fight against COVID-19 as precautionary measures of averting the infection. For examples, some advised on traditional non orthodox cure in relation to respiratory nasal congestions vis-à-vis mucus formation, dissolution and passage to the stomach by use of hot liquids gargling to flush the airways down to the stomach with hot liquids. COVID-19 has the capacity of deposition of mucus in the throat to disrupt air flow in airwaves and to the lung and the nasal chamber, thereby suffocating the victim to death and further added that, that is the more reason for the use of ventilator to force oxygen into the victim's lung to sustain the life of the COVID-19 patient.

Some also, advised that, among other precautionary measures against COVID-19 is the use of Victim-C, Chloroquine and citrus fruits to enhance immune system and the use of onions they also, claimed help disinfect the bio-system and the ecosystem and as well help decongest the lungs. Similarly, effort to neutralize deposition of mucous in the throat also help save the victim and frequent drinking of hot liquids boiled with turmeric and moringa leaves in hot salt water help reduce the intensity of the infection in human body.

They argue, hot water dissolves the thickness as well as change the viscosity of the mucous in the lungs thereby improving breathing of the victim. Oftentimes, gargling hot liquids with some little force may be of help to dissolve the mucous and change the activity of the infection in human body to clear the airwaves for an improved breathing of oxygen.

For an overall safety and improved precautionary measures against COVID-19 pandemic, the government, as an action system, has to take the burden of supplies and distribution of free facemasks, alcohol base hand sanitizers and enlightenment campaign at the grassroots level and community sensitization on the dangers of COVID-19 pandemic as well as on general biosafety in the war against COVID-19 pandemic.

To achieve an all encompassing approach to stamp out the scourge of COVID-19 then, there is the need for better understanding of, and having deeper knowledge about specific agency, knowledge about the clients (COVID-19 patients) both symptomatic as well 
as the asymptomatic patients, be it mild, moderate or severe patients of Corona virus must be understood from case study approach and a historical perspective to make contact tracing easier.

Sociology of Covid-19: Government Official Briefings, Centre for Disease Control (CDC) Taskforce and the Role OF Mass Media

The media briefing by the Presidential Taskforce (PTF) is spectacular detailing questions and answers session with the journalists from all angles that affect COVID-19 pandemic. As COVID-19 escalates in Wuhan China, to the level of pandemic, the media all over the world, both New and Masss, became agog with COVID-19 influenza. Consequent upon that, Sociology of COVID-19 is interested in the social impact of the pandemic and it's contractions through social interactions among community members.

Effective communication is important if not necessary and from all indications and by all parameters, the level of enlightenment at the community level requires certain degree of improvement to reduce vulnerability among members of the society. To properly deal with the situation, governments across all levels need to purchase a wheel portal-cabin community viewing centres and make designation of at least, two stations at strategic points in each community to reinvigorate on enlightenment to enable members of various communities to have access to government information and official media briefing as some times power failures and blackout may hardly allow for chain of communication and the good work of the PTF to trickle down communities and citizen get informed for awareness of government determination, will and onerous effort to stamp out COVID-19 pandemic. (Presidential Tasks Force; PTF Watch, 1020)

The need for the government to improve on cooperation and enhance relationship with the media is very important as must radio and TV stations nowadays are privately owned and focus more on commercial activities for coverage to enhance IGR than carrying public issues on their programming and the need to bridge people with the government activities for democratization, good governance and success going forward dealing with COVID-19 pandemic. That should be done not only in fragile societies around the world but it also has to includes, the most developed nations. From all indications, one can only get infected of COVID-19 and/or Corona virus through social interactions, hence the need for social distancing and media activities such as jingle, adverts and the need to provide an applied sociological perspective for critical analysis of the xenophobic pandemic in thematic areas of interest to sociologist and beyond that, other branches of Sociology and by extension other courses in humanities that may appreciate a somewhat standard view of the pandemic vis-à-vis government efforts and media activities to calm down the situation. Sociology of COVID-19 establishes sociological nexus between COVID-19 and its impact on social structures and institutions such as family systems and how it impacts social relationship among human race in diversity for lockdown and distancing measures. (Presidential Tasks Force; PTF Watch, 1020) And, there should be effective and uninterrupted communication between government official such as the $\mathrm{CDC}, \mathrm{PTF}$, the media and police, community leadership and members to report any emergency case and breakouts at community levels for proper indexing of Corona patients and cases to enhance national health planning and as well report violation of COVID-19 guidelines, law and order enacted for the control of the epidemic which is crucial and that would improve data for planning to overcome COVID19 pandemic in our communities and by implications enhance the work and enable the PTF to achieve it's terms of reference as they always work round the clock tirelessly to actualise their mandates and therefore, citizens support is crucial and sacrosant in that regards.

The determination of any govenment to end COVID-19 pandemic largely depends on the level of liaison, engagement and cooperation with the media for public enlightenment, sensitization, mass mobilization and community leaders and members participation and inputs, especially individual members of the society who live at the epicenter where the virus is ravaging.

And, the initiatives of the government to closely work and as well seek for the support of private sector participation on PPP especially, the network providers GSM mobile companies for constant and instant messaging, the activation of citizen's mobile phones with toll free help lines and free data for the period of the pandemic would go a long way to allow message sharing and promotion of fight against COVID-19 pandemic.

\section{Sociology of Covid-19: Trunk A, B And C RoAds, COMMUNITY AND NEIGHBORHOOD}

COVID-19 has pushed almost everybody off the roads. Major roads, inter and intra city roads, bypass and express ways are all empty at the peak of the pandemic for the enforcement of lockdown order and compliance by residents. This has been commendable coupled with the fear around Corona virus pandemic. A chance to peep into the major ways to obtain data for this research reveals that, the law enforcements officials, especially the police and members of the task force ( PTF) and checkpoint mounted almost at every 500 metres as one drives along those roads with serious checks, identification and reasons to the satisfaction of the law enforcement officials.

The only socially visible vehicles on the road were those of the taskforce and perhaps, those who convey food items for palliative and countryside small market serendipity centre to serve the city with perishables goods and food items such as vegetables to cushion the hardship of those under lockdown as three days were set aside as market days in a week. Major roads that were ideally busy with traffic jam causing serious delays in mobility with high frequency of accident suddenly turned to ghost roads as if humans never existed or drove on those roads before, especially around Abuja the Federal Capital city of Nigeria. The area councils are also compliant to the guidelines, disciplined to observe same. The taskforce is really working and operations commendable as nothing can be found in all the trunks A, B and C inter and intra city roads. (An AIT Exclusive; 2020);(Financial Times; May, 2020);(O. Peterson, K. 2020);(Heraclitus of Ephehesus; 2020).

\section{SOCIOLOGY OF COVID-19: CRIME AND DEVIANT BeHAVIOUR, MobILE COURT AND ENFORCEMENT TASK FORCE}

Sociology of COVID-19 is an analysis of the dynamic criminological issues happening; events, scenario and narratives formed around law making and orders imposed for the control of excesses of human on lockdown and during COVID-19 pandemic, 
the conflict situation arising thereof and adherence to guidelines and principle governing COVID-19 pandemic.

Many take advantage of the ills of COVID-19 to perpetuate and entrench crime and criminality, especially at the community level with high pilfering and ransacking citizens on lockdown and in some instances clash with the enforcement officials. The sociology of COVID-19 is there to give us an insight on criminologist' s sense, researches and models on prevention and its control. It is to provide integrated, diverse and contemporary approaches and perspectives that are tenable, home supported and home-enabled for each state, its peculiarities in terms of geography, people and cultural influence to differ in attempt at ending COVID-19 pandemic from around the world for better tomorrow. Sa'ad, Mohammed Ibrhami and Sam Smah need to be appreciated for their huge criminological sense and compass going forward dealing with COVID-19 pandemic from the prism of criminology as a science for crime prevention and its control. $(\mathrm{H}$. Kankiya, 2014; S.O. Smah, 2013), ( prof. Sa'ad; M. Ibrahim, 1998, 2010 )

Again, some people do not have any ill motive or deliberate intension of violating the laws and guidelines during the pandemic, but end up being trapped by circumstances beyond their control. They got arrested and convicted as violators while others deliberately, go out during the curfews and lockdown imposed to test the resolve of government. Corollary to the above, such kind of persons can easily be called as COVID-19 pathological disobedient and non-conformist individuals in the society for their excessive entrenched anti-social behaviour of roaming around the streets and major roads, getting others infected of Corona virus, especially during lockdown and at the expense of the law abiding citizen.

Sociology of COVID-19, examining such situation also requires theoretical understanding of the basics and conflict situation with empirical evidence and data for analysis of contemporary happening, issues and event in relations to the violation of law and order in the society during the lockdown for COVID-19 pandemic and beyond. Sociology of COVID-19, also deals with the social and psychological determinants for the commission of crime and various methods of apprehension and punishment of individual offenders, the social reforms that will allow orders made for the containment of COVID-19 pandemic to flourish and to achieve the purpose.

Sociology of COVID-19 is reminding us that, government measures to end COVID-19 pandemic should be more civil than criminal approach to deal with the pandemic. Therefore, the strategies should be localized to cover more of community effort and deploy more power to the base of the community for the residents to own it and as well cooperate to work with the government officials to achieve success going forward dealing with issues around COVID-19 pandemic especially, at the time of curfew and lockdown.

COVID-19 pandemic and its dynamic structures call for an immediate remedy, homegrown and home supported as solution to nip the criminality in the bud before blossoming to a proportion and magnitude that may require more and more protoneous $\mathrm{p}+$ capital and electroneous E- resource component of the social PEN theory for solution.

Therefore, the need for policy formulation, implantation and law enforcement in the short while is required pending productions of vaccine and drugs to contain the quagmire and that help enhance law and order and as well enforcement guidelines for COVID-19 pandemic.

Sociology of COVID-19, interrogates change in aggressive behaviour and attitude; manifest and latten motives of the individuals of harming fellow humans in lockdown. There are cases of burglary and theft, domestic violence and unrest in some communities by group of youths who hitherto were engaged either as taxi drivers, motorcycle or tricycle riders and daily paid jobs are today stranded for social grouping and physical distancing measures and were thrown out of their jobs and as remedy of last resort for livelihood engaged in law breaking.

However, the police are extremely, doing well to maintain law and order and to provide security for citizens as they contain such excesses on almost daily basis. At least, not less than 900 persons were convicted by the mobile court at the height of COVID-19 pandemic for violation of lockdown order. Control of a phenomenon like COVID-19 pandemic, requires a distinct approach from the conventional one in dealing with crime and criminality prevention and its control as a new way of tackling the pandemic.

The fight against COVID-19 can only be won if the government is ready to win the hearts and the minds of the citizens by providing enough palliative to ameliorate their suffering with enhanced trust and create confidence for total elimination of COVID-19 pandemic from the society.

The law enforcement must be polite, friendly as always in Africa and not necessarily, being coercive. Most members of the society are being coerced and instilled with fear through the mass media as some of the threat and punishment shouldn't be seen as solution, but rather a friendly and humane approach to deal with the pandemic. But, if severe punishments are considered with force, then it means that the laws and orders for COVID-19 is abinitio a failed assignment.(H. Kankiya, 2014; S.O. Smah, 2013),( M. Ibrahim, 1998).

Those who comply to the government actions laws and orders do so for they exemplify good citizens with self respect and enormous responsibility for ending the COVID-19 pandemic, through improved bio-safety while observing almost all the precautionary measures including the stays at-home during the lockdown for COVID-19 pandemic as well as have tremendous self respect not to be addressed as violators, deviants or ex-convict for breaking the laws in their life time.

While the other set or classification is that of people who may react badly, even violently for punishment meted out on them for contravening the laws and order while undermining government actions set out for the control of COVID-19 pandemic and therefore, may even be worse to further caused problem around arrest because they get even more violent to escalate and create numerous scenarios as it is evident, especially when subjected and punished for the violations of law and order for COVID-19. Therefore, sociology of COVID-19 emphasizes such people should be handled professionally and there should be more policy issues and principles in handling them to conform to the law and order for the control of COVID-19 pandemic.

The peace, happiness and livelihood of the community members under the lockdown for COVID-19 pandemic is crucial and their survival as citizens is mandatory as guaranteed by the constitution. Therefore, any effort that has taken the hope of the masses on 
lockdown into accounts to fight COVID-19 stands to win Corona virus pandemic. Community members must be at the centre of the fight against COVID-19 and voluntarism at different levels of community is sacrosanct and fundamental for individual' s safety and protection of their properties on lockdown and beyond to make perfect the struggle to end the pandemic and achieving success going forward in the war again COVID-19 pandemic and beyond.

There are challenges dealing with community members during COVID-19 pandemic; some abide by the rules while others go on the contrary. That may be influenced by a number of factors; some are environmental while others are socio-economic and cultural forces as the main driver for the commission of crime and violation of law and order during the sit-at-home for COVID-19 pandemic. The attitude of the citizens toward COVID-19 is not encouraging at all and their knowledge of corona virus seems to be dim while faced with glaring poverty, hunger, diseases and starvation due to lockdown. They are falling sick by day for COVID-19 and some are dying. The hospitals are also deserted and lacking in the most appropriate equipment and health facilities to handle corona cases. Such a situation calls for an immediate intervention and calibration of approach for change in strategies and improved palliatives to deal with the situation under COVID-19 pandemic. The social organisation around the law and its enforcement is also another issue to take into account to deal with COVID-19 pandemic as members of the society are forced to suddenly, comply with such laws overnight without sufficient notice and provisions for alternatives, options and gradual adaptation to the new way of life brought about by COVID-19 pandemic require some time for general shift in behaviour.

In the month of April, 2020 more than 900 offenders were charged and convicted for various offences related to COVID-19 guidelines ranging from not wearing face mask, social gathering and street roaming among other offences stated within the purview of the terms of reference of the TPF. Some offenders were fined while others subjected to community service and the most suspected ones with mild symptoms or asymptomatic were asked to observe mandatory 14 days of isolation and quarantine, test and repeated test to ensure they are safe and by extension the community in which they live before reintegration.

Sociology of Covid-19: A Clarion Call To Defeat The Pandemic as Global Emergency and Leadership Response

When Corona virus exponentially escalated as a global emergency, there were spontanous and rapid global responses among leaders of various nations of the world to contain it. The fight against COVID-19 as an emergency situation has received eminent political will. Global leadership co-operation in dealing with COVID-19 is commendable for its promptness and alignment with the United Nations goals and World Health Organization (WHO) guidelines and Centre for Disease Control (CDC) as common front of onerous spirit of camaraderie has been demonstrated in no small measures by the leaders across the globe and the front liners.(WHO Centre for Disease Control; 2020); (Presidential Tasks Force; PTF); ( D.Kieghe; 2020 ).

The escalation of COVID-19 has witnessed an unrelenting and unresolved commitment of leaders all over the world with enthusiasm, zeal and determination of the leaders and governments at various levels to consciously and collectively gear up to defeat the pandemic as a global emergency. Corollary to the meta-narratives built around Corona virus, the phenomenon has put many leaders around the world on their toes to nip the virus in the bud to contain the emergency situation. (S. Probst; N. Carrington; A.A. Howat; 2020)(Financial Times, Yoval Noah; 2020)(World Economic Forum: Insight Report; 2020).

Similarly, for an overwhelming solution, measures were taken by the leaders and infrastructures were put in place, health system enhanced and awareness around public health has been improved at different levels and the leaders have supported the war against COVID-19 as an emergency situation with special budgetary expenditure for containment and primary healthcare system has been rejuvenated. On the other hand, public health commentators are exhaustively creating awareness on social media, through cell phones and other ways to calm down frayed nerves generated by Corona virus. While scholars of various disciplines, diplomats, philanthropist, bureaucrats, media men, technocrats and representatives of all sectors of the society were seen busy and engaged in talks at all levels of leadership while doing their very best to suppress the tension generated by the escalation of COVID19 and never desire to rest until Corona virus killer pandemic is contained as an emergency situation. (S. Probst; N. Carrington; A.A. Howat; 2020)(Financial Times, Yoval Noah; 2020)(World Economic Forum: Insight Report; 2020).

Leaders of various nations are taking bold steps ramping up testing making concerted efforts around case identification and isolation with pathways for contact tracing all are possible with the power and authority established and sustained through leadership. For example, the USA under the leadership of Donald Trump has appropriated 113 billion (one hundred and thirteen billion dollars) to achieve testing and at least 1.9 million of her citizen have been tested in the second week of May, 2020 through hospital and community testing programmes. There were complexes which border the leadership, especially that of the USA for human traffic congestion and difficulties around contact tracing are seen as herculean tasks in overcoming Corona virus. And, the Rockefeller foundation has since presented guidelines on phased reopening plan of about 48 states of the USA in the third week of May, 2020 as phased modifying measures with tremendous safety around bio safety were reinvigorated for safety and security of the US citizens.(Presidential Tasks Force; PTF); ( D.Kieghe; 2020 ); (Financial Times, Yoval Noah; 2020).

Corona virus has come with its enormous threats which call for leadership response to better our existence as human. The virus is rapidly spreading, so to speak, to wreck further havoc. Therefore, the leaders must take bold steps of ending it and that should be done immediately to rescue humanity. COVID-19 at its peak, has engaged attention of diverse leaders around the world and backstroke scholars of various disciplines; all these seek for solution. Corona virus has created nightmare, it has injected unnecessary cognitive dissonance, inflicted pains, unhappiness and anger, which must be tackled and dealt with squarely to restore hope, solve personal and by extension social problems peculiar to their existence as human. All these can be achieved through good leadership, strong political will and timely delivery to contain the pandemic.

To achieve that, we require credible and responsible leadership to make an approach that is more of humanistic dealing with the public to desist from breaking the laws made to contain COVID19 pandemic. Therefore, any approach rolled out should be home- 
supported and home-enabled for such laws and policies to work and as well make impactful result. It has to be in a manner more civil and result-oriented than strategies for conventional crime prevention and control. Ending COVID-19 pandemic in the society may seem to be like putting a round peg in a square hole; the approach must reflect the physical environment, culture, behaviour and tradition of the people for whom such laws were made to handle and dealt with COVID-19 pandemic.

The war against COVID-19 pandemic must be a collective effort of the citizens to support the leadership; government and community must support and work hand in hand and in harmonious manner in the struggle to defeat COVID-19 pandemic. Credibility, accountability and accurate reporting of COVID-19 cases and violation of order is important for planning dealing with palliative and deployment of the most appropriate measures as solution is necessary ending COVID-19 epidemic from around the world.

Community leaders and stakeholders at community level should be constituted or swap existing committees, assign role, mandate and terms of reference to handle COVID-19 issues as short term and mitigating measures before discovery and production of vaccine and drugs to contain the pandemic.

Albeit, it is palpable and glaring that leaders of various nations are taking institutional measures to curtail the xenophobic (or is it quagmiric Covid-19) to its knees, it is the general believe of the critic's that, after the Corona virus scenario, economies and markets of the fragile nations would be in shamble, inequality gap will increase and there would be mass death of fearful members of the family, suicide rates would shoot up, anxiety, depression, burnout for cognitive overload would be high in many societies and social inclusion would be enhanced. Women would have more power, their rights and privileges would be ensured to the credit of feminism. In addition, human trafficking connection is on the increase and about 40,000 persons from China and Asia roam in May 2020 and they have to be subjected to observe mandatory 14 days minimum quarantine period and must be tested to confirm status for COVID-19 to access social mobility. (Presidential Tasks Force; PTF); ( D.Kieghe; 2020 ).

Sociology of Covid-19: Medical, Gerontology, Facilities and Isolation Centres

The notion behind Sociology of COVID-19 is that societies with weaker health system have higher vulnerabilities around public health, sanitation and hygiene and are said to have the higher chance of being infected by an individual carrier of the virus. Nonetheless, the stronger nations are no exception to the devastation of COVID-19.(WHO Centre for Disease Control; 2020); (Presidential Tasks Force; PTF); ( D.Kieghe; 2020 ).

In fact, its implications on demographic characteristics of community seeking for better health and health practitioners is rather high as many around the world are being infected, some with mental health issues and distress for cognitive overloads and burnouts, irrespective of their gender, education, age, income and profession. Sociology of COVID-19 is telling us that the pandemic has implications around corona virus patient's health, behaviour, environment, attitude and that of the practitioners.

There are key issues which concern sociologist dealing with the health aspect of the pandemic ranging from; knowledge about specific agencies in relations to confirmed cases, knowledge about specific patient of corona virus as client and knowledge about specific contract i.e. between corona patient and the health workers. Aside this, there is the need to have adequate understanding of the patient's value system for accepting him for who he is without necessarily looking at his status and to avoid stigmatization of the person with COVID-19.

The global health crisis caused by Corona virus has provoked universal discourse while causing disruption around local, national and international travels for accessible world class health facilities and medical health to support mental, emotional and psychosocial needs of the health seekers and patients with special cases to get health services at the peak of the pandemic and trained health experts and professional together with health and supply value chains have been disrupted thereby reducing medical tourism around the world.

The social PEN theory typically holds that, humans are faced with enormous problems around socio-economic and political issues which generate enormous consequential effects, especially at the time of COVID-19 lockdown. For instance, social-health related cases as Corona virus pandemic would have been controlled before they escalate. Those structures are at their social PEN invisible stage because we can hardly notice as they will be at their Atomic stage of PEN invisibility and indivisibility. The theory of social PEN is telling us to check for those invisible structures that are highly Atomic in relation to health issues troubling members of the society. Those with health challenges are more likely to be consumed by Corona virus than able bodied men and those who strictly adhere to social distancing guidelines are likely to be safe. (Elizabeth K. R. 1969)

However, efforts are in top gear to defeat the COVID-19 epidemic as social/physical distancing as mitigating measures is difficult to be observed by the public apparently due to the very nature of human existence as social mobile and cohere for coexistence dominated by cultural PEN forces of (+-n) to enable movement from one point to another. The social PEN theory is telling us that controlling Covid-19 to rescue society from being harmed and for improved health behaviour among members of the society, there should not only be E- (human resource capacity) and $\mathrm{P}+$ (capital funding), but we also require the $\mathrm{N}$ as calibre to calibrate and further recalibrate the actions, attitude and activities of the agencies and authority concern while dealing with public health issues and fundamentals with honesty and transparency in leadership to end COVID-19 pandemic as global emergency to rescue humanity from the quagmire.

Hospitals requires infrastructural development and supplies as Personal Protective Equipments Gowns (PPEG) for the protection of health workers, Cardiac Monitor to support and monitor intermittent respiratory dynamics of Corona patients and alcohol based hand sanitizer and antiseptic for general sanitation and improved hygiene of the health workers. Thermometer Motorized to check and gauge temperature but most of these are lacking and COVID-19 is ravaging our communities and those hospitalized are left at the mercy of mushroom health systems even at that it has been overwhelmed due to the rapid contamination of the virus making members of the society vulnerable, especially those with underlying health conditions. (Dr. Anthony Fauci); ( Dr. N. Alkali, 2020 ); Dr. Mustapha Bintube (2020); 'The Social Atomic PEN Structural Theory of Change' International Journal of Scientific and Research Publication Doi: ttp://dx.Doi.org/10.29322/IJSRP 
Skilled workforce is also key in dealing with those with Corona virus. Specialized skill is required in dealing with them in addition to proper counseling by establishing therapeutics relationship to enhance psycho social support for hopeful recovery. Sociology of COVID-19 is also concerned with the social aspects of the Corona patient" s illness and general attitude toward COVID-19. ( Dr. N. Alkali, 2020 ); ( K. Dr. Kepala, Dr. PP Devan; 2020).

The distribution of the confirmed cases, dead and discharged of COVID-19 patients, and the relationship of COVID-19 patients and isolation centres and the health workers in the hospitals and their social role i.e., patient, nurses, doctors, welfares officials and social workers' roles and their relationship with one another and that of the victim of COVID-19 greatly concern medical sociologist for change and improved health of individual members of the society. (Dr. Anthony Fauci); ( K. Dr. Kepala, Dr. PP Devan; 2020);

The role of institutions in relations to the aged referred to isolation centres, structures and facilities for referral are essential in fighting the scourge of the pandemic. Dealing with the pandemic requires an enhanced public health strategies for its isolation, and contact tracing that seem to be somewhat, difficult if not impossible, say in African countries with glaring lack of social demographic identifiers and deficit protoneous $(\mathrm{P}+)$ capital funding for managing and improving health services and electroneous (E-) human resource capacity elements of social PEN theory for general change in the patients attitude toward health seeking and health behaviour for improved health.

The role of social workers and social welfare officials is emphasized for an enhanced health system and public health practice, especially in densely populated communities and fragile societies where its spread is rampant and social/physical distancing is a nightmare. This calls for a conscious action and alternative solutions that are sociological to mitigate its spread.

In recent times, a number of approaches have been taken to get rid of COVID-19 pandemic. The Oxford University, for example, has claimed to have discovered vaccine production as solutions for COVID-19 and it is still underway. Similarly, advanced nations such as USA, China, etc are working tirelessly to achieve this feat. ( D.Kieghe; 2020 ).

However, some African countries such as Madagascar and Nigeria have made an attempt to come up with solutions though organic liquor production and claimed to have what it takes to cure COVID-19 patients. The Madagascar cure for COVID-19 is made up of Neen leaves, Pawpaws leaves, Lime, Garlic, Ginger, Guavas leaves, Mango, boiled and taken three times a day as cure for the sick person and preventive measure for COVID19.(Nmbuziseller; 2020)(R. Kafadia; 2020).

Still, there are ongoing effort to subdue the killer Corona virus pandemic which has backstroke individuals in the society with timely reflection on Elizabeth Qubler Rose 'Dead and dying', a social thought to remind us of stages of passing away and the frequency of death and dying from COVID-19 epidemic is at alarming proportion as it depletes human race on daily basis in postmodern society.

Again, Sociology of Covid-19 is a reminder of social PEN reinvigoration to overcome the pandemic by employing the PEN elements to bring about desired change dealing with health issues in relation to COVID-19 pandemic as we require the $\mathrm{P}+$ (capital funding which is necessary and prime as well as integral components to define infrastructural support and procurement for improved healthcare facilities in the onerous tasks of dealing with COVID-19 as global emergency.

Most cases of hospitalization on referral were carelessly handled in some hospitals around the world not because they wish human to die, but it was glaring that there is palpable deficit around health system, hospital equipment and facilities that are necessary handling COVID-19 cases are lacking or in a way dilapidated which necessitate people passing away. The $\mathrm{P}+$ and E- elements of the PEN theory are crucial and the role of the $\mathrm{N}$ is even more important as the calibre for balancing to ensure success in dealing with the pandemic henceforth for better healthcare delivery to rescue humanity and to ensure bio-safety and precautionary measures in badly affected communities around the world.

Dealing with COVID-19 requires equipped hospital with an Intensive Care Unit (ICU) as life support engine room and enough beds and getting to reduce the concentration and impact of the virus and oxygen cylinders/ plan for more oxygen as Corona virus reduce the rate at which oxygen gets in and out of the system as respiratory disease with mild, moderate and severe symptoms and its incubation period requires more days making it difficult to know carrier at face value. (World health Organization; Centre for Disease Control; 2020).

Albeit, Corona virus is more severe on those with underlying health conditions as persons who are with health fragility enabled by ecological influence and this is to the credit of (Burghes and Parks) and (Thresher and Shaw) Urbanism and it's zonation in relation to dead for COVID-19 pandemic and its consequential effects on human life which is tremendously social resounding the thoughts of (Bwala,1998) in Urbanism and those with terminal illness suffer the most from Covid-19 virus. (Nmbuziseller; 2020)(R. Kafadia; 2020)

The Corona virus pandemic is rather a nightmare so dangerous, sending people to their early graves. Wether the existence of the virus is true, social construct Peter L. Berger and Thomas Luckmann or the magic of reality Richard Dwarkins as some social and political commentators insinuate as a common sense of global magnitude, reminiscent of Maxwell Atkinson theorizing in phenomenology Alfred Schultz and Ethno-methodology, the sociology of Harold Gafinkel and Zimmermann, but the gist around COVID-19 has succeeded in building metanarrative around language game by authenticating its credibility for legitimacy of the claim for COVJD-19 pandemic and its existence as impactful and killing many around the world. (Jeremy Bentham; 1780); (Atkinson, A. 1978); ( P.L. Berger, Thomas Luckmanm; 1967 ); ( Zimmerman, D.H and Wieder, D.L. 1971); ( R. Dawkins; 2011).

Consequent upon that, there are consistent, incisive lines of thoughts that are sociological to illuminate more for our understanding of postmodernism and its attendant ills such as dramatizing on corona virus by members of the public and that is reminiscent of interactionism, the sociology of George Herbert Mead and Williams I. Thomas, the 'Play stage' and the 'game stage' respectively.( William I. thomas;1918-1920); ( Mead, G. H. 1934).

On the cure of COVID-19, some universities in African such as the Ahmadu Bello University (ABU), Zaria in Nigeria in conjunction with the Pharmacy Department of Medical Science has claimed to have discovered cure for COVID-19 in May, 2020. 
The University is also, said to have designed and developed an ICU ventilator and a 4-in-one automatic hand sanitizer in conjunction with the Equipment Maintenance and Development Centre of Mechanical Engineering of the University.

Similarly, the ABU, had later in April, 2020, advanced to also transform the ventilator into an ultra-modern portable E-vent automatic ventilator to be called ' Respire-19' as part of the University's effort to augment the government of Nigeria in the war against COVID-19 as global emergency.

The cure for COVID-19, developed by the ABU, in Nigeria was claimed to have been developed from local plants that are available in different parts of the country. The team leader has promised the public that upon discovery of the medicine, the public would be informed of every step taken leading to its discovery. But, the proportion of different plants used in the production of the Anti-COVID-19 would be kept confidential as it serves as the intellectual property of the University.

Sociology of Covid-19: Urbanism and Interstate Lockdown, Lower Working Class and Social Immobility

Sociology of COVID-19 is to tell us more about life in urban and semi urban or city centres, country-sides, satellites and/or serendipity centres during COVID-19 lockdown and the behaviour and attitudes of the members of the society and the changes that have taken place due to social immobility. Sociological analysis of life in urban centres is to the credit of Louis Worth in the thesis 'Urbanism is a way of life' and same to Burgess and Parks in their theory of urban Zonation or the concentric zone model of Thresher and Shaw which has shared a large network of research with the former and expanded by the latter. (Burgess; Parks 1965).

However, the taxi and bus drivers who run around urban centres before COVID-19 pandemic and who on daily basis bring in the lower working class from the suburbs to help struggle and return them back on stipends are also stranded and their means of livelihood has been put on hold due to COVID-19 pandemic. Although, the congestion in the urban centres that has always been causing problem, fights and tension has drastically reduced at the peak of COVID-19, tension, conflict, frustration and domestic violence are rather increasing at family and community levels instead.

The life and social mobility in market places are never the same, but the attitude of the public is rather not encouraging as its apparently seen at variance with the guidelines and principles for those wearing face masks, for instance, they pulled it down, as if it's a fashion thing or let's do as they say way of wearing face mask. That happened mostly in suburbs where markets are not well organised. In the residential areas too, people mostly tend to forget and mingled with peers at some level of interaction and at later time they get conscious of the guidelines and tend to abide by it.

There is also life in transitional zones which is relatively well spaced than the residential and market places and they may behave well provided they are enlightened to understand the consequences of COVID-19 pandemic. The industrial zones, as the name connotes, may probably be empty due to concentration of industries with little or no residences. The theories are telling us to understand severity in transmission understanding the complexes of each of these layers and as well help us understand the setting of the society in relation to policies on palliatives, enforcement, reinforcements and enlightenment campaign to help get rid of COVID-19 pandemic. (prof.M.H. Bwala, 1998).

Life in highly urbanized city centre is known to be expensive, largely due to the heterogeneous nature of the demographic fundamentals as the significant numbers or segment of the population are believed to have shared different norms and value system and are mostly workers in either government or private organisations and who are by their very profession socially mobile as opposed to the lower working class in the same society.

COVID-19 has disrupted supply chains in most societies. The fact that humans exist as a system with independent and interdependent relationship for survival and coexistence, some members of the society and their entire survival largely depend on the degree of social mobility among those with sound economic base and COVID-19 has sealed the entire society at the expense of those within the lower strata and are dying or often times falling sick in both urban and semi-urban zones.

This is evidence when COVID-19 pandemic blossomed, especially on Sundays the life has always been low or Friday and life returns when the wage earners and employees return to their jobs to enable the lower working class and the traders to take advantage of such movement and then struggle around to make their livelihood. The recent development as a result of COVID-19 lockdown has seized and sealed the entire society and those at the lower stratum are dying of hunger and their immune system is getting lower by day due to lack of nutrition and proper diet to help sustain their system and to ensure good health and palliative are not forthcoming to supplement their condition as expected.

Most communities have large population with weaker economic base, especially the low income earners in the urban centres. Life has been so tough and challenging for them. In Urban centres, everything is costly and life is money demanding and the rents are also high compared to the suburb, countryside's and serendipity centres where casualty of COVID-19 is somehow higher than the city centres where enlightenment is high.

The spread of Corona virus at its peak was rampant, mostly in urban slums and fragile segment of the population and insecurity and social disorganisation is high in urban, semi urban suburb and serendipity centres. These have to be checked often by the taskforce on COVID-19 and enforcement official are to focus mostly on their safety and security of the general public. That helps in enforcement of COVID-19 laws and orders including social life in an urban slums and fragile communities where tendencies of transmission is rather high and frequency of violation of laws and orders, not only for COVID-19, but any other law is order of the day as the tenets of the concentric zone model suggests. Sociology of COVID-19 as guide to highlight and bring to fore the factors and social conditions which make it possible for people committing crime and deviant behaviour antithetic to COVID-19 order and the expectations of the generality which undermines the constituted authorities and laws on COVID-19 pandemic.(H. Kankiya, 2014; S.O. Smah, 2013),( M. Ibrahim, 1998).

People in the urban centres abide by the rules and they oftentimes are vigilant in maintaining social distancing and follow all the guidelines against COVID-19 and are therefore, relatively safe. A highly heterogeneous urbanized town where businesses are high and booming as ancient city centre are facing casualty and recording deaths due to lack of enlightenment at community level. 
There are increased cases of juvenile delinquency, domestic violence at community and household levels and the cases of battery among spouse and child abuse during lockdown for COVID-19 pandemic. In some communities, it is rather palpable that mob actions and antisocial collective behaviour are entrenched by COVID-19 pathological disobedient nonconformist individuals while undermining law, order and powers of the government on control on COVID-19 guidelines.(Olu Ogunika;1998);( Haralanbus and Holborn 2008)( Burgess; Parks 2019)

The most complex and heterogeneous city centres are apparently empty and the only one that is visible on the roads are cars or vehicles parked at the lots when the lockdown was at its peak in contrast to the low density and low intensity homogeneous towns and villages where there were movement and the implications of the transmissions was said to have been high and this is evident taking a glance at COVID-19 updated index cases and death, discharge charts.

Those at the bottom of the strata had faced serious trouble than those occupying higher position or whose labour were hired by either public or the private organisation and those who provide them services were stranded and lockdown hence the rate of COVID-19 pandemic and cases on daily basses and increased hunger, starvation is the order of the day. Some groups of youths staged mob actions against their own communities, ransacked and looted the general public, especially in highly commercialized city centres and the law enforcement was neutralizing their actions against government' s laws and orders.(S.O. Smah, 2013);(Olu Ogunika;1998);( Haralanbus and Holborn 2008);( Burgess and Parks (2019).

A highly organised elite residential areas or environment seem to be complying with the law and order with minimal presence of people in the street during COVID-19 lockdown compared to slums and downtown neighborhood where people move around at will and some do not even believe the existence of COVID-19 and therefore, continued to spread the virus. It' s obvious that, the law enforcement efforts of the government may not cover the populations ensuring credible enforcement for lack of logistical support and population strength that should go round all the communities to ensure enforcement of COVID-19 order, discourage members and to ensure compliance.

Lack of education and enlightenment has contributed in no small measures to the violation of COVID-19 orders and a highly enlightened society obey the rules simply because, they understand the implications of breaking the order and therefore all their streets and major roads were empty and they also have enough means of sustenance than the poor masses who must go out on daily basis to get food on the table despite COVID-19 pandemic and more often than not trapped for being scapegoat during the lockdown for COVID-19 pandemic.

Some lower working class lack better understanding of what is happening and believe that COVID-19 is not a threat to them. Consequently they violate the rules set for the control of COVID19. For them, hunger is even more damaging and more dangerous than Corona virus. In some remote communities, the people do not even know what COVID-19 is. In fact, they cannot even pronounce "Corona virus", talk less of understanding the implications of their actions in undermining the law and
order.(S.O. Smah, 2013);(Olu Ogunika;1998);( Haralanbus and Holborn 2008); ( Burgess and Parks (2019).

\section{Sociology of COVID-19: Social Grouping and Designated} High Risk Fragile Society: a Hub for COVID-19 Pandemic.

The social distancing as precautionary measures for bio-safety is apparently zero in most fragile societies. A fragile society is a weak society lacking in healthcare system with high vulnerabilities in almost all aspect of life and short supply of amenities with tremendous public health related issues and dominated by slums. While illuminating us on the features of fragile society, he pointed out, a fragile society, would be hit the most by CCOVID-19 as it lacks structural organisation with poor environmental sanitation all over.

The conditions of the local markets that are lacking in organisation are potent hub for the proliferation of Corona virus. The behaviour of members of fragile societies on food is another source of concern with diminishing power to run essential services and storage of food and drugs for preservation and water to promote hygiene and public health. A fragile society, he further added, encourages congested structures and houses with unprofessional, substandard building designs; socially proximate with high level of dysfunction of family values system.

The healthcare workforce is relatively small even at that, the few are ill motivated to contain confirmed cases of corona virus with myriad of diseases burdens with no surgical capacity. A fragile society ravaged by corona virus is lacking unique demographic identifier for social programming to inform socio-economic programmatic action plans with weak registration systems for trace, prevention and control of not only Corona virus but any social ill that may ravage the society in the nearest future.

The fragile societies need to step up to contain the challenges as COVID-19 ravaging the world and fragile societies are lacking common testing kits and looking forward to receive donations and the supply chains are disrupted. This scenario is so troubling and so Corona virus ravages fragile societies. COVID-19, Owen notes, the nature of traditional landscape of most fragile communities is in short supply of the crucial features of Owen' $s$ definition of postmodernism are either thinner or completely non-existent in most societies that are fragile. (David Kieghe, 2020).

Sociology OF COVID-19: The Dynamics of the X,Y Axis and Conscious Effort to Flatten the Curve to Discourage Human Traffic Connection and Social Mobility.

Drugs and vaccine productions for Corona virus are still undergoing an Atomic PEN structural synthesis and are yet to be discovered, but the good news is that, of the total worldwide confirmed cases of corona virus in the months of March, 2020 disclosed $40 \%$ of those affected are ill and on admission in various hospitals across the world, 56.6\% have recovered from the sickness; while $3.4 \%$ have gone to rest in peace due to the dreaded corona virus killer pandemic ravaging the world.

There are problems around micro and macro demographic explosion with huge change in density, for example, China has recorded $(80,738)$ confirm cases as at May, 2020 with slight increase as it rose to $(84,288)$ as at June 14,2020 . While Italy' s death toll was $(312)$ in May it rose to $(4,638)$ with confirmed cases of $(236,989)$ in June, 2020. Spain was in the range of (733) confirmed cases and (366) dead in May and rose to $(243,928)$ confirmed cases in June 2020. Iran recorded (674) and (17) dead, Iran was $(6,566)$ confirmed cases in May rose to 187,427$)$ as at 
$14^{\text {th }}$ June, 2020 and (194) dead in May rose to $(8,837)$. France was $(1,209)$ had lost $(19)$ to COVID-19 while as at 14th June 2020 France had $(193,746)$ confirmed cases and $(29,401)$ dead with greater consequential effect on macro-demographic transition, shift and tension that can only be corrected through vaccine, drugs and active planning around demographic formal (statistics) and use of valid and reliable empirical data and statistical measures as guide for policy formulations to better the social wellbeing of their population for better future.

It's obvious that Covid-19 has changed the global population patterns and structures with 'demographic normal' and that has enormous implication on global population size and density for change. Sociology of Covid-19 also tells us that the population demographic gap experienced for COVID-19 pandemic may never be the same largely due to population transition and migration. For example, the USA has recorded $(80,239)$ deaths on the 11th of May, 2020 and the curve skyrocketed to $(115,436)$ on 14th, June 2020. Similarly, confirmed cases was $(1,345,307)$ in May rose to $(2,074,526)$ as at 11 th of May, 2020. It is important to rescue the population from COVID-19 epidemic for better understanding of population change and management for key policy decision.

The fear of rapid transmission of the virus has instilled tremendous panic and cognitive dissonance. For example, conservative estimates of confirmed cases for COVID-19 in some jurisdictions was 13 index cases per day before ease of lockdown and suddenly, two weeks after the ease of lockdown and ban on sit-at-home lifted, the frequency of the confirmed cases rose dramatically along the $\mathrm{Y}$ axis raising the curve and skyrocketed index to 50 per day as at 11th, May, 2020 as opposed to conscious activities that would flatten the curve and the death rate was on the increase. A cursory glance at the conservative estimate of data on death from illness associated with COVID-19, the Y and X Axis dynamics around the curve which was made available by the WHO, CDC in March, 2020 is as follows: Tuberculosis (3,014); Hepatitis B (2,430), Pneumonia (2,216), HIV and AIDS (2,110), Malaria(2,002), Shigellosis(1,644), Rota Virus (1233), Seasonal Flu (1027), Noro Virus (548), Whooping cough (440).

Fragile societies are characterized by poor health system that requires a more comprehensive, credible and vibrant technologically advanced machines as feature of postmodern world to control the epidemic. There is also the need for constructing or programming the health system with socioprogramatic action plans and improved social behaviour for distancing to reduce the calamitous quagmire and its transfer. There has been increased of death rate due to deadly COVID-19 with severe consequential effects on the macro- population density of many countries around the world as South Korea has recorded confirmed cases of $(7,478)$ with $(53)$ dead. Germany (1112) cases and none dead. This statistical value was obtained as at March 2020.

However, Sweden, Belgium, Norway and Singapore had recorded an average of 100 confirmed cases for COVID-19; none was dead except Hong Kong that has 3, Austria 2 and Australia 3 dead. All of these can be understood from the viewpoint of macrodemographic, formal (statistics) for analysis of the severity or otherwise, negative impacts of COVID-19 on a given mass population (macro-demography) and change in population density due to COVID-19.

\section{Sociology of Covid-19: Philanthropic Gesture, Volunteerism and Family Palliative for Ameleoration of Suffering}

Qualitative empirical evidence from sampled communities in Africa suggests that there are numerous problems around palliative as support to cushion the hardship being faced by the less privileged individuals under the lockdown for COVID-19 pandemic. There are issues of concern around family as a unit structure and system to support communities with a view to ameliorating their suffering under COVID-19 lockdown.

Qualitative data obtained from snowballed sample of community member suggest there were unrelenting and humanitarian gestures received from philanthropists as gesture to ameliorate their suffering. The voluntarism efforts to support government in noticeable areas of gaps, especially law enforcement on social distancing guidelines and lockdown orders had suffered largely due to lack of uniformed and defined context and framework for engagement to help volunteering and support in distribution of palliative relief materials for COVID-19 pandemic.

However, that wasn't the case in volunteering engaging medical and paramedics who had framework supported by hospitals bureaucracy and organizational structures, principles handling emergency cases and situations, prompt actions and rules guiding hospitals as guide to their approach in volunteerism as framework and context to help COVID-19 patients at various hospitals. Owing to the fact that cases related to COVID-19 pandemics are emergency situations coupled with the nature of its fatality and higher risks being on the front line advocacy for COVID-19, most countries of Africa, especially in Nigeria, special allowance has been earmarked on daily basis to motivate those on the line of duty in many isolation centres across the country to volunteer in assisting government and to further help victims of COVID-19 at various hospitals across the nation. Thus; a defined organizational, bureaucratic structures as support for a defined approach achieving voluntarism in the fights against COVID-19 is to the credit of (Marx Weber's bureaucracy).

The negative social effect of Corona virus as feature of postmodern world has provided opportunities for some cruel while harming and extorting others for their entrenched personal gain and conflict of interest. Several cases are being examined, but there are cases of deceitful philanthropic gesture and support of sharing or reselling used and contagious surgical masks and that is harmful for family members to lure the fragile individuals in the society in the name of prevention to further compound the situation, especially the naive and timid members of some families in the society who believe in anything goes as mitigation measures, prevention, control or medication for the controversial quagmiric COVID-19, a mutation associated with enormous social problem to drain individual purse, especially in the rural areas; as a high risk or fragile zones and in some cases in the urban centres.

Philanthropic gesture, voluntarism and family palliatives during COVID-19 have been poor to support compliance for COVID-19 guidelines and general principles despite the fact that the government has made provision, but there was problem around the distribution pattern. The guidelines on COVID-19 mandate individual members of the society to-stay at-home, but on the other hand, it is a known fact that, human beings, by their very nature are mobile, sociable and accommodating. As a result, they 
move around to make ends meet and ensure the survival of their family members in the face of paucity of palliatives that would cushion their hardships.

Unless the presence of the government is felt, individuals would continue to wonder around and find ways of violating the guidelines, some deliberate, while others are pressurized by hunger and starvation, apparent lack of support, especially during the lockdown period. Therefore, a credible compliance with guidelines on COVID-19, especially the sit-at-home and social distancing from groups require prompt action by the government and philanthropists in the supply of foods and non-food items for enhanced compliance with the general principles governing COVID-19 pandemic across the world.

Paradoxically, COVID-19 phenomenon has its own advantage, especially for selected families who perceived the attitude of the breadwinners does not encourage stay-at-home, the lockdown has reduced tension and anxieties of most wives for having their husbands around and abundantly so. For example, for some women or wives who were distanced from their spouses or who persistently nagged for they hardly see their husbands around to spent time with them (or for the benefit of their children' $s$ socialisation for better upbringing) are happy today with their husbands at home for the sit-at-home guide for lockdown during COVID-19 pandemic.

With enough palliatives to support families on lockdown during COVID-19, community members would do everything humanly possible to reciprocate by supporting the government achieve desired result in the fight against COVID-19 pandemic. Otherwise, there would be resistance on the part of the people as potential pathways for civil unrest, demonstrations and conflict around communities already under the attacks of COVID-19 pandemic. Deployments of palliatives need to be encouraged and from time-to-time to make individual members of the society to recognize that government efforts are felt to ameliorate their suffering. For the government to achieve that, the importance of data and statistics to improve on planning and actions going forwards require latent and manifest functional system in support of efforts ending COVID-19 pandemic and that, cannot be over stressed.

The fight against COVID-19 has been an issue of major concern not only engaging the attention of the world leaders but also communities and the entire general public from around the world were being disturbed and for some their dreams cut short due to COVID-19 pandemic. Volunteerism is rather weak and random due to lack of credible context and framework for engagement in voluntarism, especially at community, grassroots levels to deal with the global emergency; COVID-19 escalation, which caught many unprepared for alternative measures and options as precautionary to deal with it. The well-meaning, spirited individuals have done their very best and their sense of humanitarianism is commendable during the lockdown for COVID-19 pandemic.

Volunteerism in the fight against COVID-19 pandemic also requires collective commitment of the stakeholders at various levels of professionalism in the ongoing engagement and fight against COVID-19 pandemic. As the Social PEN theory Esuggests, the medical, and paramedics on the front line advocacy for human resource-backup and capacity to improve on the life saving efforts during COVID-19 pandemic and as well offer first
Aid treatment. The Sociologist volunteers and contributes in providing thematic analysis of social problems bedeviling the society and community systems during COVID-19 pandemic with a view to providing pathways for social approach dealing with COVID-19 pandemics.

Similarly, other experts and specialist such as mental health, psychologist and psychiatrist help work at the family level to offer psycho-social support to victims of COVID-19 and depressed community members and social welfare officers to give proper counseling and mental health advises and community health workers to volunteer in providing support and guidelines on how to keep communities and environment clean and adherents to COVID-19 guidelines and general principles as stipulated by the WHO and Centre for disease control from around the world.

All these experts and many more specialists are needed to volunteer to handle one aspect of the society or another as backup capacity to overcome COVID-19 pandemics that has been ravaging the universe. The fact that COVID-19 is deadly and the rate of its spread is so high and catastrophic, volunteerism is sacrosanct as support and mechanism for increase capacity and backup to defeat the pandemic.

The volunteering effort of the community based civil society organisation is important as it will go a long way to help handle creating awareness and sensitization, especially at the community level on strict adherence to guidelines on social distancing to avert transmission of the virus and to carry out specific role in their areas in support of the government to achieve an all round and systematic approach dealing with COVID-19 pandemic especially, at the community level.

There is no gain saying that, the law enforcement officials are not enough to cover the whole society, especially in ensuring law and for the general protection of individual and community lives and properties especially, at this time of lockdown for COVID-19 and the rate of crime and criminality is on the increase which requires volunteerism as backup to help the police and other civil organisations to work in the provision of security and ensure law and order for the general peace of the communities on lockdown during the COVID-19 pandemics.

To achieve sound and result-oriented volunteerism to help save the society from the ills of COVID-19 and by extension associated social problems, the governments at various levels need to reciprocate volunteerism by supporting the volunteers to ensure their helping hands during COVID-19 in support of their communities is improved and therefore, government to beef up security infrastructure for an enhanced volunteerism and provide them with motivation and greater protection of participants in vigilantism, especially providing them with all the Personal Protective Equipments (PPE) as safeguard against COVID-19 virus in their personal level voluntary support to complement the effort of the governments while working with the conventional security and curtailing neighbourhood conflicts, child abuse, delinquency, rape, theft, gender-based violence, street corner gangster activities, among other ills capable of undermining peace, safety and security of communities in lockdown for COVID-19 pandemic.

The volunteer would also be of help working with the local police and law enforcement officials especially, to cover gaps when 
necessary, achieving overall safety and general security of their respective communities on lockdown for COVID-19 pandemic for communal peace. Organising volunteers and engaging stakeholders to actively participate in communal security during COVID-19 pandemic, the individual volunteering should be screened to ensure they are not exposed to the risks associated with COVID-19 virus and other criminal attacks.

For effective and result-oriented volunteerism, there should be proper legislative framework to support COVID-19 and other related matters which may also, includes, to help protect the individual volunteering in the wars against COVID-19 pandemic. There should also be specific role allocation for effective performance as emphasised by Kinsley Devi's and Wilbert E. More in their stratification system Many countries have deployed palliatives during COVID-19 pandemic but because of lack of framework, organisation and role allocation for officials to distribute it for the target less privileged on lockdown everything gone down the drain, in some cases siphoned and purchased of items for relief diverted and in some cases there were blames that those food shared as palliatives lack proper quarantine as check for safety and fitness for human consumption at entry point to the country and that created suspicion around those items and food to be shared may cause serious harm to the end user.

Should there be defined framework to tell us a well stratified division of labour in palliatives distribution and its well invigorated, for any case of infraction, the society would have those to be held accountable and specific official may be responsible for either deviating or lopsidedness and/or deviating from the set standard dealing with issues around palliative and its distribution during COVID-19 pandemic. However, that was not the case in medics and paramedics volunteerism in the hospital where specific roles are being allocated for effective performance as it's the known fact that, the hospital has routines and structured rules and specification on who would do what when and how as defined by the organizational structure and bureaucracy.

If roles are not defined within the context of job delivery in volunteerism for COVID-19, it hinders proper evaluation of distribution patterns and may equally cause disruption and inequality in the distribution patterns of palliatives thereby creating potential obstructions of peace. It is also potent to bring in politics for segregating some members who did not benefit from the palliatives and therefore, looking at the sensitivity of the needs to have human resource capacity as back-up to the existing officials, warrants volunteerism is no longer an option but a necessity and civic duty, especially for those whose capacity are required during COVID-19 pandemic so that together we build a better place for all and to collectively nip COVID-19 in the bud for better future, virile and vibrant community systems that should come out of COVID-19 pandemic strong, formidable and socially PEN indivisible.

Volunteering to overcome COVID-19 pandemic also includes the role of the local authority and conventional governance structure must also be alive to their responsibilities in support of the volunteers and work closely with one another, avoid rivalry and above all, ensure peaceful co-existence and harmonious inter- agency co-operation to ensure equality, justice and even distribution of palliatives amongst the citizenry. That will increase trust and confidence of the citizen to be on the part of the governments and by implications support any governmental projects, policy or further directives on lockdown for COVID-19 pandemic. Anything short of this, there may be resistance to law and order for blocked opportunities, hence poverty, hunger and starvation which have apparently caused citizens civil unrest and thuggery in many communities from around the world under lockdown for COVID-19 pandemic.

\section{Sociology of Covid-19: Social Demography, Research and Social Statistics}

Sociology of CCOVID-19 is interested in examining the implication of Corona virus pandemic on micro-demography; small scale population such as; families, communities, ethnic or religious groups and the structural changes experienced as a result of COVID-19 pandemic and it's consequential effects on members. It is rather obvious that smaller groups have lost their formidability for COVID-19 with enormous change in purposeful goals for which such groups were ab-initio established. COVID19 has left group members in doubt and somewhat, pessimistic for recovery of lost value systems that had hitherto sustained members for achieving purposeful life engagement, survival and sustenance of cultural beliefs and value systems.

The social distancing has huge demographic implications on social groups and gathering such as; clubs, beach, bars and Gardens are no longer tenable for COVID-19 pandemic distancing as one of the mitigating measures. It is also the same for ethnic, tribal or community meetings and gathering during weeding, funeral, naming ceremonies, etc have been put on hold and religions gathering; churches and mosques are either closed down or assigned specific number of persons to observe prayers while observing social/physical distancing measures to avoid transmission of corona virus.

COVID-19 is a new way of life and it is obvious that it has taken away group purposeful life engagement and members coming together are still yet to be decided. Also, COVID-19 has negatively impacted the macro-demogrpaphic settings of diverse human grouping as the size and structures of larger population such as the USA, Italy and Brazil has changed so significantly and the death toll in the USA as at May, 2020 is to the tune of 80,000 and by longitudinal projection, come August 2020, the death rate could be 137,000 due to first phase ease of lockdown as enabled by social mobility amongst huge population coupled with human traffic connection to increase death rate as the model, demographic longitudinal study suggests.

There are problems around population explosion with huge change in density, for example, China has recorded $(80,738)$ confirm cases as at May, 2020 while, the death toll was (312). Italy was in the range of (733) confirmed cases and (366) dead. Spain recorded (674) and (17) dead, Iran (6,566) confirmed cases and (194) dead. France (1.209) confirmed cases of COVID-19 and (19) dead with greater consequential effect on macro-demographic transition, shift and tension that can only be corrected through demographic formal (statistics) and use of valid and reliable empirical data and statistical measures as guide for policy formulations to better the social wellbeing of their population for better future. 
Sociology of COVID-19 makes enquiry about demographic gaps caused by COVID-19 and the lives lost and change in population transition and it's consequential effects on families; social life, domestic co-workers, violence; socialisation of children; economic life, etc and society in general.

COVID-19 has caused shift in demographic fundamentals and had generated high demographic tension or speed up or slowed down cases of birth rate as meeting between spouse during lockdown may provoke persistent meeting and pregnancy issues or slow down and it is believed to be on the increase with higher death rate during the lockdown due to hunger and palpable deficit in palliative humanitarian gesture to cushion the hardship experienced by the members of the communities, especially the down trodden masses and domestic violence between spouse are said to be on the increase all of these have greater implications on socialization of children and increase in aggressive behaviour through imitation.

It is obvious that these changes have enormous negative impact than the positive, especially in change demographic characteristics of their citizens with enormous change in income as businesses are closed down, age as COVID-19 affects the aged and religion on morality and group social solidarity. Also, it affects education of children for the long stay at-home for the pandemic, sex the females are safer than the men with excessive power of having their men around and at all times.

Similarity, there are issues of discrepancies in reporting the case of COVID-19 as the female population is not separated from its male counterpart in relations to confirmed cases and dead to suggest demographic normal (statistics) to inform planning rather lumped of demographic characteristics and that has created gap in better understanding of what gender or aged group are more affect than other characteristics for clearer variability in relations to COVID-19 cases in the reporting.

However, at the moment, the situations are being examined by experts, scientists and the Mac-world for solution and COVID-19 is ravaging and has altered the general population with greater implications for some time to come. Also, Sociology of Covid-19 examines the relationship among people due to corona virus pandemic and the effect on demographic social mobility; as members of the society are now under lockdown and there is no interstate movement while the ease in the first phase lockdown is rather calibrating and speeding up the scale of the virus in terms of transmission than solving the problem as many countries whose lockdown were eased apparently experience sky rocketing of the curve than flattening it altogether.

COVID-19 has demographic implications on national and population planning as countries that are into population control programmes may experience significant reduction in population and those of Africa whose belief is influenced by cultural forces, may have population increase due to lockdown and meeting with their spouses more frequently with less family planning.

Corona virus spreads faster among diverse populations due to movement of persons around the world and that was the more reason why people get infected of the virus and social distancing a nightmare, especially in African societies. However, segments of a particular population may have moved to infect another population ca Also, migration affects population that moves for the fear of COVID-19 pandemic and the change in the population

This publication is licensed under Creative Commons Attribution CC BY

http://dx.doi.org/10.29322/IJSRP.10.07.2020.p10353 of new settlements and the implications of interstate lockdown on population growth.

It's obvious that, Covid-19 has changed the global population patterns and structures with 'demographic normal' and that has enormous implication on global population size and density for change. Sociology of Covid-19 also tells us that the population demographic gap experienced for covid-19 pandemic may never be the same largely due to population transition and migration. For example, the USA has recorded 80,239 deaths and 1,345,307 confirmed index cases as at 11th of May, 2020. To rescue the population from COVID-19 epidemic and for better understanding of population change and management for key policy decision.

COVID-19 is becoming so alarming and disturbing, a situation that can best be described as Tom Wicker knocking on the doors. Wicker was very popular for his Book entitled 'a Time to Die' just as COVID-19 is driven by social PEN energy of (+-n), it' $s$ invisible and human as carrier of the invisible virus (of death) for its transmission. Social distancing as solution, which emphasizes the imperative of sociology of COVJD-19 is to discourage its transmission to ensure change as global solution against covid-19 pandemic.

There are demographic issues around Corona virus and Sociology of COVID-19 has implication on economic, biological and social fundamentals of human existence as interdisciplinary approach to population issues in social demography and population density and change. Sociology of COVID-19 is telling us to check for changes in micro demographics for corona virus that has happened during the pandemic to individuals, small groups and neighborhoods and how COVID-19 change their behaviour and global thinking, size, health practice and migration of individual family was limited by the lockdown and as well discourage social mobility of members of the macro demography.

COVID-19 has caused a generational shift in family structures, population density, maternity and morbidity rates and social mobility or immobility gaps and that is evident looking at the index cases versus state's death from the pandemic.

People of diverse societies are suffering and their demographic characteristics should be understood from the view point of sociology of COVID-19 via individual status, culture, identity, rich or poor, but it kills and people are dying all over and everywhere around the world. That concerns sociology of COVID-19 and demography in general in understanding the dynamic structures of the population and change.

For instance, the negative consequential effects of Corona virus on diverse population of human around the globe is presented in the month of March, 2020 and the conservative estimate made available by John Hopkins multiple report tells us that the fatality rate for the epidemic called Corona virus varies and therefore, it is relative from one country to another.

The demographic characteristics and strength of the virus is influenced by the very social and physical environment, weather, geography, etc. The socializing nature of the population on faceto-face basis is neglecting the socio-physical distancing principle as mitigating measures for its spread among people.

However, drugs and vaccine productions are still undergoing Atomic PEN structural synthesis and are yet to be discovered, but the good news is that, of the total worldwide confirmed cases of Corona virus in the months of March, 2020 disclosed $40 \%$ of those affected are ill and on admission in various hospitals across the 
world, $56.6 \%$ have recovered from the sickness; while $3.4 \%$ have gone to rest in peace due to the dreaded Corona virus killer pandemic ravaging the world.

Sociology of COVID-19 therefore, presents social demographic fundamentals caused by COVID-19 on population and changes that happen overtime as a result of the pandemic and the shift among diverse population defined by their very characteristics. However, corona virus reduces the electroneous E- drained human among a given population dominated by the PEN forces (+-n) of Corona virus in the society, especially those whose health conditions are bad owing to the fact that, they can hardly compete in a diverse population and highly competitive post COVID-19 environment created by corona virus.

Post COVID-19 society is assumed to be a highly IT driven and capital intensive society of human, so to speak. Corollary to that assumption behind Sociology of COVID-19 is that, if the hypothetical statement holds, then it goes to say that the remedy for COVID-19 lockdown may be handled with ease and as short term solution, there should be conscious deployment of $\mathrm{P}+$ and $\mathrm{E}$ elements of the social PEN theory to demarcate, sieve or (if you like filter) the population with a view to isolating the class with higher index cases and contact tracing among the general population.

Afterwards, the class with higher cases can be grouped and their frequency distribution of the individual members of the society with Corona cases to tally with the sick and aged who are Edrained from the active and potential electroneously E-powerful productive young men in the population and then establishes aged institutions for referral and confinement of the old and to render professional services of helping them with a view to enhancing the capacity of their social function and to provide them with all the necessary health-related facilities that would go a long way in providing a conducive and favourable atmosphere for them as short term solution and humanitarian measures pending vaccine production, drugs and other orthodox measures and scientific approaches of handling Corona virus related cases devastating the world.

Sociology of COVID-19: Social Distancing a Sociological Perspective, the First Phase East of Lockdown and the Dynamics of Reopening

The dynamics of the reopening during the first phase " ease of lockdown' doesn't speak well of the attitude towards COVID-19 with insignificant degree of observing the social distancing measures. The problem of associating and socializing on the basis of group and inability of individual members of the society to maintain social distancing at business places, community level and market places, is rather a nightmare. By and large, simply put, 'social distancing' as perceived feelings of social separation or distance between or among groups which of course, includes separation of two or more groups in practical application of the term dealing with covid-19 pandemic.

The first phase of the ease of lockdown in some jurisdictions witnessed a mass and densely congested people in most strategic business places such as banks and market places, falling short of stampede, with glaring push and pull, body-to-body and shoulderto-shoulder while trying to have access to premises of most banks to get cash. (O.H. Opeyemi; 2020)( Laster F. W. 1968);( Thomas K. 1962);(Elizabeth K. R. 1969).
Dealing with Covid-19 and its mitigating measures such as social group segregation/social distancing, principle and guidelines, including the lockdown or site at-home, are completely a new way of life and socialization on 'Bogardous scale' and as a onerous tasks leading us to a newer world of Covid-19 world completely, a schema defined by 'sociological determinism' and it is to the credit of 'Darwinism' and by implications 'Malthusian theory on Population' as consequential for COVID-19 pandemic.

Sociology of COVID-19: the Sociological Definition of the Term 'Social Distancing'

Social distancing: Simply moving away from social group activites to be safer and taking responsibility to ensure a safer society. It's purely 'social' and the definition of 'social distancing' has been supported by established sociological literature in the work of ('Hogan Sociology', 2006, Pg: 331) while the space of 6ft between individuals (if you like) man-to-man or social dispersion from group or isolated social molecular groups to avoid contraction or being infected of Corona Virus. There is paradigm governing 'social distancing', and so it has a philosophy and epistemology governing the guidelines policy on COVID-19, transmission from human to human through social interaction. Therefore, to avoid being infected, members of the society need to be socially distance from one another and safeguard themselves with face masks and as well adhere to the high powered authorities at the level of the $\mathrm{UN}$ and $\mathrm{CDC}$ guidelines and principles on 'social distancing'.

Corollary, to the above, there is an ongoing debate among scholars that, physical distancing should be the most appropriate term to use other than social distancing as one of the mitigating measures against COVID-19 pandemic. The left wing conservatives highlight their argument on the simple ground that, the distance is physical and social distancing allows conversation on phone so, humans are therefore, still socially connected. They argue that, if people are socially distanced then it means they cannot converse on phone. Since people distance themselves from one another and to also get opportune to converse on phone, it means they are not socially distanced. This argument lacks substance, because there is an existing literature to support social distancing as the most appropriate term to be used and not physical distancing. The crux of Sociology lies on empiricism, i.e. the sense perception reference FGD, and interviewer-interviewee situation, verbal and nonverbal responses and gestures constitute the core of the discipline of Sociology for evaluation and gauging the social life of an individual or individuals. The fact remains that, there is nothing like physical distancing if we are to talk about distancing as mitigating measures against Corona virus.

Conversation on phone, as they argue, lacks perfect relations as social but rather, the face-to-face interaction is considered as social where emotions and sense perception are gauged. Talking on the phone is communication and not social interaction and therefore, social distancing is the most appropriate term and not physical distancing as erroneously perceived by some scholars. Although social distancing is a nightmare and that is why it is difficult to be maintained and practice, hence violation of guidelines and distancing principles. Social distancing has it's weakness as human must relate for his own survival and as well for their livelihood as members of the society largely need to depend on congregation than group segregation. 
(Hogan, 2006, Pg. 331) has provided a comprehensive sociological definition of social distancing as it has been the one applied to COVID-19 pandemic and as well as social telesis which shows the relations between physical and social world. What is social in conversation is the scenarios which unveils the face-toface, the verbal and non verbal, the emotions, gesture and senses perception constitute empiricist imperatives and consideration in Sociology and social science in general.

Social Telesis is a term used by (Lester F. Ward) meaning as 'social Telesis' an idea or a conscious and rational control of societal development in an intelligent and orderly manner for the attainment of 'social goals' in the 'physical world' for 'social ends' and the 'social world' for 'physical ends'. COVID-19, is ' social fact'. Applied sociology of Covid-19, sees social facts as the bedrock upon which sociology as a discipline revolves.( Laster F. W. 1968);( Thomas K. 1962);(Elizabeth K. R. 1969).

This is so because; Covid-19 is a 'social facts' external to all members of the society and it has, to some extent, constrained individual' $s$ action in the society. The fear of Covid-19 is highly coercive and it is an objective reality than subjective in its believe and by its definition, standard, power and practice. However, the term social distancing is contextual here and is utilized as one of the mitigating measures for ending Covid-19 pandemic that has taken the world by surprise, hence relative and contextual,(Hogan, 2006).( Laster F. W. 1968);( Thomas K. 1962);(Elizabeth K. R. 1969)

However, this notion is relative to social segregation, a viewpoint once reinforced by W.A, Ghazali, 1998 to mean as feature of a more organic society like postmodern society characterized by COVID-19 pandemic. The more society evolves, he noted, the higher the degree of sophistication and complexity and increasing individualism to permit distancing. And, the society he reaffirmed would have more capacity of increasingly higher sense of 'I' than that of the 'we' and such a society, he went on, would have higher sophistication with high degree of division of labour and simplified ways of doing things, facilitated by technological advancement as Organic fundamental to enable all these to happen to affect man's life in the society, a caricature of the phased change in societal evolutionism typical into 'The New Normal'. (W.A, Ghazali, 1998)

Most traditional concentric residential settlement around slums are made up of 'broken homes' so to speak, with little or zero level of tolerance for distancing as red zone concentric for criminal hideouts and a hub for law breakers for COVID-19 pandemic. Covid-19 has expressly demonstrated power over all men, all societies from around the world as members of the society run away for it, lockdown for it, closed borders for it and commit colossal sum of protoneous ( $\mathrm{P}+$ capital funding) and electroneous (E- human resource capacity) for its containment and all seek for solutions overcoming Corona virus, a threshold and stepping stones for post-COVID-19 world of human as social fact. (Emile Durkheim, 1895).

Be that as it may, what is considered as sociological is the ability of men to mutually agree to come together and to disperse afterward better yet, interact in spite the distance communicate through a medium such as handheld (cellphone) provided by IT is enough a point to underscore the relevance of the concept 'social distancing' and the process through which one get to be infected of COVID-19 is more of sociological than any other means and therefore, the dominance of sociology in that regards cannot be underestimated.

Sociology of COVID-19: Ease of Lockdown, Stigmatization, Police Brutality and Blacks Uprising into 'The New Normal'

The first ease of lockdown has been characterised by horrible atmosphere especially for the black race in the USA were shocked and traumatized. Similarly, the Asians also, did not escape from the stigmatization that Corona virus blossomed from Wuhan China and the Africans were abused and manhandled in some jurisdictions and more often than not humiliated and frantically evicted from their homes, hotels and rented apartments, passports were allegedly confiscated and brutally stigmatized as carriers of Corona virus. The ease of lockdown has witness a hangover of COVID-19 crisis so to speak, a midst Corona virus pandemic as the situation has degenerated and evolves into a full blown blacks uprising and murmured crowds protest and blacks uprising for racism into 'The New Normal' and beyond that is still evolving. However, the only remedies for that is global consensus building to allow for mutuality and coexistence and respect for dignity, the rights and privileges of human person and as well reciprocal respect to constituted authority and demonstration of obedience to law and order. Aside the social ills, COVID-19 cases in the USA have been on the increase, the same in Brazil, India and other jurisdictions as Texas and so on as potent hubs of the pandemic owning to social distancing being a nightmare in the absence of drugs and vaccines for the cure of COCID-19. The conservative statistics of the affected persons on global scale for COVID-19 is estimated at 4,165,752 confirmed cases and 285,307 deaths as at 11th, May 2020 compared to 10,168,657 confirmed cases and 502,387 deaths as at 29th June 2020. However United States alone recorded approximately 80,000 deaths and 1,345,307 confined cases for COVID-19 in May 2020 and 2,549,069 confirmed cases and 125,803 deaths as at 29th, June 2020.

COVID-19 is an invisible virus and as well indivisible as to it's existence as real which has ravaged the universe of diverse human race. Corollary to that, COVID-19 pandemic is ravaging and changing the world albeit, gradual and that change must happen in phases reminiscent of social evolution of C. Darwin, W.W. Rousseau phases of development, Maslonian hierarchy of human needs or Comtean theoretical phases of human progress of scientific stage and so ' The New Normal' is not an exception to such gradualism in its evolution as a transition towards comtean positive stage of the society.( Maslow, A. H. 1970; Darwin, A. Comte; WW Rousseau; John Hopkins, 2020). (A.K, Jihomborykwau, 2020).

Again, there was wrangling between the police and the public culminating to blacks uprising and struggle for redemption of blacks civil rights for equitable justice. The blacks staged protests against alleged murder of fellow black and that also has aggravated and sustained real and perceived injustice and discrimination that is systemic created scenario synonymous to 'Blacks Versus White' pandemic in the west and 'hunger Versus Corona' pandemic in the most fragile and vulnerable societies around the world.

A mammoth crowd took to the streets while protesting and it was all over the world seemingly preponderated struggles in the street of the USA and the UK for perceived police brutality and alleged manhandling and murder of George Floyd who was strangulated in Minneapolis in the USA by a police officer while kneeling down 
on his artery around the neck obstructing blood flow around his veins. This ugly trend led to protest and eventually, culminated once again, to the shooting of Mr. Rayshard Brooks during the struggle for blacks' redemption in the USA and similar protest was staged in the streets of the UK and elsewhere.

A number of commentators perceived such scenario as the hangover of sustained cognitive dissonance, stress and burnouts for COVID-19 aggravated systemic and sustained discrimination and lack of justice for the Black's as many of such ugly trends had happened in the past without justice for such manhandling by the powerful against the powerless in the USA and elsewhere around the world, 'Iron law of Oligarchy'. Post COVID-19 society atmosphere will degenerate and if not carefully managed it may escalate into another crisis.

'The New Normal' as post COVID-19 society is characterized by stress boredom and psycho and physiological consequences due to uncertainty, hence oblique for many who ask; What next? The ease of lockdown and COVID situation which has threatened many, especially those in a capitalist society as USA and UK require psychosocial support for the panics and cognitive overload and burnout during work from home and being in the front lines while volunteering. However, COVID-19 might have been the causative agents for distress and anxiety as many were seem during the protest looting, shoplifting and pilfering public items in the name of fighting for right and justice..

Social evolution is waxing stronger. This viewpoint is supported by Khaldum and Darwin (1968 [1859]) in one of the most actively cited theories of evolution which was supported by Durkheim (1965 [1912]). Society is never static but a dynamic social system now and beyond, COVID-19 pandemic with protest and wrangling for justice and power balancing. This view point is reminiscent of Harber Spencer's proposition and further supported by several works that human society changes due to happening and events in the society through social interactions.

Similarly, Ralf Randerendorf (1959) Notion of society has been characterized by conflict situation and emphasized on 'Authority and Conflict and 'Class and Class Conflict in an Industrial Society'. However, the position of police forming part of authority vis-a-vis the role of citizen and the interplay of the two parts determines the perceived racism and struggle for justice and liberty for example, in the context of US society. Karl Marx (1848) buttressed on the conflict which ensures change and eventually ensures an egalitarian society antithetical to Iron law of Oligarchy characterized by utopian mentality of the highest order albeit evenful.

Emile Durkheim emphasized the need for peace and consensus building for ending the conflict situation and equal resistance may be conflictual while capable of throwing the society into 'Anomie' conditions. The power of the USA can hardly be undermined. Just as a reminder, William Blum had this to say; the powers of the Mac-World has been captured by William Blum in his Book "The Rogue State; A Guide to the world only Superpower".

Blum narrates, "Never before in modern history has a country dominated the earth totally as the United States does today". America, he added, " is now the Schwarzenegger of international politics: showing off muscles, obtrusive, intimidating...The Americans, he concluded, in the absence of limits put to them by anybody or anything, act as if they own a kind of blank cheque in their 'MacWorld'.(Der Spiegel, Germany's leading
Newsmagazine, 1997) quoted by William Blum (2006). And, consensus building and civilized ways of handling two incompatible forces to coexist in peace and harmony should be the prerequisite synonymous to respect for law as the newer norm to govern 'The New Normal' and beyond postmodernism to usher in establishment of the Comtean positive (scientific stage in the development of the society. (W. Bulum, 2006); (Dahrendorf, R. 1959);(Francis F. 1992);( Kaufman R. J. 1992).

Furthermore, there was also increase stigmatization. Only during COVID-19 pandemic, Vancouver police recorded 20 hate incidences in 5 month compare to 12 altogether in 2019 mostly directed on East Asian, and they were looked at with disdain for COVID-19 blossomed from China. The attitude of the public on Chinese people was disturbing and the level of stigmatization and hate was on the increase. Data reveals that an insulting statements directed at East Asian were recorded as ' go back to your country; that is where it all started'.

The Chinese were seen with suspicion all over the world for the Wuhan escalation of the novel Corona Virus. There are hatefuelled incidences and racism. And, there were agitation and bigotry in Canada and such scenario appeared to be strength for the Chinese and they lament of physical, mental and psychological imbalance for such accusations just being citizens of China and the labeled against their person. Chinese all over the world are in great fear, anxiety and some are depressed for the unnecessary harassment. (Globe and Mail, May, 2020).

All of these human activities would have impact and consequential effects in changing decision and shuffling policy bearings and directions in an attempt to address the ills of the society and thereby induce change that are immediate for long term gains, hence change the working of the police for better and that by implications would change the structural arrangement of law enforcement as an institutions of government and subsequently change is achieved as the USA' s reformatory measures and parliamentarian are also debating on issues of national importance and bill as it relates to racism and justice system.(S. Probst; N. Carrington; A.A. Howat; 2020).

However, Robert K. Marton propounded on the 'American dream' which depict social justice, equal rights, opportunities and privileges but member of the society are constrained and as well restrain by the role of the institutions from achieving those goals. Robert K. Marton therefore introduced 4 modes of adaptation thus; Conformity, Innovation; Ritualism; Rewrites and rebellion. This mode of adaptation has perfect frameworks to describe the behaviour of the crowd during such protest against racism and agitation for redress around justice issues. Robert (K. Marton,1952); (Talcott Parsons, 1945)

The USA was under fire as protesters took to the street and the rebellious, disobedient individuals are also taking the laws into their hands by destroying the Confederates; artifacts Statues and non-artifacts material aspect of man's historical monuments. COVID-19 pandemic has sandwiched a huge mammoth crowds of protesters coupled with Corona Virus pandemic at the other end of the spectrum.

However, here come a voice from Sociology of COVID-19 and as a black race, I share the grief with you guys as folk and the sad moment of global crisis characterized by confusion and we are concerned and well affected by the melancholy. My prayer for your struggle is for peace and social justice to reign supreme.

This publication is licensed under Creative Commons Attribution CC BY

http://dx.doi.org/10.29322/IJSRP.10.07.2020.p10353

wWw.ijsrp.org 
There is no point for racism or racial discrimination in a highly rated civilized society as the USA. Even countries in transition would have no better place to undermine social freedom, liberty, rights and social justice in postmodern world like ours. Discrimination should be seen and viewed with disdain as archaic, antisocial behaviour in a globalized world and it has negative sociological implications around thwarting societal progress, peace and unity among diverse and multicultural complex human grouping as the USA.

The blacks struggle against racism henceforth, requires tremendous sense of organization around group behaviour and the struggle should also combine with an outlined areas of dress to channel through the most appropriate legal means than to allow the protest to escalate and furthermore, to deteriorate to stage two or three for the hoodlum to take the garbs of the protest as many shoplifting, looting and pilfering were seen taking place in the streets and major road. Agitation and demands for justice requires systematic step-by-step approach dealing with situation in a round table and dialogue while eschewing differences through mutual consensus than taking all to the street at the expense of peace makers.

Unorganized group behaviour as protests in an organized society like the USA in postmodern times, may be 'a waste of time' and perceived as anarchy, act of terror and challenging constituted authority is rather altogether a zero sum game but there is benefit in maintaining peace and exploring opportunities of dialogue and compromise.

Sociology of Covid-19: Critical Issues, Radical Departure from MetanaRaTives, Public Views and Opinion

The sociology of COVID-19 presents critical issues that are historically located, politically potent and economically relevant and of course, socially significant derived from the voice of the individual members of the society from around the world while findings are presented herewith. However, those views and conceptions may be true, biased with inclination to prejudice while some may be altogether false. Therefore, what is to be presented under this sub-theme may be subject for further interpretation and reexamination for their factual nature and disposition. They are not my saying or views but examination and analysis of data. High or low data speak volume and are therefore not sacrosanct. Data analyzed under this sub-theme are mainly, primary; through verbal face-to-face and telephone conversation, transcription of video clips and secondary written text as data and composed short stories as expressed views of the commentators about COVID-19 pandemic. Also, write-ups were utilized as sources and frame for this line of thoughts. There were haunches around the following questions: Why COVID-19 pandemic? Who should be held accountable for COVID-19 pandemic? Where was the genesis of the pandemic? Where is COVID-19 pandemic leading us to?

However, the belief of the majority is that there are number of indices and some also were of the belief that, COVID-19 is rather from God as Corona virus was sent by God as punishment for the sins individual members of the society had committed on the surface of the planet earth and therefore, held the believed that, COVID-19 is an act of God as punishment.

Some respondents and sources may be sentimental with political undertones and the stance of their views and conception for COVID-19 may be questionable in terms of its reliability and validity criteria and therefore, may or may not be ascertained and some may be true, exact or near exact and others are mere fishing expedition as COVID-19 is so slippery to be concluded upon. Yet, the individuals are entitled to their opinion as empowered by Freedom of Information Act.

Perhaps, such views may provoke consciousness and potent enough to create pathways for rethink as pedestal to ponder upon a little more of COVID-19 pandemic and its implications on society and for our existence as human. It is also the belief of others, especially political sociologists and demographers who are very much keen in demographic characteristic of the population who had suffered for COVID-19 pandemic and population density and its control, power relations, change and the effects of COVID19.

The general public has array of perspectives on Corona virus pandemic. They have presented different views and conceptions and this views are aggregated to explain their feelings and majority have stronger believe in the existence of the virus and have since put in place the social distancing principle as a new world order of sit-at-home or is it stay-at-home and/or clampdown for quarantine and improve hygiene. People are keen in avoiding handshake, washing hands regularly, using surgical marks and encourage elbow greeting. It is obvious that government, through its appropriate agencies, is going round to discourage public gathering in some instances, forcing public not to have clubbing around and so on.

While there are perspectives contrary to the 'meta-narratives' built around social distance as radical departure from the general believe, some members of the public go about their business and have since resigned to fate that Corona virus is not their portion and God is in control. Churches, mosques around observe their prayers and hold community services and meetings as usual. The world is changing and very fast for that matter.

There were insinuations around technology as the main cause of the pandemic. Some people claimed that, $4 \mathrm{G}$ network is somewhat, not effective to provide the kind of speed needed for efficient use of digital identification and therefore, $5 \mathrm{G}$ network is required for its efficiency at short distance. The wrangling trade deal between the USA and China that was signed on 15th of December, 2020 had created a lot of suspicion around COVID-19 pandemic and who should be held accountable.

A source also claimed that, six weeks after the trade deal was signed, the trade truce was further signed again as phase two of the deal. The source also, claimed that, "the Chinese had made a very clever out clause that, they made sure was not in there which said, "if there was any kind of an act of God, Pandemic" then within days they announced the first 'Corona Virus'.

The compelling question is that "did the Chinese know that Corona Virus was running around the world for six weeks before they shut down Wuhan?" The answer provided by the source was "Yes! Another question raised, did such actions amount to crime and criminality? The source further said in affirmative!" "Does this deserve to go in front of the world tribunal? The source answered Yes it does!. The source further added that "the unfettered travels that made the virus a global phenomenon impossible to contain and claimed that, China knew it almost 6 weeks of its escalations and wanted that out clause and still underreported what happened in Wuhan.

Therefore, China should be held accountable for not providing valid and reliable data of the damages caused by COVID-19 in 
Wuhan". "For, if that has been done earlier, the rest of the world would have been prepared for fewer people to die". The source felt that, "COVID-19 was equivalent to an act of war on the part of China" and, added that "COVID-19 was first reported as flu and within 24 hours of the South Korean's first case was reported, the USA case also been reported and reiterated that, someone should be held accountable".

There was further argument that, "Of all these happening, for almost six weeks of enlightenment among Americans that, it's just a flu while South Korea was testing her citizens for COVID-19 and shutting the country down". Therefore, the source argued that, "there were many responsible bodies that had taken the world to the point of where we are right now". "They may be inside the country or in China and they need to be held responsible".

While responding to a question, the source said, "there is no point to ask whether or not it was a manufactured virus and set upon the world". She further held the belief that, "you don't even have to go that far, "If that was known by China for six weeks before saying anything at the global stage just to get the trade deal signed, so, somebody needs to look into that because countless lives have been lost and people are still losing their family members as a result of that". And "the scenario is capable of bringing about suicide, economic hardship, and all of that would have been mitigated if China had been honest of the virus...." (Withheld, an electronic source, 2020).

In some quarters, some were of the opinion that COVID-19 is an attempt for global siege to control human being. COVID-19 enables control of members of the society, same as we control our devices by sending signals to the brain. Some of the claims make reference to movies such as 'Divergent from 2014, a new world order;' that COVID-19 is an attempt to control the world via vaccination containing microchips digital ID-2020 alliance manifestos, highly innovative as public private partnership (PPP) committed to improve life through digital identifications, so that, human beings can be manipulated and controlled for global domination and change.

Nonetheless, for some, Corona virus epidemic is interchangeable with transition to another world of IT for global capitalism and its expansion among 19 COVID (or is it 20 COVID) countries to take over the markets of the smaller nations. The world ruled by information technology, monitors everything. Movement would be monitored, transaction would be monitored.

The entire world is left at the mercy of the most dominant-19White-Winged-COVID, corona in the world. There are great beasts of burden on individuals, families and communities who are perhaps, innocent and not ready for such biological warfare from around the world. There would be severity around social responsibility and commitment of individual members of the society if the Corona virus is not contained by observing the mitigating measures as precautionary, and immediately so.

In post COVID-19 world, there would be significant change around moral values. Social life would be automated for COVID19 and relationships are further reinvigorated on wire than physical face to face. There would be significant change in structure, social economic and political life. There would be excessive regulations and capital reintegration to define the brand new phase of human life. Our relations to IT facilities would be improved with enormous cost and there would be clampdown on sites and applications would be paid and to the credit of COVID19 , same as we purchase token for electricity.

There would be uniformity in social relations with pattern and individual action and life would be changed tremendously, a pathway to what (Hogan, 2006), called 'mathematical sociology' with exact formulas to define activities of human by eliminating the qualitative aspect of life such as face to face relationship.

Travels for businesses, leisure and tourism will reduce and there would be more official travels and engagements in the post Covid19 human society. There would be high precipitation of social dynamic density in the society. More structures would be converted to warehouses, humanitarian institutions and hospitals. The rate of charity and humanitarian assistance will increase, only to exist for a short period of time.

Social distancing may be seen to have provided a safety net in curbing the spread of corona virus but it has pushed the downtrodden masses or the most fragile segment of the population to high risk zones, leaving them in situations best described as jumping from " frying pan to fire" as no provision was made for their sustenance. The imposed lockdown, being a necessary aspect of social distancing and the new world order in postmodernism, has proved to be more of a nightmare for the ordinary citizens Downplaying and declining on genuine statistics, Corona virus and its implications have enormous existential threat to social life as gatherings and meetings are forced to extinction, businesses are closed down and members of the society are forced to avoid social demographic meetings of over a hundred (100) persons because of the virus. Consequential multiplier effects on socio-economic and political fundamentals are as highly communicable as the virus because the acceleration of its transmission among human is faster and calamitous.

More so, if the so-called killer pandemic is not properly handled and urgently checked, it may exponentially and profoundly increase in its intensity and open up to a range of bio-holocaust of very high magnitude around the world and only strong countries with a credible workforce, health system and capacity would survive the momentum. Stringent measures must be taken to improve on the health system and the WHO guidelines on quarantine for safety, prevention and control must be totally complied with, if we must overcome the ills associated with Corona virus.

\section{Sociology of Covid-19: Anthropology African Society's Belief} System and Religion

Sociology of COVID-19 examines the pandemic from comparative Anthropological study of human race, the goals humans set for themselves and how they could attain to such goals especially, with the changes experienced as a result of COVID-19 pandemic. This dimension of Anthropology is oftentimes, referred to as an 'Action Anthropology'. African's belief system and comparative cases of diverse religions and its implications on man's social life, while taking into accounts the African societies, their cultural activities such as belief system, norms, values, cultural rite and religious practices and the influence of COVID19 pandemic on those structures.

The Anthropological analysis of issues in relations to COVID-19 pandemics take into accounts the emergence of new culture 
associated with COVID-19 which has changed the attitude of community members and direction of their life and social relationship within their social milieu.

Religion, cultural practices and some of the scientific approaches that had been employed in phased reopening of lockdown and its implications on human race across the globe is enormous. COVID-19 has contained in it social forces of redefining the entire race and their existence as human with consequential effects on man and by extension the entire society due to the consequences associated with the pandemic.

The emergence of the new culture, interrelationships of cultural traits, geographic, environment and historical context which also includes social structural changes is rather due to COVID-19 pandemic and that can be understood from diverse dimension thus: Socio-cultural, Physical, Archeological, Linguistics and Ethnographic and Action Anthropological perspectives in relations to scientific study of human race, cultural evolution and how human races differ in their life style and cultural identity, ( Hogan, M. O. 2006).

Sociology of COVID-19 also examines the influence of the pandemic on human race and development and the capacity of COVID-19 when it was at its peak banned congregations, no naming ceremonies and gathering and it has entrenched new value system characterized by social distancing washing of hands, no handshake are the orders of the day. All of these new changes have transformed and altered man' s skills and knowledge in search of traditional cure or medicine against COVID-19, orthodox and non-orthodox peculiar to his tradition as solution against COVID19 pandemic.

However, COVID-19 has changed perception of diverse people due to the forces associated with it and the emergence of new culture and socialization has introduced shift in many cultures and that has the potential of changing or transforming attitudes and behaviour of members of the community, especially with social distancing guidelines and their relationship with other humans and population change.

This incisive line of thought is reminiscent of Anthropological thoughts and classification of human race by Processor, Musa. Abdullahi (1998) in our undergraduate study referred to as "Mongoloid, Caucasians or Negroid". COVID-19 has higher intensity of curtailing social relationship and to encourage social distancing especially, for those who must hump around to get their livelihood. Corona virus has enormous capacity/potential for slimming down the hope for better tomorrow. However, for those who deliberately roam about the street during COVID-19 pandemic and since their behaviour is not sanctioned by the government and leveled roaming around during pandemic as deviation from the set standard as norms, then the society needs to deploy 'guilt' and/or 'shame' culture against the erring individual's abnormal behaviour. (M. Abdullahi, 1998)

Shame or guilt culture in Anthropological sense is a form of 'social control mechanism' in which society members would collectively make deliberate actions of curtailing a person's behaviour in order to transform his attitude and to align to context and general expectations of the entire society. Although, 'guilt' and 'shame' culture in Anthropology is an approach of transforming individual behaviour to align with context and it may be effective in rural societies where you have homogeneous population willing to partake in such social control mechanism than in the urban settlement that is complex and heterogeneous and that is relative to other cultures as witchcraft and manhunts.

Similarly, Sociology of COVID-19 is telling us that, there is an emergence of new culture. The culture that has substituted our previous forms or ways of life for COVID-19 and that has challenged not only religion but also social, economic, political, family values and education and to reverse those trends requires sufficient time for the discovery and production of drugs and vaccine to suggest the next line of action and perhaps, the reversal of some of the changes may not be feasible, but the decision on the phased change plan as guide will suggest a newer tradition for COVID-19, especially the new life in post COVID-19 world. This is to the credits of Tariq Ali, illuminates on the 'Clash of Fundamentalism, Crusade, Jihad and Modernity'. ( T, ALI; 2002 ); ( Y. Trofimov; 2005.

Although, the North Toronto police were of the opinion that, those acts were campaign of calumny against religious practices, as a few Eastern Asians had put-in some calls to the police that, they were targeted with hate and nasty racial comments. There were cases of high profile property damage at several Buddhist Temples were sledge hammer and statutes that guards their gods and holy temple were destroyed and the police perceived such nasty attitude of the deviants as crime of hates as COVID-19 has transformed individual attitude and behaviour in their relations with fellow human from around the world. The statues are seen by the practitioners as religious and holy symbols as far as they are concern. This is resounding the thoughts of Tariq Ali, in his Book entitled 'The Clash of Fundamentalism Crusade Jihad and Modernity'. ( T, ALI; 2002 ); ( Y. Trofimov, 2005).

There is the debates among $19^{\text {th }}$ century philosophers; Durkheim, Montesquieu and August Comte on the nature of society moving from simple homogenous to a more complex one heterogeneous and globalizing and COVID-19 world is normalizing. A World well configured on the tripod of the social PEN fundamentals of $\mathrm{P}+$ protoneous capital reintegration and $\mathrm{E}-$ electeoneous human resource capacity for change around IT in the phases of normalization, a post COVID-19 world of men built upon Eelectroneous IT capacity for change and $\mathrm{P}+$ protoneous capital as vehicle for change and progress of mankind.

Evolutionism is also to the credit of many more scholars such as C. Jeremy, R.Y., posits that development is a progression from primary to the secondary group; Spencer viewed the movement as one from homogeneous to heterogeneous units; George, C. Hommans, pointed out that E. Durkheim, viewed change or development as evolving from mechanical to organic solidarity. Furthermore, Tonnies expressed change to mean some sort of evolution from Gemeinschaft to Gesdlschaft which also means transition from community to society and COVID-19 is forcefully, ravaging and changing the world to a more IT driven world of men. (W.A. Gazali);(George, C. Hommans, 1950);(C. Jeremy, R.Y.1959);(E. Durkheim, 1912) 
Corollary to the above, many perceive COVID-19 from the view point of having bio-effects that may kill or rather eliminate human instantaneously (or is it gradually). Congregation in mosques on Friday is banned; churches are sealed by the government until it is safe to reopen. COVID-19 has entrenched danger on public health. The general belief around the faithful suggests it is rather more peaceful to suspend prayers in congregation for COVID-19 has higher velocity in its transmission, hence the social life of the faithful is never encouraging and members may end up being infected as processions, handshake and contacts shoulders to shoulder may increase vulnerability at prayer points and the advises to suspend and to reopen when the pandemic calms down is a welcome idea for some faithful, ( Dr. A.U Tilde; 2020).

However, compared to the market places, some argue, it likely takes approximately 10-15 minutes to solemnized on prayers and held the belief that if market places would be open for a whole day or good number of hours and then equally the authorities concern should have allowed faithful to go on their routine prayers which altogether may not be more than matter of few hours put together the whole day prayers. There are country opening to that, especially from the elderly who are more or less vulnerable than the youths are exposed to risk and the vulnerability is even higher among those who go to the mosque early, in Muslim dominated communities considering the attitude and behaviour of the worshipers and how close they sit and how proximate the row are and siding shoulder-to-shoulder as compulsory or prophetic traditions has been taken over by the COVID-19 social distancing as mitigating measures against the pandemic.( Dr. A.U Tilde; 2020).

Often times, some fellow worshippers cough while in some cases others sneeze and as well breath around as they bend and raise up and exchange pleasantry by shaking bare hands with no glove as traditions demands and are not wearing face masks with higher degree of vulnerability of transmission of the viral infection called COVID-19. In prayer grounds, many may have flu with droplets and the populations all in one hall densely populated, so stuffy and worshipers sweating even under Air conditioner and fan for the hot weather and attendance as hub for COVID-19 infection and such a situation is risky and it is so bad. COVID-19 has already changed the world, if not completely, but to certain degrees. It has influenced a number of structures, beliefs, attitude as well as our behaviour. Qualitative data suggest that, in some societies, members removed, destroyed and/or demolished their (gods) and temples on the simple ground that, those gods lack the power of saving them from harms as COVID-19 despites they worship them periodically and some community members see no reason to retain those statutes again for worship. (Dr. A.U Tilde; 2020).

For example; at the heights of the pandemic, there were cases of high profile property damage at several Buddhist Temples where sledge hammer and statutes that guard their gods and holy temple were destroyed and the police perceived such nasty attitude of the deviants as crime of hates as COVID-19 has transformed individual attitude and behaviour in their relations with fellow human from around the world. Most Temples and symbols of religious practices in some communities were demolished or destroyed on the simple ground that those symbols worshiped as gods could no longer rescue humanity from calamitous situations as COVID-19, hence rendered those Artifacts useless in the eyes of their practitioners, especially the Artifacts (material) and as well the non-Artifacts (non-material) aspects of man's culture and religious beliefs and practices were rendered useless by COVID19 and turned those objects into mere symbols of anthropological analysis, forming narratives about man and his relation to those symbols as gods at a point in time of man's existence in planet earth.(Financial Times, Yoval Noah; 2020).

The power behind COVID-19 is enormous and it is changing the world. Marx Weber, viewed the change in social organization as evolving from traditional authority to legal-rational authority. Furthermore, August Comte, propounded the stages of development as: theological, metaphysical and to scientific stages in human evolution, E. Durkheim, talked about mechanical and organic solidarity which was later expanded by F. Tonnies, to describe how phenomenon changes from one stage to another and coined what he referred to as the Gemeinschaft and Gesdlschaft. ( Marx Weber; 1947); (Spencer H. 1971);(Auguste Comte; 1986).

Again, the Archaeologists as Anthropologist would also make one to believe that, for example; those that had existed in the past 700,000 years had practiced religion distinct from what is obtainable today. They would also proof by excavations that they had different looks from us and our way of live. And then give an account for inevitability of human evolution and change in human existence and they prove those changes scientifically with evidence and data to established facts and social reality for their claims. Today COVID-19 is here ravaging and changing our way of life. What next?

If COVID-19 is changing the world it is not a new thing but, normal way of life. What the evolutionary theorists such as Herbert Spencer and Durkehim et al referred to as ' complexity' can be understood from the viewpoint of Boko Haram becoming complex, defensive and offensive in what (Mao, Tse-tung, 1972) alluded to in his study of the "Strategic Defensive and the Strategic Offensive in Guerrilla Warfare. He described the fluidity, something similar to the ravaging nature of the COVID19 pandemic of today.

There are socio-cultural beliefs in some African communities that, death is a normal thing and for some others believe one dies when it is his time to go. Death can come at anytime and it is God who sent the Angel to end one' s life either by accident, kidney failure with systemic deterioration, heart attack, stroke, HIV or any medical related condition as terminal sickness leading to death. This is reminiscent of the social thoughts of Elizabeth Qubler Rose stages of 'death and dying' and it depicts the last stage of hopelessness and giving up for death.

COVID-19, they say is not an exception when the time comes. Once it's your time you must die and some also, believe that God has sent angels to land on the surface of the planet earth to be taking lives same as some died of insurgency, terrorism, famine, earthquake, plane crash, flood disaster and other harms and monumental consequences and therefore, they argue COVID-19 is nothing other than a curse, if truly it can kill and when it is time and as ordained by God; no one can escape death.

Religion is so powerful to be undermined, but the forces of COVID-19 have ridiculed its practices at a point in time of our history in human existence in the year 2020. The significance of religion as moral revitalizer is rightly observed by (Emile Durkheim,1912) in his book 'the Elementary Forms of Religious Life' as religion has some functions to perform in the society, 
especially that social solidarity and social cohesion, but being ridiculed by the forces of COVID-19.

Some believe that, the forces of globalization have greater influence on not only religious, but of course, all the institutions of human society thus: social life, economic fundamentals, religion, education, family and the polity are all shaped for the attainment of globalization which coincides with postmodernism intertwined with the forces acting and reacting around COVID-19 pandemic that has changed most things in our everyday life.

Similarly, on precautionary measures, for some cultures, face masks as one of the mitigating measures against COVID-19 may be seen as taboo due to our differentials in cultural orientation. So, due to these complexities, some societies around the world may not survive the momentum and sharpness of COVID-19 pandemic unless, mass mobilisation and enlightenment campaigns are mounted and citizens are informed through various media of communication to appreciate and as well embrace those precautionary measures for dealing with COVID-19 pandemic for the overall bio-safety of humanity.

For example, in some African traditional societies, covering mouth and nose is rather a thing that should be done and fit for animals than for human. A term known to be 'Nzambu' is a name synonymous with a (face mask) in Kanuri dialect. 'Nzambu' are more frequently used for covering the nose and mouth of either a lion or hyena to avert bites, especially when wild life's are taken down to community levels for cultural display to scare away children in order to mould them get stronger, rugged and used to a wild life as they grow up to be strong men in the society.

In such Africa societies, the use of face mask may either be undermined or seen as a funny thing to be hanged on the face. Different societies see face masks differently and their attitudes and behaviour are greatly influenced by their culture and traditions to observe wearing masks as mitigating measures. After all, it is costly considering the economic base of some communities around the continent of Africa for apparent low income.

Again, for some culture and tradition, the use of face masks may altogether be seen as a taboo. For example, in India castes system, it may be difficult for the king to wear face masks and for the poor caste member of the same community to also wear one as that may also be perceived as taboo.

So, there are cultural forces that may influence and increase vulnerability thereby increase transmission of COVID- 19 . Therefore, understanding the general principles, knowledge, attitude, value systems and some of the traditional fundamentals which sustain human are crucial factors that have to be considered dealing with COVID-19 pandemic and its precautionary measures and guidelines is important, if not necessary ingredients for good result while dealing with COVID-19 pandemic, especially in African countries.

The African society belief system and culture are under severe attack from COVID-19. Corona virus has ridiculed not only the continent of African but the world at large. However, today, Corona Virus has entrenched existential threat on both the capitalist and the mixed economic countries around the world; the rich and the poor are vulnerable and at the mercy of credible health system and rapid health response facilities available to contain it irrespective of human race. Covid-19 pandemic has thrown many families, businesses, social events, communities, cultures and traditions into severe pain and with high frequency of transmission and social upheavals on health of young and old, women and children, strong and fragile; a society characterized by widows and orphans. When we are yet to settle the displaced populations, we are managing another round of holocaust of global magnitude. What will be the fate of the IDPs? May Allah, with his infinite mercy and wisdom protect us all, Amen!

Corona virus is huge threat to social solidarity and moral revitalization in our mosques, churches and other social gathering that may enhance social cohesion for social progress. Corona virus is threat to morality as children who should be in schools to learn morale values are today locked down and at the mercy of their parents. However, it is for the common good of all to deal with the pandemic as conscious effort to nip it in the bud. Covid-19 pandemic has the capacity/potential of monumental structural changes which cut across social, economic and political life, a caricature depicting periodic transition to moral crisis as Emile Durkheim reminded us in his thesis 'Elementary forms of Religious Life' as a new lease of life in our existence as human on the surface of the planet earth.

What we experience today is a kind of early warning signal and periodic transition to moral crisis as family members are no longer attending mosques, churches as places of worship have been closed down for the first time in the history of religious practice in the world as religious rights had been practiced even during face to face wars, but for Corona members of the society abandoned religion for COVID-19 at its peak. Is that not a test of faith? Countries' borders are closed down, economies of nations around the world are rather galloping with severe structural negative (-) impact on family social life and political structures and decisions of our leaders and as individuals members of the society.

\section{Sociology of COVID-19: Postmodernism as Philosophy which} Drives the Dynamics of 'The New Normal' and Beyond

Postmodernism was first coined by Jean- Francois Lyotard in the 50's. Unlike Comtean and Durkhemian who are modernist and believe that social reality such as COVID-19 can be established through scientific method of positivism. Lyotard, the proponent of postmodernism argues that building narratives around a phenomenon such as COVID-19 pandemic with authentication and credibility of the person theorizing is enough evidence to establish facts and that can be taken for granted in postmodernism to enable generalization and inference to discover realities such as social distancing of 6 feet to discourage velocity of Corona virus and further infection. (Lyotard Francois, L 1884), (Anthony Glidden, 1990).

The mitigating measure is being friendly and constant use of face mask to curtail rate of transmission within the physical environment during social interactions and this assertion is to the credit of (ecological theory of Burgess and Parks, further expanded by Shaw and Mckay to say more of man's natural adaptation to his environment during interaction and adaption is to the credit of Talcot Parson acronym (A) which depict (AGIL and /P).( Robert K. Merton; 1968) ( Spencer H. 1971).

Frequent and periodic hand wash/use of alcohol based sanitizer is to discourage transmission of Corona virus as handshake and touching face, eyes and nose may enable the virus to easily get into biosystems, hence infect those that are vulnerable and employing all of these mitigating measures seems a nightmare for significant number of population and safety dealing with COVID-19 around the world and major threat to distancing guidelines and principles.

This publication is licensed under Creative Commons Attribution CC BY

http://dx.doi.org/10.29322/IJSRP.10.07.2020.p10353

WWW.ijsrp.org 
The earlier thinkers, (the modernism) Comte, Mauss, Sine Simon, Durkheim, R. K. Merton, T. Person, Kaufmann David Hums and the likes of Neo-modernist theorist, such as Robbert D. Putnam's and Anthony Giddens etal insist that it will rather be difficult to either do away with such normative standards of measurement and it's orientation or compromise on same because they are the major source and foundation to ensure falsifiability as one of the attributes of a coherent theory, testing and validation as Karl Popper wants us to believe, employing deductive method for scientific examination of a phenomenon as COVID-19 pandemic. The theory of postmodernism rests upon the concepts of ' miniaturization', reducing the broad nature of society to a manageable size. The emphasis on social and physical distancing for COVID-19 pandemic that has been emphasized by the philosophy of postmodernism and commercialization of machines emphasizes the importance of computer technology as principal force of mass production depicting post COVID-19 world of human.

Simply put, postmodernism is the philosophy behind 'The New Normal' and postmodernism is a triumph over adversity while ensuring the position of science and technological advancement with flexibility of a hitherto, rigid and tough modernism, which was perceived as throwback. The dynamics and complexes of postmodernism determine the evolution of 'The New Normal' after the pandemic and the role and relevance of postmodernism institutions in driving 'The New Normal' cannot be overemphasized. Postmodernism is a process and not an automatic but has automated systems as post modernities to determine production, supply and value chain for justification sustainability. Post-COVID-19 world is characterized by highly simplified post modernities with tremendous result that should improve humanity now, and in the future it's fast, flexible, instantaneous and sustainable. (Lyotard Francois, L 1884), (Anthony Glidden, 1990).

Alluding to the intellectual thoughts of Professor, Olu Ogunika who forecasted a world as COVID-19 and this scenario is synonymous to 'Ogunika social thought'. He was utterly coherent in his prediction far back in the year 1998 as rightly observed in his lecture series that, 'very soon a time would come, a time defined by the world of technology in which one big 'paradigm as COVID-19 would emerge to swallow everything and in the end all conflicting paradigms would cease to exist and give way to that one big paradigm'. Perhaps, the erudite Professor alluded and predicted about a kind of society redefined by the momentum and sharpness of COVID-19 pandemic as 'The New Normal'. ( Anthony Giddens; 1973)( Olu Ogunika;1998).

Postmodernism is a threshold for ushering in COVID-19 world of human and globalization is to ensure an irresistible expansion of social, economic and political systems, including social structures for the common good of good governance and government (the action system) and by inclusion for more the benefits of the world population as (the target system) for greatness and social progress in the evolution of the society in the next phase. COVID-19 World is firmly supported by philosophy of the postmodernism as a transition from analog way of life (modernism) to a more vibrant, virile, efficient, and cost effective digitalized ways of achieving socio-economic and political goals (Postmodernism).

Be that as it may, many believe that what is called Corona virus has come with an option of either to be rich and strong and formidable with electroneous (E-) human resource capacity to drive the bandwagon of Postmodernism. Again, in post COVID19 World, there will be more and more professionalized jobs, but Social PEN electeoneous (E-) human resource capacity is required and everything will be done through IT facilities unlike the archaic fashion regarded as throwback in the times of modernism.

The more we distance ourselves from one another for COVID-19 pandemic, the closer we become and so proximate to COVID-19 World; 'The New Normal' built on the very foundation of information technology, a world of social dispersion and more cities were empty and traffic jam reduced to the barest minimum and life would never be the same at the peak of Corona virus. COVID-19 World; 'The New Normal' would have values as normative cultural standard, principles and dictates and it allows labour migration, but for a short while to allow humans to settle to attain normalcy for the business of the new world. Jobs can be done remotely and there would be rush in residential and serene environment to allow an uninterrupted and smooth delivery on job assignment.

The complexes of COVID-19 World; 'The New Normal' will make humanity to face social change of unimaginable magnitude and the post corona virus society redefine social life, events and the mode of doing things. In post COVID-19 World, content development, production and co-production of knowledge would be marketable. Society would be defined only in terms of electroneous (E-) human resource capacity and protoneous $(\mathrm{P}+)$ capital for further development and 'The New Normal' as society must support the $(\mathrm{P}+$ and $\mathrm{E}-)$ reintegration as neutroneous value for successful calibration of systems to context and relative equilibrium to ensure structural change that are sustainable in man's life and for the benefit of the generation yet unborn.

These proposition is not different from what Max Weber told us in his thesis "Protestant Ethics and Spirit of Capitalism" and global capitalist expansion and reintegration and the survival of the fittest. COVID-19 is the spirit which defines the ethics of Protestantism, a hand over of social, economic, and political, perhaps, cultural practices for virus in Marxian sense of analytical examination of happening and events leading to COVID-19 World; ' The New Normal'.

In COVID-19 World, 'The New Normal' individual members of the society would place less emphasis on culture, ethnic identity and primordial sentiments will perish. There will be burst on rationality, a transition synonymous to what Professor, W.A. Gazali, 1998, in his lecture series far back in 1998 referred to as low intensity of 'we' and higher sense of 'I' with tremendous sophistication around specialty, occupation, production and coproduction of industrial goods and services and all of these changes lead to 'The New Normal'. It happens gradually in phases and it can never be sudden and the $\mathrm{N}$ element of the PEN need to calibrate the $\mathrm{P}+$ and $\mathrm{E}$ - to attain relative equilibrium for structural change to happen in social economic, political, cultural and institutional fundamentals to affect all spheres of man's life for a positively balanced change to happen. (Professor, W.A. Gazali, 1998)

Alas! To Jean Francois Lyotard who described postmodernism and the forces associated with the ills of COVID-19 World shapes global consciousness, socio-economic and political structures while on the impact and momentum of globalisation, Professor, A. G. Shettima,1998 in his lecture series on globalisation, far back 
in 1998, reinforced the viewpoint that, globalisation can be seen as a 'brakeless train' and Corona virus is a nightmare with gigantic fear that has already loosed many societies to fluids, pushed business into shambles. Human activities are halted to some degree and responsibilities are shrinking, individual members of the society are lacking in their personal and communal commitments and it will be so severe in COVID-19 World. (A. G. Shettima, 1998).

And, social inclusion would be enhanced. Women would have more power. There would be significant change around moral values. Social life would be automated as post modernities to reflect the needs and expectations of the COVID-19 World; 'The New Normal'. Relationship among individual members of the society would further be reinvigorated on wire and physical faceto-face interaction would reduce.

'The New Normal' would come with significant change in structure. Social, economic and political life will change. There will be excessive regulations and capital reintegration to further redefine the brand new phase of human life for its normalization. Our relation to IT facilities would be improved with enormous cost and there would be clampdown on sites and new applications would be introduced with innovative increase and everything would be paid, to the credit of COVID-19 World, same as we purchase token for electricity and other similar bills in our normal life.

There would be uniformity in social relations with pattern and individual action and life would be changed tremendously, a pathway to what Hogan, 2006, called mathematical sociology with exact formulas to define activities of human by eliminating qualitative aspect of life such as face-to-face social interaction and relationship. The rate of travel by air and road for leisure, tourism and businesses would drop. G. Emefiele, 2020 noted that global Airline has lost about USD 252 billion in revenue in 2 nd quarter 2020. COVID-19 World, the new normal may witness trips only embarked for official reasons and functions and sea transportation would be enhanced. There would be high precipitation of social dynamic density in COVID-19 World as normal way of life.(G. Emefiele, 2020); (Hogan, 2006).

More structures would be converted to warehouse, humanitarian institutions and hospitals and cottage industries. Reminiscent of the thought of T. R. Fehrenbach in his Book entitled 'Korean History' reflected the work of General Walton H. Jonny Walker thesis on 'perimeter' as he illuminated on 'the need to learn to ride hard, march hard, and live light and to co-operate in what he referred to as the 'isolated column'.

Postmodernism also, argues that, control over knowledge is increasingly becoming more marketable as the major source of power. Knowledge, they added, is no longer an end in itself, but something to be bought and sold, perhaps, even fought over and therefore, advocated for a new vista of understanding society as a response to logical positivism and quantitative analysis to inform theorizing COVID -19 world.

The postmodernist argues that, discovery of COVID-19 as a social reality characterized by social distancing principle and lockdown lie significantly on who has the primary source of such claims with the privilege of the claim passed on to wide variety of demography and that is what is called in postmodernist as (selflegitimation).
Jean Francois Lyotard argues that science is unable to get rid of itself of chains of narrative and knowledge. The application of scientific methods to the study of social phenomenon, to Lyotard, is a deliberate attempt by the Positivist School to distance science from social convention, i.e. to ( keep sociology separate from the social life) so that, it can remain objective to the members of same scientific community, with same orientation background and belief system and therefore, advocates a postmodernist approach as a philosophy of discovery with the power of erasing borders in instantaneous manner .

Postmodernism, as a philosophy, says more of the social life in the most developed nations with enormous power and influence to control power as it's the case for COVID-19 era as a philosophy as well as a development strategy to drive globalization through institutions for change synonymous to post COVID-19 society; 'The New Normal'. He further argued that, the theory does not require procedural and tedious processing of scientific tools and its application but simply by 'language game' and credibility around it to ensure positive change with tremendous opportunity and mass production.

According to the postmodernist theorist, application of such rules by logical positivists are somewhat, outdated, hence they clamour for an alternative way of establishing social reality to bring about in the society. Postmodernism believes that comprehensive analysis of social facts, and discovery to give better description about the 'why' and ' how' of a social phenomenon such as COVID-19 is possible with the utilization of dominant institutions, literate society from the whims and caprice of tradition and culture to a more simplified, dynamic and tough society in which knowledge is seen as commodity typical of COVID-19 world of the new normal.

Sociology of COVID-19: 'The New Normal' and the Nexus Between Marxian and Weberian Notion of Society

'The New Normal' as the name implies is an 'Ideal Society' and this is to the credit of Max Weber who constructed an ideal type of rationale-legal bureaucratic organization with the following characteristics as activities required to achieve organizational goals are distributed in a fixed way as official duties. This feature of a rational legal bureaucracy has stressed the importance of Kinsley Davis and Wilbert E. More theorizing on stratification system for each official has a clearly defined area of responsibility for the attainment of organizational goals in a rational legal bureaucratic setting. Complex tasks are broken down into manageable parts with each official specializing in a particular area. Bureaucracy's complexes and dynamic structures of institutions are intertwine just like the thoughts of Max Weber and Karl Marx are inseparable because you cannot talk about economic system that is achieved via e-institutions without the electroneous E- social value of human resource capacity and as Eelectroneous representing (human resource capacity, IT and otherwise) as advocates of social PEN theoretical components being prime source of decision making at all levels as COVID had engaged the E- component capacity for bureaucratic know-how dealing with the pandemic at the centre of decision making at the level of UN and policy formulation at level of various governmental levels as bureaucrats and/or administrators are working round the clock tirelessly briefing media to get out of COVID-19 quagmire. (Marx Weber; 1947)(Karl Marx 
(1978[1867]); (Waziri Ahamad Gazali; 1998);( Robert K. Merton; 1968); ( Spencer H. 1971).

'The New Normal' is return to normalcy as post pandemic atmosphere, a leeway establishing a sort of society built on the very foundation of Weberian lines of thoughts of an enhanced rationalization of man's life from all ramifications, hence establishing the nexus between Max Weber's notion of society and thoughtful beliefs around his theory of protestant ethics and spirit of Capitalism' and Karl Marx theory on society and production of surplus value accumulation through the role of e-institutions for the enhancement of e-capitalism as an economic system. The two theoretical positions are relevant not only because of COVID-19 but as gear which moves society forward since time immemorial and therefore, 'The New Normal' would not be an exception to societal fundamentals and the roles of institutions that has been interned in the recent history of mans existence. Corollary, to that, would investigate under this theme.

Some businesses are successful and some others are failure because an entrepreneurial activity has a social PEN structure to suggest the directions of business and investment fortunes. The social energy of (+-n) provides powerful tool for causal analysis on how to rationally minimise cost and to maximise profit by rationalization akin to (Macdonaldization) of business enterprise in a manner rationally weighing cost and benefits of investment. Social PEN structural change of individual mind will be at work to enable objective, unbiased and rational decision in business, provided the manager is equipped with sufficient Protoneous $\mathrm{P}+$ resource capital funding and Electroneous E- human resource for causal analysis of business trend and pattern to enable Atomic structural analysis of risks that are apparently invisible along demand and supply curves and fundamentals for appropriate utility.

Utility as social value is synonymous to the social philosophy and thoughts associated with J. Bentham and J.S. Mills (thoughts precursor such as T. Hobbes, J. Locks and D. Humme) that placed the satisfaction of the individual' $\mathrm{s}$ want (utility) at its core. Consequently, as the greatest good was defined simply as the greatest happiness of the greatest number of people with consequential effects on social action in which individual rationally pursue their own self-interest and it's conception of society as the aggregation of social Atomised individual united by self interest. Hence, understanding and reading the directions of social PEN structure for change ensures optimal utility and it enables chances in business and ability to employ the social PEN structural analysis influences one' $\mathrm{s}$ business over another to produce more Protoneous $\mathrm{P}+$ value of capital funding in relations to structures of the business and more opportunities for investment over another. This is what social PEN structural theory of change is trying to give description of social life in business related venture for utility and investment.

There is no way one can talk about social investments within a newer or an innovated environment that has been altered due to the impacts and COVID-19 pandemic without asking fundamental questions on risks assessment, groups networking and some basic social and economic decisions. Thus, the Weberian theory of 'objectivity in sociology and by extension other disciplines in social sciences is to provide deeper understanding of the complexes and dynamic structures of how capitalist system and its e-institutions are ideal for 'The New Normal' 'work from home' .
This reduces burden of payment for office accommodation due to COVID-19 pandemic with a view to guarantee development as Weberian wants us to believe in what he referred to as 'Objectivity' in social science with particular emphasis on Sociology of Professor M. Abdullahi, (1998) shared similar feeling with Max Weber's perspective of Sociology. (Marx Weber; 1947), (Karl Marx (1978[1867]) (Robert K. Merton; 1968) ( Spencer H. 1971).

I can vividly recall as he then said that "Sociology is the scientific study of human social actions and interactions. Sociological knowledge is objective and NOT subjective. It is scientific and theoretical owing to the discipline's approaches and application of scientific methods in practice and analysis of society as a social system". He further added that, "the objectivity of the discipline does not depend upon the attitude of a researcher, but public evaluation done by the researcher. This view point has reinvigorates Sociology as the mother of all sciences and geography provides the environment as enabler for practice". Corollary to that, Prof. M. Abdullahi, like Max Weber, agreed that, Sociology enables the social thinkers and its practitioners to better understand and situate any global problem such as COVID19 pandemic within the context of Weberian causal explanation and cultural interpretation of diverse human race from around the world who suffered COVID-19 pandemic and the way forward to avert the social impart and rejuvenation of structural failures, fractured and resuscitation of the failing ones or those that had faced elimination, comatose or extinction. This is only possible when the social PEN elements play simultaneous roles and perfect PEN configuration, ensuring protoneous $\mathrm{P}+$, electroneous $\mathrm{E}-$ and $\mathrm{N}$ for calibrations of all structures that had suffered for COVID19 pandemic to attain social, economic and political context. The relative equilibrium and the approach has, to some extent, a Verstehen approach combining (both Aktulles and Aklarandes) to achieve reconstruction of society in Post COVID-19 pandemic for change and good of all and sundry. ( Marx Weber; 1947); (Musa Abdullahi, 1998).

Vestehen approach is a way of dealing with social issues in the society as a whole looking at the social action of the phenomenon under investigation by explanation and understanding and that can be achieved by asking fundamental questions around: What instrument do we use to measure the benefits associated with post COVID-19 pandemic as 'The New Normal'? What are the comparative cases to be drawn in prior Corona society in terms of factor of production for development to ensure comparative advantage for utilization and success, moving into 'The New Normal' and beyond? What are the necessary services and deliverables needed for systemic overhaul for overall benefit and development as we usher in 'The New Normal'? What are the states of the institutions prior to COVID-19 and e-practice in 'The New Normal'? How much resources are invested and Protoneous $\mathrm{P}+$ capital integrated to ensure and guarantee value for protoneous $\mathrm{P}+$ capital and return on investment? What competitions do 'The New Normal' provides environment and electroneous E- human resource potentials and capacity for improved production in large scale comparatively for an enhance import/export substitutions to increase Gross Domestic Product (GDP)? Also, how do we woo and/or attract foreign direct investment (FDI) into 'The New Normal' with integrity, trust and credibility and assurance for 
enabling business environment? (Marx Weber; 1947).(Karl Marx (1978[1867])( Robert K. Merton; 1968) ( Spencer H. 1971).

Though these questions may sound more of economics than sociological, this is what I refer to as the point of convergence and divergence of Durkheimian sociology and Weberian theory of objectivity and perspectival nature of knowledge and relativity in sociology. When Durkheim wanted to isolate and differentiate sociology from other disciplines, Marx Weber debunked and argued on the contrary and showed the link and interconnectedness of sociology to other disciplines, necessitating the aforementioned questions.

For instance, how do we employ Weberian theory of social action and explanatory interpretations (vestehen) and causal explanations to improve on policies of government, especially in post COVID19 pandemic 'The New Normal' with a view to better the lives of the individual members of the society? If Marx Weber's causal analysis is a preliminary to inquiry into cultural significance of social phenomena; then we can ask questions around new policy in 'The New Normal and beyond as: Is the policy people-centered? Whether or not the new policy conforms to people's needs and expectations cum 'The New Normal' standard operational procedures as prerequisite and as well as post modernities achieving newer cultural inclination?

What policies do we intend to establish in Post COVID-19 society or improve upon the existing ones as e-practice? What are the options to the new policies to come soon and what are the backup plans? What provisions for substitution and what are the obstructions or inconveniences to such new policies in 'The New Normal'? What is the relationship between the new policy in 'The New Normal' and the existing ones as hangover of Corona virus ridden societies? How is the new policy different from similar policies for Example say in Nigeria and elsewhere? Is the new policy evidence based? How do we benchmark it to global best practice? What is the degree of sustainability of the envisaged policy in post COVID-19 society 'The New Normal'?

According to Max Weber's preliminary inquiries, objectivity and causality also allow to ask questions such as: What economic benefits should it bring to the doorsteps? What is the level of commitments on the side of both government and citizens as individual members of the society? How is it a support for national ambition as always reaffirm by David Kieghe and as he uses to champion? As far as Sociology is concerned, Max Weber was the first analyst of bureaucracy and he sees it as an ingredient for the expansion of capitalism and provided an ideal portrait of bureaucracy with norms and values system as 'The New Normal'. Weberian and Marxian sociology like other theoretical considerations are interdependent and interconnected and so are other theories in sociology.

No one theory is independent of others, but they are all intertwined. No capitalist development will take place without the social configuring of the PEN component of Protoneous $\mathrm{P}+$ capital integration, electroneous $\mathrm{E}$ - human resource capacity; talent knowhow and the power of IT, industries and Neutroneous $\mathrm{N}$ calibration of structures to attain context and relative equilibrium. No industry survives without taking major economic decisions of what to produce; how to produce and for whom to produce? These decisions are taken by the electroneous E- human resource capacity as bureaucrats for subsequent change in 'The New
Normal' and beyond enhanced return on investment and that would have consequential effects on productivity and effective service delivery in 'The New Normal' as a milestone for overall development in the history of mankind.

Marx Weber was of the believe that, for such a development to happen in any organized set up, we need a charismatic leader to champion the crusade that should allow successful outcome and such a leader should possess qualities of a 'Supra-Mundane Personal Master like' sort of personality; a highly charismatic personality to influence the course of organizational goals in 'The New Normal and beyond. Max Weber has also provided three discrete but interconnected realms of sociological concepts such as Class; Status; Party and the corresponding variables as Economics; Politics and Culture respectively, as inevitable social situation to define bureaucracy, people, leadership and good governance especially, in 'The New Normal' and beyond postmodernism society. (Marx Weber; 1947).(Karl Marx (1978[1867])( Robert K. Merton; 1968) ( Spencer H. 1971)

There is also, a chain of command and responsibility and the operations of bureaucracy are governed by a consistent system of abstract rules which limit the power of those in the position of authority and hence, establishing Durkhemian notion of the 'Division of labor' which Karl Marx in his radical posture and contrary opinion referred to as 'Alienation' to mean, what you have generated by your own actions and talent is favorably competing with you and to some extent limits your behaviour in an organized setting.

Independent of bureaucracy and its fundamentals is the role of einstitutions and activities of man as a driver for change and life improvement engagements. Classical example is Weberian rationale action and McDonaldization, according to Marx Weber used to optimize business by cutting cost and maximizing profits. 'The New Normal' as post COVID-19 society has embraced newer cultures such as 'work from home' which has tremendously reduced and cut off pay for renting spaces and office accommodation for maximizing profit with COVID-19 and transition to 'The New Normal' as a new lease of life, everything would be on internet, fragile business are to gear up in their enterprises conforming to the newer culture entrenched by COVID-19 and beyond it's standard operational procedure as prerequisite. This is positive stage in man's and societal development as envisaged by Auguste Comte as scientific stage of societal development such as 'internet of things' (IoTM2M). Macdonald is a merchant who operates continental business by applying Weberian rationalization of cutting cost and maximizing profit as the newer business environment into 'The New Normal' may stand to portray.

Sociology of Covid-19: Political Sociology, Imperialism And Development Strategies

Sociology of COVID-19 tells us the perception of the people from around the world in relation to COVID-19 pandemic, social groups political attitude, behaviour and knowledge of power relations and change, including social relationship among countries and how influential is the power behind COVID-19 to change the behaviour of individuals and groups at the community level and by extension the society as a whole. Under this subtheme, Sociology of COVID-19 intensifies efforts to gather as well as analyse public views and conceptions about COVID-19 and challenge man's social and poetical milieu while applying 
cross-sectional approach to interrogate the general feelings of the members of the society about COVID-19 pandemic with a view to marking a longitudinal projections of the causes and the changes as well as highlights the sociological effects of COVID-19 pandemic on individuals, groups and community members with a view to understanding the negative effects as social problem faced by community members as a result of COVID-19 and then proffer solutions - short, medium and long-term as available data would suggest remedies and solution around humanitarian gesture as palliative to cushion the hardship being faced by individuals in diverse societies.

The expansion of corporation and enabling business environment for meeting local demands has made it possible for the need to have more raw materials and the impact of globalization has made many countries around the world richer than what they were at the expense of the poorer countries. A nation's development should be understood from the point of view of its relations to the political power, a rightful business environment, means of productions and distribution and activities of countries and relations to those with enormous political power determines the power relations amongst or within countries. Since the political structure and power of a nation state is the reflections of, and determines her political behaviour and by extension the changes that may take place within the physical environment.

The dynamics which define monetary and fiscal policies of smaller countries are also determined by their political arrangement and inclination with the superpowers and political structures of their respective host countries and their zeal to succeed ensuring change and development of a given nation state. Although, modernization paradigm emerged as a response to dependency paradigm and later postmodernism for globalization of social, economic, political and religious, to some lesser extent, and the power of technology has been dominant to achieve the Millennium Development Goals (MGDs ). However, all of these are possible only with Social PEN reinvigoration and role equivalent of $\mathrm{P}+$ and $\mathrm{E}$-. The $\mathrm{P}+$ here means the protoneous capital integration for liquidity of economic system and E- value of human resource capacity of the citizen in IT and building their hands for constructive innovation and invention that would create competition within the global economy and host country's revamping of all ailing industries and for the creations of new one in tandem with global needs and expectations for the stabilization of 'The New Normal' however, in essence, that's what the social PEN theory of structural change stands to explain and discover as a new vista making inference to social life from Atomic properties.Dr. Mustapha Bintube (2020); 'The Social Atomic PEN Structural Theory of Change' International Journal of Scientific and Research Publication Doi: ttp://dx.Doi.org/10.29322/IJSRP.

Similarly, since time immemorial, the history of man has been characterized by monumental events and happening which determine the survival and wellbeing of humanity and that has also, defined man's relations to the forces of production, distribution and economic decisions of what to produce, how to produce, for whom to produce and the urges for those questions were (and still are ) correlated with monumental historical events as Slave-trade (slavery), colonialism and neo-colonialism, dependency and to modernization and that chain trickled down to postmodernism as threshold for ushering in COVID-19 world of men with USA and China at the centre while the peripherals are gradually collapsing getting into a state of recession and dissolution to give change for globalisation and the idea behind globalisation is 'One World'. Social distancing is the power which precipitates the human and Corona virus is ravaging and killing citizen of the peripheral nations and the super powers are not exception from the ravaging nature of the phenomenal COVID-19 pandemic.

The notion of development in modern capitalist society and the dynamics around development vis-à-vis imperialism is to the credit of Vladimir Lenin, in his book, "Imperialism is the highest stage of Capitalism', 1917"; Max Weber's book on the "Protestants ethics and the spirit of capitalism". Capitalist economic and political domination are not new things. There was push and pull around credibility and responsibility of whether or not one of the two countries; USA and China would be responsible for the COVID-19 pandemic. USA is blaming China and China is turning 'donkey ears'. USA President was asked by a journalist at the White House press conference that COVID-19 is a catastrophe of global magnitude and why is it so? The USA President in response felt that question was so nasty and retorted, "Ask China". USA and China are in face-off using threat words at each 'bloc', suspicious of each other while COVID-19 is ravaging humanity around the world.(D. Triumph, 2020);( Lenin V. C 1971);( Marx Weber; 1947).

Similarly, the recent scenario around global economic and political scene, especially the USA and China trade deal of December 2019 has generated major socio-economic and political issues. Beyond that, it has the potential of impactful political life of the world population in so many different ways. The fact that human society evolves from one phase to another cannot be downplayed as the doctrine of Darwinism. This is more of a fact than an assumption or a mirage and this viewpoint has been corroborated by the very tenets of (evolutionary theory of Charles Darwin) which suggests that human society progresses in phases and each phase has its own characteristics peculiar but similar to the previous kind of society from which the new society emerged and each phase is characterized by struggle and survival of the fittest. Those passing away for COVID-19 pandemic may be an account for the tenets of Darwinism survival of the fittest. (Durkheim and Mauss, M, 1703); (Darwin, C. 1859]);(Spencer H. 1971); ( Lenin V. C 1971).

The sick and those with terminal illness are locked down at the very first phase of change. Again, this is reminiscent of the debates among $19^{\text {th }}$ Century philosophers such as Durkheim, Montesquieu and August Comte on the nature of society moving from simple homogeneous to a more complex one, heterogeneous and globalizing and COVID-19 world is normalizing. A World well configured with social PEN fundamentals of $\mathrm{P}+$ protoneous capital reintegration and $\mathrm{E}$ - electeoneous human resource capacity for change in phases of normalization, a post COVID-19 world of men built upon E- electroneous IT capacity for change and progress of mankind.(Durkheim and Mauss, M, 1703)( Karl Marx (1964, [1840])

However, Sociology of COVID-19 is telling us those developmental strategies, agenda, frameworks, marshal plans for reconstruction of the societies around the world somewhat, have political interest and the dominance of the imperialist has on so many occasions influenced the development or underdevelopment of many countries. In addition to the economy, it also includes 
social life with the power of institutions and COVID-19 pandemic is seen by many as global siege achieved by lockdown and compulsory quarantine necessitated by Corona virus.

The present precarious social, economic and political situations and the threat posed by COVID-19 pandemic such as shutting boarders and lockdown has crippled the economy of most countries and economic recovery in post COVID-19 would be a herculean task for many countries around the world due to global power wrangling and competition and the palpable power struggle between USA and China and the COVID-19 dangling situation.

The power of China in the world economy is enormous and that has accelerated the dominance of Chinese corporations in the west, China is said to have taken about $17 \%$ of the world GDP going into the production of cheap goods with sufficient electroneous E(human and material resource capacity) and P+ capital for the purchase of raw materials and large productions in postmodern society. The availability of markets and large consumption of her products within, China and everywhere around the world has given China economic leverage with enormous power (David Kieghe,2020).

The momentum of this power wrangling for economic and political pursuit has not only undermined and trapped the economies of the smaller nations, but has equally quarantined them and as well locked them down in their houses with the power of COVID-19 pandemic for the next decision on global scale to determine man's life in phases still for development interest and gains of the eastern and western blocs at the expense of the rest of the world a business to be determine by Macworld and Rockefeller foundation determination of phase reopening and guide to the world as observed by William Bulum, only the super powers.

To say that the USA is powerful is a fact. On the imperialist political and economic power, William Blum, in his Book "The Rogue State" said, throughout the history of mankind, man's social, economic and political development is controlled by developmental forces acting and reacting upon the society and its institutional arrangement. These forces are changing and shaping the fortunes and destinies of political, social, cultural and religious forces and are crucial for the understanding of the developmental setting of nation state.

Again, each of these epochal events came with its peculiar characteristics and forces which define the history and existence of man and his relations to the forces of production and distribution for change that are beneficial and such benefits are in the interest of one nation over another with consequential effects on man's history and social progress which encompasses; social, economic, political, religious and cultural spheres of man's life and is today changing by the forces of COVID-19 pandemic. Those events say much about individual country's development or her underdevelopment reminiscent of U.A.Tar, 1998, in his lecture series on imperialism and development strategies in 1998, has this to say, to paraphrase his lines of thoughts on dependency paradigm. He concurred that, the whole idea of development, underdevelopment, marginality and spatial-imbalance between developed and underdeveloped countries of the world, is more or less a vicious circle of international division of labour. He affirmed that the surplus values produced by the peripheral countries were extracted for the use of the metropolitan economy, ' the centre satellite' relations. This kind of economic relation, he affirmed, is what most Asian, Latin American and African scholars referred to as; disarticulated economy.

In line with the above, the viewpoint of the dependency paradigm has been echoed by scholars such as Andrew Gunder Frank, Samir Amin, Paul Barons, Osvaldo Sunken, Theothonous dos Santo's, Emzo Palatal, Puranado Henrys Kadoso, John Kaltun, Walter Rodney, Ralph Raplysky and to some degree of perceived exploitation Emmanuel Wallenstein. In the words of Claude Ake, those countries at the periphery always have disarticulated economies due to lop-sided power relations. Samir Amin calls it disconnected economy and Ibrahim Ayage often refers to it as trapped economy. (U.A.Tar, 1998).

The power struggle and wrangling between USA and China and the emergence of Corona virus is more than just a coincidence. It's seemingly affecting the population the entire world and not only the people but the economies of many nations have gone into comatose. Smaller businesses, infant cottage industries, informal, semi-formal, indigenous/local techniques are gradually facing extinction for COVID-19 syndrome.

The smaller countries' relations with the superpowers has always been at the expense of the developing nations and their independence as nations has always been undermined, economies jeopardized, shortchanged and exploited. Countries with least political power are always subjugated, segregated or even lockdown and sealed as we can witness so glaring at the time of COVID-19 pandemic.

Similarly, Blum, quoted President Bill Clinton, 1996, in his Book "The Rouge State" while, reiterating the determination of the United States as... "When I came into office, I was determined that our country would go into the 21 st century still the World's greatest forces for peace and freedom, for democracy and security and prosperity". (Bill Clinton, 1996) quoted in "The Rogue State" by William Blum.

The notion behind the escalation of COVID-19, to some people, comes with some political interest which is somewhat core as the handball and COVID-19 was perceived by many around the world as it is intertwined with certain degree of interest around MDGs and agenda with entrenched interest and power relation for change in global socio-economic and political fundamentals and that is to be achieved through technological advancement.

Consequent upon that, an x-ray of the Corona Virus pandemic reminds us of tremendous sense that are sociologically inclined and political sociology is there to tell us more about global politics around social grouping, re-grouping and social dispersion for power and change to champion a cause in postmodern societies of men. Corona Virus depicts the ills of postmodern society driven by global capitalism for expansion of social, economic and political system for surplus profit accumulation which looks exploitative, hence antagonistic in nature; a view antithetical to fragile society, which Karl Marx described as a 'sack of potatoes typical of fragility'.( Karl Marx (1964, [1840]);( Karl Marx and Engels, F. (1950[1808]).

Capitalist economic domination is not a new thing and history has it that in 1883 the entire economy of the USA was taken over by financial moguls, the likes of John D. Rockefeller, Andrew Carnegie, JP Morgan, E.H. Harriman and Henry Ford. The global politics for power relation and change around Corona virus is enormous, that has been echoed by Yakubu Mukhtar, 1998, in his 
lecture series.Karl Marx and Engels, F. (1950[1808]);(Mukhtar, 1998).

However, the majority believes that there is interest around COVID-19 as it is a strategy entrenched by the most dominant and economically powerful countries in order to achieved their goals of world domination as well as control of humans on the surface of the planet earth through imperialist power and iron law of oligarchy. The roles of the multinationals and corporationalization of institutions and dominance of their parent headquarters over subsidiaries is a sort of centre versus periphery and manipulation for achieving global agenda. Sociology of COVID-19 is telling us that, COVID-19 can only be transmitted from person to person through human interaction as the core and the crux of the subject matter; the science and discipline of sociology.

There were (and still are) a number of insinuations and feeling about COVID-19 for global change agenda and the scenario around it has completely changed the attitude as well as thinking and behaviour of some people in the society with enormous fear of the pandemic. That has huge implications with differential narratives at global, regional, national as well as the community levels in respect of what COVID-19 really means.

The USA, China economic war and politics around 5G, some respondents claim is the main reason for COVID-19 pandemic. China, they argue, was so fast to roll out $5 \mathrm{G}$ networks, sometimes in July, 2019, in the city of Wuhan and that follows USA, UK, France, Italy, Iran and other countries around the world to follow suit and installed same network in some of their major cities. Primarily the intension was NOT to kill; rather it is inevitable for technological advancement for change and development. (VERDICT with TED CRUZ; 2020)(Mrs. Abdullahi; 2020)( S.M. Innocent; 2020).

Although, the $5 \mathrm{G}$ network was known to have been harmful to human, but no one knows the degree of danger it carries and China was the first to roll it out and as the source claimed, they deliberately did so in the city of Wuhan where people eat live animals to justify the fact that, the deaths due to emissions from $5 \mathrm{G}$ to virus from those animals that can easily be transmitted to human and source claimed that it was the main reasons why Wuhan was used for the test of the technological innovation. (Mrs. Abdullahi; 2020)( S.M. Innocent; 2020).

However, the effects of the radiation from the $5 \mathrm{G}$, the source claimed would take nothing less than 5-6 months to evidently manifest as science made us to believe that. The source also, believes that the casualty/dead bodies due to radiations are used as samples for experiment to carryout research with a view to understanding the effects and damages to human cell and to quickly write a code that can quickly prevent damages that should have taken place within the bio-system. Those that are dying from COVID-19 now are collateral damage that must take place before vaccine and drugs are discovered to calm down the situation.(VERDICT with TED CRUZ; 2020)(Mrs. Abdullahi; 2020)( S.M. Innocent; 2020).

Nonetheless, sociology of development is there to tell us the motive and intent behind COVID-19 as Emilie Durkheim illuminated 'capitalism as ills of the society' characterized by social disorganisation as human are today disembedded from the context of social relations via social distancing, albeit for the protection and common good of humanity to get rid of Corona
Virus and it's okay. Some were of the believed that, COVID-19 quagmire is aided by a world driven global politics and it is antithetical to bio-system (human); (Durkheim and Mauss, M, 1703); ( Karl Marx (1964, [1840]).

A turning point in global history and corona virus is paving way for the emergence of a new world of information technology (IT) and the role of sociology in this regard is enormous to rescue society from the social ills of corona virus, the most common of it all is suicide, depressions and cognitive dissonance and burnout from work overload.

We require social psychology to add more to the understanding of individual' $s$ feeling, cognitive thought processing and behavioural disposition of individuals in the society for attitudinal change while encouraging social distancing, elbow greeting so as to handle and contain the so-called filthy Corona Virus epidemic for an overall protection, prevention and control which is perhaps, the base line for analytical examination by the medical sociologist. Sociology of Covid-19: Semi-formal and Informal Businesses, Labour Force and Power

Sociology of COVID-19 is telling us that a lot of families and groups attached to smaller businesses, especially in informal and semi formal sectors in the society would face the consequence of COVID-19 as we usher in 'The New Normal'. Employer/employees relationship would be in sour and labour crisis, disputes, litigation and arbitration would be high in post COVID-19 society and there would be increase in consensus building for solution in the short term to handle the situation. The impact of COVID-19 has pulled down informal and semi-formal business and that has affected the employers from getting value and return on investment and the employees' job too is facing threat or risk of losing their employment and that assertion has been supported by finding of several researches including that of the ILO.

Similarly, Out of the 389 million global demographic strength of workers in the informal and semi formal workers, 232 million of them engaged in wholesale and retail trade and the sectors account for $30 \%$ of the GDP and represents $70 \%$ of global employment in retail, $60 \%$ in the accommodation and food services sector and that is a reflection of the severity and vulnerability posed by COVID19 which requires immediate fiscal policies as shock observer with huge stimulus package on the short and medium term.(ILO, April,2020).

Workers whose earnings are below 50\% of the Median earning in the population are worse hit. As at April, 2020 it was projected that about $45 \%$ of the workers whose income are below $43 \%$ of the median earning, especially in informal businesses would face poverty and $21 \%$ in poorer countries globally.

Employer and employees of lower middle income earner countries are affected as their businesses are characterized by informality with limited fiscal policy to quickly respond to the needs and expectations of enterprise and informal businesses with high risks of insolvency. COVID-19 lock down has crippled smaller business's with ease of lockdown, a lot of businesses would face challenges and therefore, need to struggle to get back on their feet and such recovery would be slow and that requires calibration around fiscal and monetary policies and that of the business environment need to be safe and secure injection of protoneous $\mathrm{P}+$ capital and electroneous E- human resource capacity of the social PEN theory to change business structures is necessary for 
business adjust and as well put in place a mechanism to reflect the change and realities of IT environment and it has cost implications.

The $\mathrm{N}$ element of the social PEN theory as Neutroneous business norms and systems to enable resuscitation of the global supply chains that has already been disrupted by COVID-19 pandemic and revival of the forward and backward chains of global supplies as COVID-19 has affected business activities all over the world and reduction in economic activities are rather galloping with slow phase and that, requires boost in the physical and monetary policies to enable some calibration of the P+ and E- as booster for businesses to get back to context and relative profit margin and that has to be gradual to reach equilibrium. However, for those businesses to come to normal there may be new policy and requirements that may come with the reopening of business as another challenge that constrain business.

\section{Sociology of Covid-19: Summary of Major and Minor Findings}

Qualitative data obtained from the sample frames in relation to the narratives about the genesis of Corona Virus severity and the social and economic impact of COVID-19 on socio-economic structures and the possibility of post pandemic changes to shift paradigms are eminent. The survey also probes into consequential effects associated with COVID-19 pandemic and narratives build around it and proffered the way forward.

The survey also interrogates the study population on difficulties achieving effective and all-round compliance to distancing guidelines, especially in designated high risks and vulnerable societies cannot be achieve due to human factors such as feeling, emotions, habitations and the need for 'sociation' has greatly hindered social distancing measures.

The terms "social distancing", "physical distancing" and "Social Telesis" were first coined and operationalized by Hogan in 2006 pg. 331 and pg. 332 respectively. The most appropriate term to describe human social grouping vis-à-vis distancing from groups is the term ' Social distancing' and NOT ' physical distancing' However, as corroboration to Hogan' s definitions, this research discovered that, social distancing is more appropriate terms to be utilized and therefore, there is nothing like physical distancing when talking about social interactions as enabler for the transmission of COVID-19.

Members of the society can be physically distanced yet, socially connected. Therefore, physical distancing is more of providing the physical description of the space in relation to inanimate objects in terms of measurement. Human may be distanced from one another, yet socially connected and the space in between human is referred to as social distancing between animates human as opposed to inanimate objects. So, social distancing is the most appropriate term because it doesn' t' take away the social aspects by distancing. COVID-19 can only be contracted or one get infected through social interactions and the inverse is social distancing as mitigating measures to get rid of COVID-19 or Corona Virus.

There are empirical evidences to support the fact that, the rate of criminality at community levels was high, especially at the time of the lockdown and height of the pandemic. Recent happenings suggest and finding from respondents confirms that youth' $\mathrm{s}$ unrest, looting, organized protest, gangster and other criminal activities were slightly higher than prior to the pandemic due to job losses and panic around unknown. Qualitative data suggest that, vices such as stealing, armed robbery, burglary, theft, pilfering, shoplifting, harassment of law enforcement official during lockdown for COVID-19 pandemic was rather glaring.

The finding also shows that COVID-19 has carted away jobs; hence the disobedient individuals in the society were left with no options than to revolt resounding thoughts of (Tom wicker) typical of American prison revolt. Conversely, on COVID-19 pandemic, the research establishes that, more than 426 million smaller businesses, informal and semi formal are faced with severe disruption and 1.6 million of informal economy workers accounting for $76 \%$ of informal employment globally were seriously impacted.

Similarly, Airline has lost about USD 252 billion in revenue in 2nd quarter 2020 and this is a huge threat which has curtailed the social electroneous (E-) social value of rendering human resource capacity that should improve labour and enhance services and evolution of structures for the benefits of mankind.

Some of the findings suggest that the USA has taken a proactive measure by longitudinal survey while looking into the future with the aim of arresting any evolving conditions related to COVID-19 pandemic while forecasting dead to increase from 80,239 in April to rise approximately, 137,000 come August, 2020 due to increase in human traffic connection and social mobility of both macro and micro population during the first phase ease of lockdown. Qualitative data obtained has supported the fact that, the USA is among the worst hit countries by the pandemic and to reinforce the significance of the measures taken by the USA to project the implications of the pandemic.

Sizeable respondents have agreed that, the dead and the impact of COVID-19 pandemic has inverse implications on the electroneous (E-) human resource capacity of the United States of America (USA) and that of the world at large as the consecutive estimate and statistical strength of affected persons for COVID-19 across the globe as at 11 th, May, 2020 stood at 4,165,752 confirmed cases and 285,307 death on global scale.

Again, literature and empirical findings suggest that the pandemic has overwhelmed the electroneous (E-) human resource capacity of not only the USA but many other developed nations. The health care systems ranging from hitherto, testing capacity to healthcare workers of otherwise viable healthcare system with limited beds to admit COVID-19 patients were overwhelmed, talk less of ICU and ventilators as it was apparently the case in most developed nations of the world at the height of the pandemic.

There is strong qualitative evidence to support the finding that, COVID-19 has disrupted 436 million enterprises, 232 million are retailers and wholesellers globally and COVID-19 has risked and threatened 1.6 million informal workers across the world.

The sociological implications is that, the family dependent and relations of those directly affected by the pandemic, would have to experience major shift and by approximation about 500,000 household globally would need support around small and medium scale businesses and loans to cushion their hardship.

The philanthropist, industrialist, diplomats, bureaucrats and technocrats, including good Samaritan to help contribute in their professionalism to volunteer in supporting the government in creating public health awareness, contribution of material and 
non-material items to support the fight against COVID-19 pandemic, ensuring healthier and COVID-19 free society. Community volunteering efforts among citizen must be recognised and respect the people they are dealing with for who they are and as well accept their value systems and to see them as those in need of help irrespective of their social class and status. The whole process of achieving voluntarism should be home supported and home enabled for quick and win-win successes against COVID-19 pandemics around the world.

The source also claims that the whole programmatic action plan behind COVID-19 boils down to two options of 'life and death'. Some believe that the objective behind COVID-19 is centered around three fundamental prerequisites of 'one world economy', 'one world government' and 'one World religion'.

Some hold the belief that 'COVID-19 is to cage humanity and take over power to be controlled by few individuals and big corporations utilising 'artificial intelligence' so that, human beings can be manipulated and controlled, same as machines for developmental, businesses and life essentials.

Some hold the believe that COVID-19 can be fought to the letter while others are pessimistic and doubtful of its control while looking at our setting as human and the building designs around may permit and promote more of transmission as 'must-handshake' and association for cultural group inclinations at community level.

For some, our attitude hardly allows people to observe social distancing guidelines and not to take anything serious to support government initiatives and to see it as crucial and that calls for an aggressive, unrelenting collectivisms of prompting social action guidelines and credible enforcement around compliance and respect to laws and order ending COVID-19 pandemic in our diverse communities.

Electronic sources and qualitative evidence have proved that patients could be seen lying on the bare floor at various hospitals and persistently coughing some symptomatic while others asymptomatic but the degree of their illness could not be measured as this research is more interested in narrative and social impact and effects of COVID-19 pandemic on social structures than the health aspect which is purely medical.

Therefore, some respondents were of the opinion that serious enlightenment campaign be mounted to discourage interpersonal contact, to stop or rather employ conscious effort to avoid it and block or reduce the chain of spread.

Small enterprises from around the world are the providers of jobs all over the world, especially in low and middle income earners countries. Corollary to that, a number of smaller businesses would perish due to lack of access to credits and loans with weak capital base and are more likely not to benefit from fiscal measures.

There is strong evidence for an increase stigmatization, only during COVID-19 pandemic. Vancouver police recorded 20 hate incidences in 5 month compare to 12 altogether in 2019 mostly directed on East Asian, and they were looked at with disdain for COVID-19 blossomed from China. The attitude of the public on Chinese people was disturbing and the level of stigmatization and hate was on the increase. Data reveals that an insulting statements directed at East Asian were recorded as ' go back to your country, that is where it all started'.

The Chinese were seen with suspicion all over the world for the Wuhan escalation of the novel Corona Virus. There are hatefuelled incidences and racism and there were agitation and bigotry in Canada and such scenario appeared to be strength for the Chinese and they lament of physical, mental and psychological imbalance for such accusations for just being citizens of China. Chinese all over the world are in great fear, anxiety and some are depressed for the unnecessary harassment. (Globe and Mail, May, 2020).

During the lockdown for COVID-19, many people have lost their jobs and in Ontario Canada alone, about 2.2 million people lost their jobs. In April 2020 alone, statistics reveal that about 689,200 people lost their jobs and unemployment rate rose to $11.3 \%$ in Ontario Canada.

The job loss of almost $87 \%$ during the lockdown, just within two month and the demographic characteristics of those affected were significantly women from the private sector. About 577,200 women lost their jobs compared to 514,800 men and are mostly from the industrial sector. The job loss has also affected wholesalers and retailers as 230,900 jobs were lost while accommodation and food services account for 215,800 job loss. At least one out of three jobs was affected by COVID-19.

Similarly, many have appreciable level of agreement that it is no longer news that hospital beds and other health facilities - safety nets and protective devices and equipment are rather in short supply and the entire hospitals in most dominant nations across the globe have been overwhelmed for COVID-19 cases at the expense of the population who are in dire need of hospitalization.

COVID-19 is no respecter of anybody. Empirical evidence and reliable sources have confirmed that many healthcare workers at different hospitals and isolation centres have fallen victims and contracted the virus. The paramedics themselves are not safe of the infectious COVID-19. Sources also confirmed that, the Prime Minister of the UK had contracted COVID-19.

Equally, the Vice President of the USA and some few White House officials were not exempted from the dreadful, devastating nature of the novel corona virus and quagmiric momentum of COVID-19 which must be discouraged by social distancing measures of at least 6 feet distance as mitigation strategies against droplets or flu from infected person.

Conversely, on COVID-19 pandemic, the research establishes that more than 426 million smaller businesses, informal and semi formal are faced with severe disruption and 1.6 million of informal economy workers accounting for $76 \%$ of informal employment globally were seriously impacted. Similarly, Airline has lost about USD 252 billion in revenue in 2nd quarter 2020 and this is a huge threat which has curtailed the social electroneous (E-) social value while rendering human resource capacity that should improve labour and enhance services and evolution of structures for the benefits of mankind.

The enforcement guidelines and the law and order put in place to address excesses of human for the spread of COVID-19 mean 
different thing to different people of diverse population of Africa and beyond?

To the poor, fragile and vulnerable it is probably a way of displacement and rejection. For the mentally retarded lunatics who roam the street during COVID-19 pandemic who were evacuated by the enforcement taskforce for safe keep and who at some instances and subsequently referred to either relevant institution or isolation centre, it means an improved livelihood for survival and a source of free food at the cost of government budgetary expenditure for the control of COVID-19 pandemic.

Human society tends to evolves from time-to-time and some of the changes are positive (+) while others are negative (-) and it is enabled by social PEN energy of (+-n) to complete the circle. Again, some of these changes are socially visible while others are socially invisible, but it has to happen at their social indivisibility. Similarly, others have divergent opinion that COVID-19 came from live animals and attributed the virus to the Chinese who live in Wuhan and are used to eating live animals such as reptiles and seafood, frog, snake etc, hence they got infected of COVID-19 from those animals.

On the 1st of January, 2020 COVID-19 was declared as the first patients in Wuhan started experiencing symptoms of the sickness on 1st of December, 2019. COVID-19 is sending humans to their graves, cemeteries are full and cued, yet there is negligence at community level, especially in most vulnerable ones where touching and kissing corpses suspected to have died of Corona virus due to traditional and cultural forces as goodbye blessings are rampant.

While for some segment of the sampled population studied, Corona virus otherwise, 'SARS-COV-2' abbreviated as COVID19, some critics have contrary opinion to connect COVID-19 to mean 'Certificate of Vaccine ID-19' (COVID-19) translates Corona virus to reflect a global economic domination through the power of 5-G network radiation which according to the source of the data may have positive relationship with microchips to be implanted through vaccine and crypto-currency bit coins to regulate the economy and as well determine online transactions as the 5-G is having higher emissions, more powerful, capable and faster than the $4 \mathrm{G}$ that has been in use.

There are speculations in some quarters with some political commentators describing Corona virus as genetically manipulated, so powerful to shape humanity for structural change and its fundamentals; social, economic and political life and the forces of COVID-19 as pedestal and leeway to the threshold of a new world of human.

Although, the 5G network was known to have been harmful to human, but no one knows the degree of danger it carries and China was first to roll it out and as the source claimed they deliberately did so in the city of Wuhan where people eat live animals to justify the fact that, the deaths due to emissions from $5 \mathrm{G}$ to virus from those animals that can easily be transmitted to human and source claimed that it was the main reasons why Wuhan was used for the test of the technological innovation.

Social distancing is the most appropriate terms because there is an existing literature to support 'social distancing'. There is nothing like physical distancing as insinuated by some scholars. The term isolation has underscored social distancing. When someone is isolated, means he/she is off the human scales of social actions and interactions situation. So, social distancing is social segregation or social dispersion from social groups.

Members of the society can be physically distanced to maintain the space but still socially connected. In an interview situation you can be physically distanced due to space, but socially connected as you gauge responses of the interviewer and it' $\mathrm{s}$ called social scientific interview situation and NOT physical space interview. When you talk on phone with someone in strict sense of social, it doesn't mean that you are socially connected and therefore, the most appropriate definition of the term social appreciates social networking in practical terms and ability to connect sense perception verbal and non verbal responses.

The finding of this research has confirmed that, there are early warning signals around suicide due to depression, acute anxiety and mental imbalance for the devastating nature of COVID-19 and a further excessive regulation of the society and deregulation, emerging inflation, hunger and starvation are on the increase, especially at the height of the pandemic before it gets to normalcy (post-COVID-19). After all, the society is already tensed-up and tough dealing with socio-economic issues. Sociology of COVID19 examines the social ills and conflict situation associated with COVID-19 pandemic.

The enforcement guidelines and the law and order put in place to address excesses of human for the spread of COVID-19 and its enforcement too may altogether be value laden, i.e. a different thing to different people as COVID-19 law and order and/or enforcement guidelines are established to curtail the spread of COVID-19 and what does it means to the people of diverse population of Africa and beyond?

The COVID-19 enforcement guidelines mean something different for the poor, fragile and vulnerable and probably a way of displacement and rejection for them. As for the mentally retarded lunatics who roam the street during COVID-19 pandemic who were evacuated by the enforcement taskforce for safe keep and who at some instances and subsequently deferrals to either relevant institution or isolation centre, it means an improved livelihood for survival and a source of free food at the cost of government budgetary expenditure for the control of COVID-19 pandemic.

There are speculations in some quarters by some political commentators describing Corona virus as genetically manipulated, so powerful to shape humanity for structural change and its fundamentals; social, economic and political life and the forces of COVID-19 as pedestal and leeway to the threshold of a new world. Although, the $5 \mathrm{G}$ network was known to have been harmful to human, no one knows the degree of danger it carries and China was first to roll it out and as the source claimed they deliberately did so in the city of Wuhan where people eat live animals to justify the fact that, the deaths due to emissions from 5G to virus from those animals that can easily be transmitted to human and source claimed that it was the main reasons why Wuhan was used for the test of the technological innovation.

However, the effects of the radiant from the 5G, the source claimed would take nothing less than 5-6 months to evidently manifest as scientifically. The source also, believed that the casualty/dead bodies due to radiation are used as samples for experiment to carryout research with a view to understanding the effects and damages to human cell and to quickly write a code that can quickly prevent damages that should have taken place within 
the bio-system. Those that are dying for COVID-19 now are guinea pig or sacrificial lamb before vaccine and drugs are discovered to calm down the situation.

A community may record death of a prominent person that could lead to condolences and handshakes with some other members of the same community. Many get infected in the process and all of these happened because COVID-19 incubation period is time bound and the symptoms are PEN invisible, hence people don't care about it, mingling and humping around sick persons. Something urgent needs to be done to curtail the rate of the spread. Most people get into depression, distress boredom, anger and aggression causing serious psychological imbalance, cognitive overload and dissonance to inform escalation that may call for hospitalization. In April, 2020, more than 102 export restrictions were placed by 75 countries over 120 countries were subjected to lockdown during the pandemic.

COVID-19 was perceived as paving a path for a post COVID-19 society, a world guided by the philosophy of postmodernism to bring about mass production, create competitive environment while delimiting space and time for enhanced business and capital reintegration for competitiveness with higher intensive on economy, a society of human driven by IT for better tomorrow.

Government hospitals are apparently lacking in the necessary tools; test kits, PPE, etc. Hospitals that are functional operate below optimal performance, grossly inadequate; medical personnel are ill trained and ill equipped to handle special cases related to the novel Corona virus and those who were tested and found positive are referred to isolation centres.

Considering the devastating nature of the pandemic, the government of the USA appropriated 113 million (One Hundred and Thirteen Billion Dollars) to achieve testing and at least 1.9 million of her citizen have been tested in the second week of May, 2020 through hospital and community testing programmes.

The inter-states lockdown which has trapped individuals who, on a normal routine, move out of their county to get orthodox medicines and traditional herbs; integrated healing charms from their traditional and personal physicians respectively are now confused on what next to do due to Corona virus pandemic. Those people are left at the mercy of their immediate community for healing and many may eventually pass on due to the ailment aggravated by hopelessness, especially the aged and those with underlying health conditions who are more vulnerable to COVID19 pandemic.

In addition to the fear of the Corona virus and the consequential rising cases of infected persons that is yet to witness decline, there are hunger related cases associated with the pandemic apparently due to incapacitation and inadequacies around palliative to cushion the hardship caused by COVID-19 pandemic.

COVID-19 or Corona virus would perish over time, but the impact would remain for a long time. It has caused major shift, some reversible while others have come to stay and evolve furthermore to advanced stage to change the world. Sociology as a discipline is relevant at all times to provide analysis about society and the relevance of the science of Sociology in providing analysis about man and his environment cannot be discarded nor underestimated. Sociology is everywhere to say everything about humanity and change in all sphere of our existence as human in a scientific manner.
Fight against COVID-19 pandemic, especially in volunteerism requires tremendous sense of camaraderie demanding maximum cooperation and therefore, the relationship between the law enforcement and civil volunteers is necessary to enhance compliance to guidelines and general security of the community members and that also has to be supported by the government to achieve success in the fight against COVID-19 pandemic.

Qualitative empirical data obtained from informant explores challenges in most vulnerable, weak, fragile social groups in areas where criminals are preponderated and those communities may end up adding up to the existing crime statistics of the police during lockdown for COVID-19 pandemic if volunteerism is not enhanced to contain those excesses to free the society of crime during COVID-19 pandemic.

Available studies and findings have suggested that Corona virus is relative to geography, race weather, environment and climatic changes. Therefore, the impact varies from country to country and those in the USA are ten times times more likely to be infected and four times (4) likely to die of COVID-19 pandemic.

\section{SOCOOLOGY OF COVID-19: CONCLUSION AND RECOMMENDATIONS}

The research has discovered strong empirical evidence supported by theoretical grounds that in the absence of empiricist and scientific discovery of drugs and vaccines for the cure of diseases, not only COVID-19 but any other disease capable of bringing upheavals to render humanity helpless poses existential threat to mankind.

The delay around drugs and vaccine production to arrest COVID19 calls for immediate actions by all governments from around the world to collaborate and nurse scientific maturity to speed up the process and that includes laboratory science techniques to rescue individual members of the society at the time of COVID-19 pandemic. There is consistent data to proof that humans can easily be lured and deceived for anything as cure for COVID-19 and other diseases without probing into the claim of the so called cure claimants.

When faced with an emergency situation leading to death, human attitude can be altered as many compromise science for nonOrthodox approach solving biological disease and that also includes the scientists themselves who believe in concoction for cure without proscriptions, level, instruction and proportionate scaling of dosage, hence individuals can easily be fooled around in the name of cure with little effort to justify claims. COVID-19 has made so many individuals in the society to go on fishing expedition for the cure of Corona, with trial and error everywhere promoting the traditional, non-conventional herbal medicine and its development as homegrown dealing with the pandemic.

There is strong empirical and theoretical evidence and data profiled both primary and secondary suggesting that one fact is imminent and it is universally unchallengeable that, COVID-19 is a phenomenon sugeneris as reality that, for the first time in the history of mankind a phenomenon as COVID-19 came to dominate man's life completely cutting across all facets of man's institutions. COVID-19 has induced newer culture and fine-tuned social group networking as well as changes the working of institutions and man's relations to groups and socio-economic and political structures in parts and whole as the emphasis of 'structural functionalism' in Sociology. 
Newer changes could take place in the society once structures are altered by any force not necessarily pandemic, but any other force as cause effect and systemic change is necessary as we witness job loss hence the need to support and upgrade the informal sector to attain the standard of business fashion within 'The new Normal' business environment.

However, reversal of those changes and or adjustment is inform by the $\mathrm{N}$ component of the PEN structure to enables calibration of P- and E- structural elements of a system to ensure change at various institutional parts and levels through human activities and relationship in the society to bring about consolidation of 'The New Normal' to attain 'an indivisible society that is socially PEN as a wholesome society.

There is the need for collaborative effort and support to deal with COVID-19 pandemic as the behaviour of the curve has not been encouraging as it goes up on daily basis. There should be regulations around social mobility and mass human traffic connection and curtailed heterogeneous and unnecessary ceremonies that would allow hugging and dancing. The ease of lockdown in the first phase has been worrisome and individual in the society are not adhering to the social distancing guidelines and precautionary measures and the law enforcement is up and doing in the enforcement. Some countries have slim hope overcoming the virus and having second thoughts of another lock down and interstate restrictions of social mobility to ensure discouragement around human traffic agents for further transmission.

Cross sectional examination of the study population showed that, the level of preparedness of many government from across the world has been weak and that includes the most developed ones, hence the need to look into the future, for containment of any other emergency quagmire capable of undermining rationality of human beings and should similar pandemic like this one erupts, leaders of various nations are to place the most rightful infrastructures in place and around strategic geographical areas especially, the needs to improve on public health awareness and primary health care to ensure containment while placing emphasis on research and development and promotion of establishment and support for institutional research that should interrogate philosophical questions not only in the area of health but rather all facets of human endeavour and to connect those research institutions and their finding as content with other institutions, agencies and parastatals of government charged with the mandate of policy making and development fundamental improving lives of their citizens.

Dissemination of the content masterpiece and finding propelling from findings is also crucial to share with the elites, the political class and strategic managers of manufacturing firms in partnership other entrepreneurs alike for improved policy and enhanced and prepared environment that should nip any pandemic in the bud. Empirical finding has shown that precautionary measures are necessary tools to guard against and overcome the pandemic but the finding of this research suggest individual members of the society were financially weak and as worse hit by the pandemic hence in some jurisdiction could not even afford to purchase facemasks and hand sanitizer, especially members of the hard hit and vulnerable society whose earnings relied on and from the non formal sector sources of the economy. Therefore, buying facemasks and hand sanitizers don' $t$ form part of their scale of preference and choice to have one and most people's economic decision, especially at the heights of the pandemic need more of food for their intake and survival not buying (PPEG) wasn't part of their scale of preference or choices.

There were instances in which individual members of the society lend their peers facemasks to access formal premises as the guidelines around most formal setting are still adhered to and could only beat the guidelines and used another person's facemasks whose COVID status were not known. The government officials are still on top of the enforcement measures and adhered to the guidelines and the PTF briefings is on top gear and CDC is still going on in many jurisdictions around the world as at 27 th, June, 2020 at the time of writing this research thesis.

This research has established the fact that the $\mathrm{CDC}$, in conjunction with the PTF on COVID in most jurisdiction is assiduously working round the clock and tirelessly so with support from the mass media for coverage and subsequent dissemination. Also, there exists evidences that the lockdown has received $100 \%$ support and compliance of most citizens, especially between the months of January to May 2020 before the ease of lockdown and as all trunk $\mathrm{A}, \mathrm{B}$ and $\mathrm{C}$ roads, community and neighbourhood were calm and indoors with full hope as they awaited palliatives from their respective governments to ameliorate their suffering under the lockdown.

However, qualitative data suggest that there was pilfering genderbased violence and community ransacked and attacked by group of hungry and angry youth and some unscrupulous elements took advantage of the lockdown to engage and perpetrate ills as the rate of crime and deviant behavioir were on the increase. The enforcement received the blessing of the officials and the mobile court and task force prosecuted, fined, and engaged many offenders on community services for the violation of the guidelines.

There were number of issues around urban centre and settlement, especially at the time of the pandemic and more were pinned down by the interstate lockdown, mostly the lower working class had suffered and felt the brunt with excesses around social immobility, reducing in urban, semi urban, suburb and country side. There was serious discouragement around social grouping and unnecessary outdoors $\square$ relaxation $\square$ during the first phase 'ease of the lockdown' with higher sense of risks around fragile and the most vulnerable settlements and communities.

The ease of the first phase does not provide any solutions against the pandemic, but rather increased the rate of transmission as the dynamics of the X,Y Axis along the curve suggest increased while government in conjunction with philanthropists, volunteers and formal setting were still making conscious effort to discourage human traffic connection and congestion in public places while ensuring adherence to social distancing guidelines and other mitigating precautionary measures..

There were difficulties around maintaining social distancing which was nightmare in some settings, but it works perfectly in formal and government settlements that are enlightened, but almost zero at the local levels and communities that seem unorganized or rather broken slums. The first phase east of lockdown and the dynamics of reopening has increased the rate of transmission and many cities are afraid of second phase lockdown due to the increasing nature of the virus.

The government, philanthropists and good Samaritans, nongovernmental organizations, the faith based mosques and churches 
had all extended hands of gesture and committed enormous resources such as food, material items and finance to cushion the effects of COVID-19 pandemic on the lives of the needy, destitute and down trodden masses and of course including the working class who were in dire need of assistance during the lockdown and are apparently facing hunger and starvation and the vulnerable who by all standard measurement and parameters could not afford three (3) square meals and the government had provided truck loads of foodstuff as palliative and had since distributed to the community members, but could not go round some respondent interviewed at some quotas observed.

Although, the ease of the lockdown has freed members of the society, but it has posed gigantic threats around transmission and to further monitor and control the pandemic researches and models were put in place as longitudinal projection of the USA case confirmed increase up to August 2020 and that, has challenged both macro and micro population and are expected to face some social demographic issues and population decrease is imminent.

Similarly, the finding of the research also reveals that number of cases of COVID-19 would still skyrocket and USA alone is reading approximately more than 2 million confirmed cases only in July, 2020 with increasing and shooting curves in Texas. Brazil is now taken over by COVID-19 as centrepiece of the pandemic. The ease of the lockdown, especially in the USA was characterized by Police brutality and blacks uprising into 'The New Normal'.

COVID-19 has dislocated and induced newer culture such as 'work from home' 'social distancing' and 'elbows greeting' amongst other newer ways of life and postmodernism as philosophy which drives the dynamics of 'The New Normal' while finding has provided nexus between Marxian, Contean and Weberian notion of society in post pandemic characterizes by large scale instantaneous production of goods enables by positive and/or scientific fundamentals for an ideal society respectively. This research has uncovered the newer scientific innovations and the imperative around Weberian rationalization and Comtean scientific stage as socially PEN indivisible society antithetical to Marxian egalitarian society. The notion behind postmodernism is surplus profit accumulation and large scale production with values are seen as driven by the imperialist power and control of protineous $\mathrm{P}+$ capital who more or less have control of the development institutions and strategies map out by Eelectroneously endowed citizens for an overall development.

Historically, according to Social PEN theory of structural change, society changes from 'loaned pathological as weaker' and fragile society for being lones to form and combine in human activities at all levels of interactions of groups to form 'PEN Molecular society as relatively stronger with more defining characteristics and features for projecting into another formidable system of PEN elementary with differential identity and similarity and orderliness for the attainment of PEN composite society as more heterogeneous society with complex behaviour and interdependence and independence that are indispensable for social progress to a more formidable PEN indivisibility society that can no longer form and combine but it maintains its stage and keep on consolidating with newer scientific improvement on the gains of the earlier stages until the Comtean scientific stage and Weberean ideal society built on the basis of rationalization of the postmodern society comes into play and the 'The New Normal' is a leeway for such a society.

Corollary to that, the social PEN theory, the actualization which depicts a wholesome indivisible society are achieved and driven by highly protoneous $\mathrm{P}+$ capital integration and E- electroneous human resources capacity; head, hands, mind, IT and Telecom skills and know how as a scientific stage and stabilization as envisaged by sociologist such as Auguste Comte, the positive and/or scientific stage in the history of mankind. The finding of this research has confirmed the fact that science and objectivity rule the world. This fact is indisputable and therefore, it is not debatable. COVID-19, has confirmed the scientific stage of societal development as abdicated by Auguste Comte. COVID-19 has posed challenged around institutions, experts, leaders and people, in fact every single structure was proved to be challenged by COVID-19 and the pandemic is still ravaging as at June, 2020, especially USA, Brazil and some selected major cities are experiencing shooting in the curves of COVID-19 and global economy is creeping or is it galloping with difficulties around recovery. It is therefore, necessary to expedite actions to speed up discovery and subsequent production of drugs and vaccines as solutions to rescue humanity from the dreaded monster called COVID-19. COVID-19 has thwarted humanity and thrown more into darkness.

Between February and March, 2020 people had chewed, swallow or rob anything as it goes for cure without dosage. Many herbs and green foods were eaten as cure for Corona virus. And, that emphasise the need for scientific, orthodox approach that should completely stamp out COVID-19 pandemic. There is need to place all the traditional approaches for further test to ascertain their efficacy and encourage support for the ABU Zaria projects on ventilator for home utilization, income generation and over all interest of the country.

The global leadership response for the containment of COVID-19 was rather unparalleled, devoid of political waves. It was characterized by onerous tasks and all hands were on deck to contain the pandemic. The leadership response was prompt and instantaneous. Perhaps, that decision was a reflection of a decision at certain political pedestal and global. Therefore, whatever change that is to come in post COVID-19 pandemic is seen as again, a unanimous effort to amend the socio-economic and political structure to return to normalcy and there might be a marshal reconstruction of the damages caused by COVID-19 pandemic.

The emerging decision from the global leadership at the level of UN, World Bank and WHO with their counterpart subsidiaries, as the Bretton Woods institutions, perhaps may not fall short of the initial subscription to global decisions as unanimous to receive the magnificent magnanimity enhancing and improving the life of the individual members of the society for the betterment of humanity now and the future.

COVID-19 has demonstrated that science is still premature to rescue humanity and therefore, it is still evolving, until then, men are vulnerable and exposed to tremendous natural threats; hence stand a chance of being consumed by disaster. The newer scientific norms as innovations and discoveries would gradually emerge to differentiate into conventional norms, rules, guidelines, code of conduct to further direct the behaviour of the individuals members of the society as 'social determinism' to say more about 
man's 'social existentialism' and through such process and man's activities we witness change of the society.

Should another pandemic so deadly as COVID-19 emerged again or a biological disaster erupts in the future and the chance of this world to survive it through scientific principle is oblique. That is the experience and lessons learn from the current COVID-19 pandemic, hence man will be at the mercy of the natural laws; the natural selection, a pat on the back of Charles Darwin evolutionism, survival of the fittest.

The theme of this research is Covid-19: applied Sociology of the Pandemic and The dynamics beyond 'The New Normal' in the Context of Social PEN Theory of Structural Change and it recommends further study and improvement around key areas of COVID-19 challenges while taking into cognisance the needs and expectations of both macro and micro demographics population and with more policy around promoting scientific paradigm, feminism while catching the younger and utilization of their brains should be the number one target as the target action while government, relevant institutions and private sectors as system target are to make deliberate efforts of building the hands of the youth ensuring that, they are electroneously E- configured for future challenges. If trajectory are maintained this kind of process would continually increase the global populations and countries electroneously with E- human resource capacity for further change and development. 'The New Normal' is a way of life. It's an envisaged society which redefines human rationality and fundamentals in social, economic and political structural arrangement and power relations for change. It may also, mean to be a post COVID-19 world which can interchangeable be used as 'Postmodernism and beyond' in Anthony Glidden's classification of modern societies as PEN Indivisible society driven by science and the power of IT for simplification to enable large scale production for surplus profit accumulation.

Post COVID-19 environment would be driven base on science and technological requirements again, synonymous to establishment of Comtean connotation of society as positive stage driven by scientific fundamental and to its greater height which confirm Weberian ideal society built on rationalization and all are achieved through social evolutionism of Charles Darwin enabled by social PEN energy (+-n) for moves of conglomerates of systems beneficial to define value chains around social, economic and political structures. This ignites further progress into motion as envisaged by Herbert Spencer's 'social static and social dynamic' theorizing and all are possible through rationales activities of the members of the society and interplay of institutional social PEN energy to bring about positive developmental for change in socio-economic and political systems.

Consequently, 'The New Normal', is post pandemic society driven by scientific forces of social PEN energy of (+-n) in man's relation to other societal fundamental and the role and dominance of institutional innovations enables by configuring of the $\mathrm{P}+\mathrm{E}-$ and to be supported by $\mathrm{N}$ to enable and ensure competitiveness of the 'The New Normal' social economic and political environment for more profit and gains 'only and only if' the society is able to promotes projects and programmes around youths empowerment and configuring their electroneous E- component of ( human resource capacity, building and developing their hands and head while tasking them to engage in activities that would bring about change) through a rationalized systems along as echoed by Max Weber and the thoughts of the younger citizens to attain positive scientific requirements again, as unequivocally believed by August Comte for change and development of onerous tasks to come into play.

Change and development of the society in post pandemic is only possible when the three integral components of the 'Social Atomic PEN Structural Theory of Change' which must work simultaneously and in harmony to inform structural change and that, must be supported by the $\mathrm{N}$ neutroneous value for sufficient calibration of the $\mathrm{P}+$ and $\mathrm{E}$ - to context and relative equilibrium. Social Protoneous $(\mathrm{P}+)$ : positive social value as capital integration as funding support for liquidity of any system for change. Social Electroneous (E-): negative social value as human resource capacity both IT and Telecom Technological capacity, natural or acquired by man in the society through training to support change for development. Social neutroneous $(\mathrm{N})$ : the societal norms and values systems to serve as calibre to support protoneous $(\mathrm{P}+)$ and electroneous (E-) to calibrate and further recalibrate any social structure or system to context and relative social equilibrium for change to happen (societal support). 'The New Normal': What is key to the stabilization of the society to attain 'The New Normal' are the newer scientific norms and the role of e-institutions and the emerging structural fundamentals would have influence on social, economic and political activities of societies to enable the change in phases in post COVID-19 society.

The human society is evolving and fast changing by the pandemic. This is is to the credit of Charles Darwin Evolutionism enable by social PEN energy (+-n) for moves of static phenomenon to get into a dynamic state of affairs as exponentially, propounded by (Herbert Spemcer). New changes could take place in the society and within a system, which is only possible when the $\mathrm{N}$ component of the PEN structure aide calibration of $\mathrm{P}$ - and E- structural elements of a system to ensure change at various institutional parts and levels through human activities and relationship in the society to bring about consolidation of 'The New Normal' to attain scientific stage and stabilization as envisaged by sociologists. And, all of these could be achieved with the role of instantaneous telecommunications activities to enable change for example; the working of 'Internet of Thing' (IoTM2M) as some of the guides to the world of science of only the super powers.

News on cure of COVID-19 was like food during the pandemic and the political class, including the aged were so scarred and very careful while avoiding group behaviour and social grouping as a run from the pandemic than the able bodied men. There is enough qualitative evidence to support that the rate of divorce has been on the increase just as domestic violence between spouses.

Literature and facts behind this research have supported the establishment of 'The New Normal' and beyond postmodernism is the proof to confirm Auguste Comte's scientific stage scaffolding the establishment of the Apex of societal progress to depict by change. A day before lockdown was horrible as everyone was busy shopping and that has provided traders a pedestal to hike prices of commodities and the economy was faced with unnecessary, artificial inflation with high rate of vehicular accidents for confusion around market places and street corner shops and stalls. Some items were apparently out of stocks and some were busy travelling to meet up with their families while 
others were trapped by the lockdown and were faced with trauma, anxiety and distress for missing their family. The rate of sudden death was high and self administered drugs leading to drug abuse at community level was also apparent for the fear of going to hospital only to be tested for COVID-19.

There is the need for psychosocial support to calm the affected victims of Corona with timely advice, therapeutic and counseling to reposition the mental health of individual affected by COVID patient in the society, especially those in the front line who more or less had suffered and felt the brunt of COVID-19 for handling Corona patient, cadavers and are in panics, especially when the pandemic was at its peak. This research has discovered that from qualitative standpoint, the health workers, volunteers and members of the tasks force, mobile courts and field workers required specialized and skilled support and treatments in the case established in line with mental and medical health practice. Also, there is the need for an enhanced social welfare units at various hospitals and deployment of medicals sociologist to assist in providing case history, case study and to cover more on attitude, personality and case study about social life of the Corona patient as backup support information to enable medical practitioners perform their jobs effectively and efficiently with better grasp and in-depth knowledge about the sick person through studies that are evidential.

There is need to upgrade hospitals to meet world class standard and to support hospitals for improve health seeking behavior. The hospital database are to be connected to research centres, institutes and other health research facilities and universities for an all round and inclusiveness in research finding utilization and onerous data management, especially in African countries for future pandemic and upgrade those resource centres with technological equipment and IT facilities and that would go a long way in timely utilization of findings from research commissioned in specific areas of professionalism as support and that is sacrosanct and necessary to contain pandemics in the future. There is the need for commissioned research both medical and social impact which is necessary for better understanding of health seeking behaviour and the social effects of future pandemic and COVID-19 in particular as guide going forward to contain.

Indigenous researchers need to be supported to further their research in social health issues for the utilization of their results as home grown and home supported. The level of preparedness for unknown escalation of diseases like COVID-19 has been weak hence the need for plan B as always, safety nets and improved palliative should crisis like COVID-19 escalates in the future. Research institutes in both developed and countries in transition are to be connected to the university with research support grants to play supplementary and complementary roles for formidable finding and use of various health and social agencies for amelioration of human needs and subsequently, cushion the hardship of the affected persons especially, the lower working class citizens.

There is enough evidence that COVID-19 is causative agent and the world is evolving; as a result new changes are emerging not abruptly but gradually as natural selection characterised by the power of science and institutions. This finding has supported Comte' s positive (scientific stage) and reinforced by Darwinians (social evolutionism; the survival of the fittest). Paradigms are conflicting and shifting in their bearings and man is being dominated by IT in all spheres of existence ranging from; hospitals, market places, schools, work place, eatery to ATM dispenser and to all payments for purchases and other transactions are done electronically online with the use of value-MasterCard supported by IT as 'Internet of Things' (IoTM2M) as postmodernities, as a way of life opposing to life practiced in modernism.

The research has uncovered problems achieving social distancing, that adherence to social distancing guidelines is been affected by so many factors ranging from human feelings; emotions and uncontrollable reflex actions in addition to the natural social energy (+-) for attraction which allows natural humam traffic connection and forgetfulness, hence threat to implementation of the distancing guidelines to the fullest. It's therefore, recommended in the short term that, the high powered authority UN, CDC and PTF to encourage and support media activities both new and mass media to create awareness, sensitization and mass mobilization with the support of the government. The need from civil society groups encouragement and enhance motivation around law enforcement to work closely with (well guarded PPE volunteers) at the community level and those volunteering at the hospitals and community levels must be checked to ascertain their COVID- status, mental health and intentions both latent and manifest actions to ascertain that they are sound, credible and well motivated civil society groups. Volunteers and stakeholders' participation in both formal and informal control mechanisms; government and community respectively to ensure social distancing measures are adhered to by members of the society.

The informal sector requires support and special grants and loan, especially small and medium scale as support for economic resuscitation as qualitative evidence has supported the finding that, COVID-19 has disrupted 436 million enterprises, 232 are retailers and whole sellers globally and COVID-19 has risks and threatened 1.6 million informal workers globally. The findings suggest that, normalcy would return, but the devastation of COVID-19 stays beyond the extinction of Corona virus. This is indisputable and therefore it's undeniable fact that, there would be a newer World, as post COVID-19 world driven by postmodernities and sophistication to facilitate the phased evolution of 'The New Normal' as postmodern society characterized by science and technological advancement in all its ramifications as the 'Comtean Positive society'.

Post COVID-19 world and the role of conscience commune, the rise of science, newer norms and tradition, customs, rationality of law, morality, civilization and information technology IT would take account of further change in human behaviour in post COVID-19 society and it has to be gradual to descent to 'The New Normal' and it has PEN energy (+-n) effects to indicate the directions of change via technology. The social PEN effects have positive (+) social as well as negative (-) PEN consequential to suggest change and to indicate direction of any society undergoing change in structures. (Emile Durkheim, 1938), (Durkheim and Mauss, M, 1703), (August Comte, 1986). Considering the casualties, index cases discharge and deaths for COVID-19, is rather so alarming and disturbing, a situation that can best be described as Tom Wicker knocking on the doors.

Wicker, so popular as he was for his Book entitled 'A Time to Die' and Covid-19 pandemic is an invisible Virus driven by human and facilitated by social PEN energy of (+-n) and individuals members 
of the society as carriers. Again, it's transmission are also possible and enable only through social interactions while social distancing as one of the mitigating measures to avert the pandemic supported by human social actions through networking and distancing from groups and social gathering. COVID-19 has tremendous consequential effects on institutions, structures and social relationships in the society, especially during lockdown and for social distancing of individuals members of the society from social gathering as lone with enormous pathological implications. Corollary to the above, COVID-19 World; 'The New Normal' dictates and redefines relationship and monitor human activities to curtail excesses which hitherto held some countries to lag behind. and offices are no longer necessities but rather an exception with numerous options of discharging official functions and routines at home or anywhere convenient for its flexible and connectivity supported by IT facilities. This viewpoint is reminiscences of the study conducted by (M.S.E, Shahrentani, 2015).

"A smart home application based on the management of thing internet platform" he argued that, society would evolve to attain a milestone in IT to further simplify the society. The dominance of IT to control heterogeneous appliances and managing them from a distance, he argues, is enabled by 'Internet of Thing' management, platform to bring connectivity to every physical object around us, a two tier model which enables communication between things to things with minimal human intervention to drive industrial needs and supply value chain. He echoed that, in no distant time society would largely depend on 'Internet of Things' and automation becomes more increasingly integrated into 'Internet of Thing'.

The role of crucial institutions would be dominant in ushering in 'The New Normal' post COVID-19 society. Some jobs will perish and the down trodden masses would have more trouble to face around knowledge delivery and dynamics of systemic change with cause and effect on man's socio-economic and political life. The result of this research has confirmed that the society is tilting towards the apex of society in Comtean notion of society as positive and/or scientific stage of social evolution enabled by social PEN energy (+-n) for change. For the first time in the history of mankind a phenomenon as COVID-19 came to dominate man's social life with newer culture for adaptation with tremendous shift in the working of institutions and man's relations to socioeconomic and political structures was completely overhauled by COVID-19 pandemic.

For example; there seems to be newer culture as; 'work from home' which has changed organizational structure and this is a huge concern for organizational study and organization as an institution may experience change as this is maintain in 'The New Normal'. Social distancing is also another norm which defines COVID-19 era with effects on heterogeneous human grouping. This view point is reminiscent of structural functionalism in sociology which sees the roles of parts for the maintenance of the whole. The fact that science and objectivity rule the world is indisputable and therefore, it is not debatable while in social domain is to the credit of Auguste Comte. When science is mentioned in social sciences for management of fundamentals to ensure change and development, again it's to the credit of Auguste Comte the founder of Sociology and master of logical positivism who reinvigorated his philosophy on the pedestal of science with emphasise and relevance on sense perception.

\section{REFERENCES}

[1] Ashamabi, A.K (2020) "Proven COVID-19 Survival Tips: COVID-19 is not a Dead Sentence " An Electronic Source.

[2] Abba .G. Shettimai (1998) " Sociology of Development"; Lecture Series" Department of Sociology and Anthropology, University of Maiduguri, 1998, Nigeria.

[3] A.K Jihomborykwau (2020) "An Appeal to safe the Soul of Africans" a clip on theme 'Abuse of Africans, simply because they are Africans'. To the President of China on the eviction of African's in Diaspora from their homes. An electronic Material, 2020.

[4] An AIT Exclusive, (2020) On COVID-19 Lockdown "A Taxi Driver in Violation of Lockdown Guidelines" A Drama Stage an electronic Source.

[5] Anthony F. (2020) "Presidential Press Briefing, White House, USA" on CNN News

[6] Anthony Giddens (1973) "The class Structure of the Advanced Societies" Hutchinson, London in Haralambos and Holburn, 7th Edition.

[7] Anthony Giddens (1991) " Modernity and Self- Identification: Self and Society in the Late Modern Age, Polity Press, Cambridge.

[8] Atkinson, A. (1978) " Societal Reaction to Suicide; in discovering Suicide". MacMillan, London.

[9] August Comte, (1986), "The Positive Philosophy" Bell and Sons, London.

[10] Auguste Comte, (1986) "The Positive Philosophy ", Bell and Sons, London.

[11] Burgess and Parks (2019) "The City" University of Chicago.

[12] Burgess and Parks (2019) "The City" University of Chicago.

[13] Burgess and Parks (2019) "The City" University of Chicago.

[14] Cross rivers State (2020) "Supply of seedlings to States to Address Post COVID-19 Pandemic Hunger in Nigeria. An Electronic Source.

[15] D.Kieghe,(2020) " Global System Sub-Saharan Africa: Global Systems and Societies, a lecture delivered at School of Geography University Lincoln.

[16] Dahrendorf, R. (1959) "Class and Class Conflict in an Industrial Society" Rutledge and Megan Paul, London..

[17] Darwin, C. (1968, [1859]) "Origin of species" Penguin, Harmonds worth,

[18] David Hume (1739) "A treatie of human beings nature"

[19] DCP. Abba Kyari (2020) "Caution over Security Concerns: From Inspector General of police - intelligence Responses Team(IGP-IRT) Commander, DCP. Abba Kyari. A Security Write.

[20] Donald T. (2020) "Presidential Press Briefing, White House, USA" on CNN News

[21] Dr. A.U Tilde (2020) "Lockdown Between Mosques and Markets" A Write Up On COVID-19 Pandemic.

[22] Dr. David Kieghe (2020) " "COVID-19 No Good Choices: Making us Think More About the Future Together" 5the May, 2020

[23] Dr. Mustapha Bintube (2020); 'The Social Atomic PEN Structural Theory of Change' International Journal of Scientific and Research Publication Doi: ttp://dx.Doi.org/10.29322/IJSRP.

[24] Dr. N. Alkali (2020) "On COVID-19 Pandemic laments About Northern Governors: Why Doctors in Kano Reportedly Absconded from Work Recently and Why Sick Nigerians Prepare to Seek Treatment in Dubai, Egypt, India, UK etc ?". A Write up on COVID-19 Pandemic.

[25] Dr. T.S. Chandrasekar, Dr. K.R. Yogesh(2020) "COVID-19 Guts Connection" A published Article on COVID-19 electronic Source.

[26] Durkheim and Mauss, M, (1703), "primitive classification" Cohen and West, London.

[27] Elizabeth K. R. (1969) " On Deaths and Dying" MacMillan.

[28] Elizabeth K. R. (1969) " On Deaths and Dying" MacMillan.

[29] Financial Times (May, 2020) " Body of Knowledge: Head to Toe Coron Virus Symptoms" challenge Medical Science -American signal Rising Unease over Trump's handling of Crisis.

[30] Financial Times, Yoval Noah, (2020) "The World After Corona Virus"

[31] Francis F. (1992) " The End of History and the last Man" Tree Press.

[32] Francis F. (1992) "The End of History and the last Man" Tree Press.

[33] G. Simmel (1948) " The Problem of Sociology: The Eassy Presents Simmel's understanding of the Proper Object of Sociology which he refereed to as 
'Sociation' and his opinion about how Sociology Differs with Psychology " in Peter Kivisto- Social Theory Roots and Branches 2000 Roxbury Publishing Company.

[34] G.Emefiele(2020) "Turning the COVID-19 Tragedy into an Opportunity for a New Nigeria" Governor Central Bank of Nigeria.

[35] Gddsns, A. (1990) "High Modernity and Beyond" in Haralambus and Holnon-Themes and Perspectives, 7th Edition University Tutorial Press, 2008.

[36] George H. M. (1934) "Mind self and society" . Published posthumously by his students.

[37] Giddens Anthony (2009) "Giddens Sociology" 6th edition published by Polity Press 65 Bridge Street Cambridge CB2 1UR, United Kingdom.

[38] Hamza Kankiya, (2013) "Sociological Theories; Lecture Series" Department of Sociology University of Abuja, 2013, Nigeria.

[39] Haralanbus and Holborn (2008) " Sociology; "Themes and Perspectives" Seventh Edition, Harper Collins Publishers Limited 77-85 Fulham Place Road Harmsworth, London w 68 j b.

[40] Heraclitus of Ephehesus (2020) " COVID-19 "A New Normal" and other Quotidian Proclamation: Living and Dead, Walking and Sleeping, Young and Old are all Subject to Change.

[41] Hogan, M. O. (2006) "Dictionary of Sociology" 1st Edition, Published by Arrangement with Academic (India) Publishers, New Delhi-110008.

[42] International Labour Organization, ( April, 2020) " ILO Monitor: COVID-19 and the World of Work, Second Edition Updated Estimates and Analysis.

[43] J. Charms (2020) " A bloody Wednesday: COVID-19 guidelines Violators Clashed with the Police on 15th, April 2020 an electronic Source.

[44] Jean Jacques R. (1962) "The Social Contract" France.

[45] Jean Jacques R. (1962) "The Social Contract" France.

[46] Jean Jacques R. (1962) "The Social Contract" France.

[47] Jeremy Bentham (1780) "An introduction to the principles of morals and legislation.

[48] K. Dr. Kepala, Dr. PP Devan (2020) " COVID-19: How to Treat Corona Virus in Initial Stage" an electronic Phone Call Conversation.

[49] Karl Marx (1964, [1840]) "The Economic and Philosophical Manuscripts" International Publishers, New York.

[50] Karl Marx (1978[1867]) "Capital" Vol. 1, Penguin, Harmonds Worth.

[51] Karl Marx and Engels, F. (1950[1808]) "Manifesto of the Communist Party" in Karl Marx and F. Engels, Selected Works, Vol 2, Foreign Languages Publishing House, Moscow.

[52] Kaufman R. J. (1992) "Sound " F. Watts

[53] Kaufman R. J. (1992) "Sound " F. Watts.

[54] Laster F. W. (1968) " Dynamic Sociology " Green Wood Press. University of California.

[55] Laster F. W. (1968) " Dynamic Sociology " Green Wood Press. University of California.

[56] Lenin V. C (1971) " The State and the Revolution Russia.

[57] Lenin V. C 1971) " The State and the Revolution Russia..

[58] Lyotard François, L (1884) " Postmodernism and Knowledge " in Haralambus and Holnon-Themes and Perspectives, 7th Edition University Tutorial Press, 2008.

[59] M. E. Sayed Sharestani, (2015) "A Smart Phone Application Based the internet of Thing, Management platform. 2015 IEEE, International Conference on Data Science and Data Intensive Systems Sydney Australia.

[60] M.H. Bwalai, (1998) " Sociology of Urbanization"; Lecture Series" Department of Sociology and Anthropology, University of Maiduguri, 1998, Nigeria.

[61] Marton. R. K. (1968) "Social Theory and Social Structure at Large" end Free Press, New York.

[62] Marx Weber (1947) "The Theory of Economic and Social Organization ", Free Press, New York.

[63] Maslow, A. H. (1970) "Motivation and Personality" (Rev.end.) New York Harper and Row In Theory and Practice, and Tends in Human Services an Introduction to an emerging Profession. Second edition, Wadsworth Books/Cole.

[64] Mead, G. H. (1934) "Mind, Self and Society" edited by E. Morris, University of Chicago Press. Chicago.
[65] Mrs. Abdullahi, (2020) "COVID-19 Pandemic, the God's of this World wants to Reduce World Population for easier Control and Management "One World, Economy, One World Government and One World Religion" An Electronic Source.

[66] Nmbuziseller (2020), " One Metre- Maassai Kenyans Volunteer" for the enforcement of guidelines policy in Kenya, an electronic Source.

[67] O.H. Opeyemi (2020) COVID-19 Lockdown and Ease Reopening Mormoured Crowds Clashes at Bank Premisses" An Electronic Source.

[68] O.Peterson, K. (2020)" COVID-19 pandemic and Economic Crisis: The Nigerian Experience and Structural Causes" MPRA Munich Personal RePEc Archive.

[69] ODDTV, (2020) "Action News Corona Virus: COVID-19 Versus Microchip Implant " Electronic Source.

[70] Olu Ogunika, (1998) "Sociological Theories; Lecture Series" Department of Sociology and Anthropology, University of Maiduguri, 1998, Nigeria.

[71] P.L. Berger and Thomas Luckmanm ( 1967 ) " The Social Construction of Reality " Doubleday and Company, Inc, 1967. Printed in USA.

[72] Parson T. And Bales, R.F. (eds) (1955) " "Family, Socialization and Interactions Processes", Free Press, New York.

[73] Parson, T. (1977) "the Evolution of Societies" Edited by J. Toby, Prentice Hall, Engle Wood Cliffs, N. J.

[74] Presidential Tasks Force (PTF) on COVID-19 (2020) "Implementation Guidance for Lockdown Policy, Enforcement and Protocol, Office of the Secretary to the Government of Federation-Nigeria.

[75] Putnam R. And Feldstein, (2003) "Better Together: Restoring the American Community", Simon and Schuster, New York.

[76] Putnam R. D. (1995), "Tuning out; The Strange Disappearance of Social Capital in American" political science and politics", 28, 664-83.

[77] R. Dawkins, (2011) " The Magic of Reality- How we know what is really True" Transworld Publishers Uxbridge Road, London, A Random House Group Company

[78] R. Kafadia,(2020)" The US and China have a New Front in the trade War 5G-5G will Shape a New Generation, Artificial Intelligent and Data Collection. Neither the US NIR China is willing to fall behind.

[79] Robert K. Merton (1968) "Social Theory and Social Structure" Enlarged eds, Free Press, New York.

[80] Robert K. Merton, (1968)" "Social Theory and Social Structure, Enlarged" Free Press, New York.

[81] S. Probst, N. Carrington, A.A. Howat, (2020) "COVID-19 Operating in the New Normal : A back Door to Increase Fraud Risks"

[82] S.M. Innocent, (2020) " COVID-19 Not an African Virus: Who Gains More the Nigerian Government in the Test Tube. A Write Up on COVID-19 Pandemic.

[83] S.O. Smah, (2013) "Theories of Crime and Deviance" Lecture Series" Department of Sociology, University of Abuja, 2013, Nigeria.

[84] Sine Simon (2000) " Start with Why" portfolio.

[85] Sine Simon (2000) " Start with Why" portfolio

[86] Spencer H. (1971) "Structure, Culture and Education" Nelson London.

[87] T, ALI ( 2002 ) "The Clash of Fundamentalism: Crusade Jihad and Modernity", Paperback edition, UK:6 Meard Street, London W1F 0EG.

[88] T. Honjo, (2020) " Corona Virus is Not Natural" Japan's Novel Price Winning, Profsssor. An Electronic Source.

[89] Telecommunications Engineering, Department of Communication, Ministry of Communication, Government of India (March,2020) "Technical Report M2MIOT Enablement in Smart Homes Tech-TR-IoT-M2M 007-0, M2M Smart Home Working Group".

[90] Thomas K. (1962) "The Structure of Scientific Revolution" University of ..... Press.

[91] Thomas K. (1962) "The Structure of Scientific Revolution" University of .... Press.

[92] Tottenham Town Hall, Church (2020) "Less Privilege Line Up in Queues at the Church in the United Kingdoms, for Food as Palliative to Cushing Hardship During the Lockdown" An Appeal to Assist the Less Privileges. An Electronic Source.

[93] U.A. Tar, (1998) "Development and Underdevelopment" Lecture Series" Department of Political Science, University of Maiduguri, 1998, Nigeria. 
[94] Valuetrainmen, (2020) "COVID-19 Pandemic Who is Responsible and How Much of this Do you Think is Corona Virus" An Electronic Source.

[95] VERDICT with TED CRUZ, (2020) "TED CRUZ Reveals Huge Corona Virus Bombshell" An Electronic Source.

[96] W. A. Gazali, (1998) "Urbanization and Labour Migration"; Lecture Series" Department of Sociology and Anthropology, University of Maiduguri, 1998, Nigeria.

[97] W. Bosyauni,(2020) " COVID-19 Lockdown: Reflecting Upon Our Situation Staying at Home' an electronic Source.

[98] Waziri Ahamed Gazali, (1998) " Social Change"; Lecture Series" Department of Sociology and Anthropology, University of Maiduguri, 1998, Nigeria.

[99] William I. thomas (1918-1920) "The polish peasent in Europe and America".

[100]Wion News Gravitas (2020) "Making Sense of the News: China's Play Book Five Ways to Exploits Crisis. An Electronic Source.

[101] World Economic Forum: Insight Report (2020) " COVID-19 Risks OutlookPreliminary Mapping and It's Implications, in Partnership with Mash and McLennan and Zurich Insurance Group. Committed to improving the State of the World.

[102]World health Organization; Centre for Disease Control (2020).
[103]Y. Mukhtar, (1998) " USA since 1877" Lecture Series Department of History, University of Maiduguri, 1998, Nigeria.

[104]Y. Trofimov (2005) "Faith At War: A Journey on the Front lines of Islam, from Baghdad to Timbuktu", Henry Hold and Company, LLC Pubkishers Since 1866, 175 Fith Avenue, New York

[105]Zimmerman, D.H and Wieder, D.L. (1971) "Ethnomethodology and the Problem of Order in J.D. Douglass's (end) "Understanding Every Day Life" Rutledge and Kegan Paul, London.

\section{AUTHORS}

First Author - Dr. Mustapha Bintube, (ECRTD, UK).

National Assembly, Directorate of Senate, Department of Journal and Visiting Senior Lecturer, University of Maiduguri,

(Unimaid), Department of Sociology and Anthropology, Nigeria: drm.bintube@gmail.com (+2348023586870, (+234 905239

4036) 